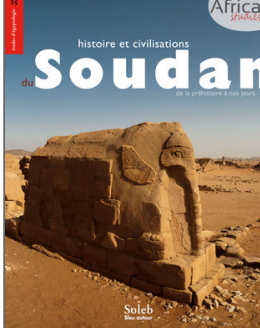

Histoire et civilisation du Soudan

De la préhistoire à nos jours

\title{
2. La création du Soudan moderne 1820-1885
}

\section{Bernard François}

DOI : 10.4000/books.africae.2892

Éditeur : Africae, Soleb, Bleu autour

Lieu d'édition : Paris, Khartoum

Année d'édition : 2017

Date de mise en ligne : 17 janvier 2022

Collection : Africae Studies

EAN électronique : 9782493207074

\section{(2) OpenEdition}

\section{Books}

http://books.openedition.org

\section{Référence électronique}

FRANÇOIS, Bernard. 2. La création du Soudan moderne 1820-1885 In : Histoire et civilisation du Soudan : De la préhistoire à nos jours [en ligne]. Paris, Khartoum : Africae, 2017 (généré le 28 janvier 2022).

Disponible sur Internet : <http://books.openedition.org/africae/2892>. ISBN : 9782493207074. DOI : https://doi.org/10.4000/books.africae.2892. 


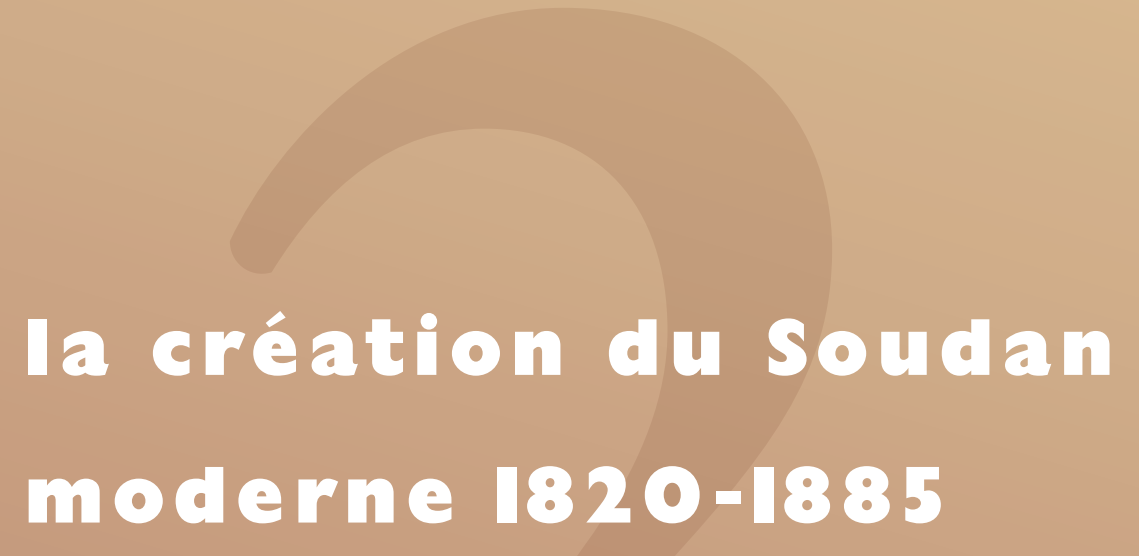




\section{La conquête initiale}

Le Soudan intéresse Méhémet Ali, le vice-roi d'Égypte, pour quatre raisons. D'abord, il lui faut poursuivre et achever l'entreprise d'éradication des mamelouks qu'il a entreprise au Caire en 1811 et sécuriser sa frontière au sud. De petits groupes de fuyards se sont réfugiés au Soudan. Dès 1812, des émissaires ont été envoyés à la cour du royaume de Sennar pour demander l'expulsion d'un parti de Mamelouks regroupés autour de Dongola.

Le vice-roi a également besoin de fonds, et les fabuleuses mines d'or du Soudan devraient lui en procurer. Il cherche aussi à capturer les esclaves dont il a besoin, pour les transformer en soldats disciplinés. (Méhémet Ali souhaitait, depuis 1815 , mettre en ouvre le Nizam el Jedid ${ }^{1}$ mais il rencontrait des difficultés.)

Or et soldats devraient dès lors lui permettre de concrétiser son rêve de transformation de l'Égypte en puissance conquérante destinée, dans sa vision stratégique, à grandir sur les ruines de l'Empire ottoman dont il a perçu la décomposition. Au départ, il souhaitait conquérir les rives de la mer Rouge et l'Abyssinie chrétienne, mais il rencontra la ferme opposition de l'Empire britannique, sûr de représenter le point de vue des autres puissances européennes.

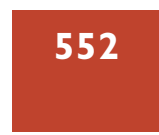

de 1820 à nos jours

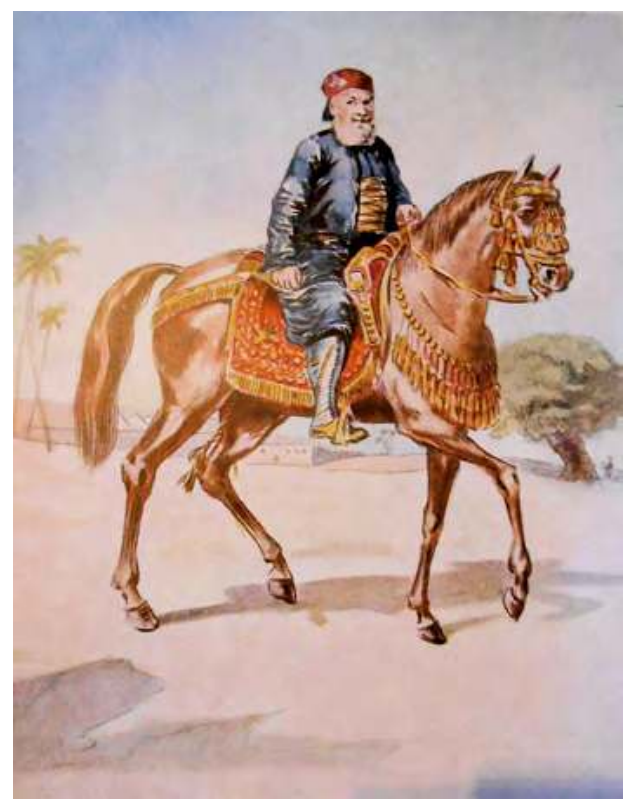

Méhémet Ali en 1813 .

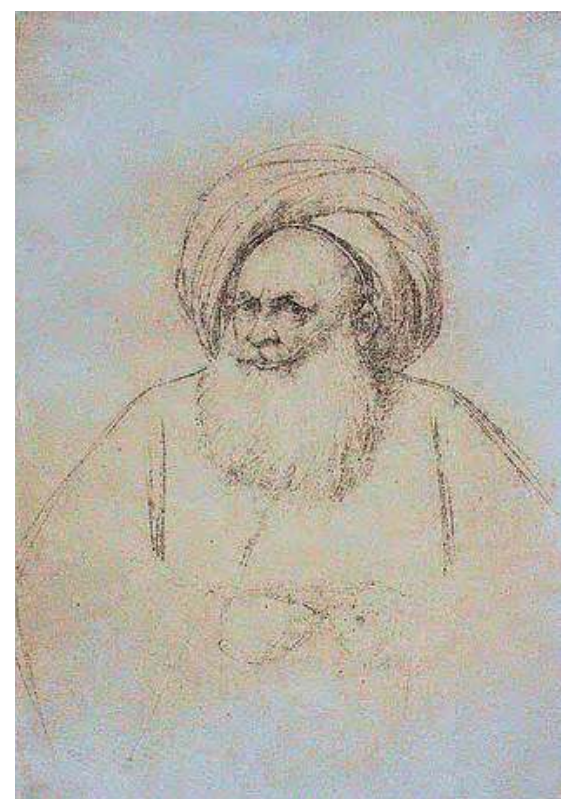

Méhémet Ali en 1835 .

1 Al-Nizam al-Fedid (arabe) : la nouvelle organisation des forces armées; Méhémet Ali souhaite réformer l'armée en s'inspirant du modèle des armées professionnelles européennes. 
La Nubie égyptienne ayant été pacifiée dès 1813, les troupes de Méhémet Ali quittent Wadi Halfa dans les premiers jours d'octobre 1820. Fort de 1600 cavaliers, de 2100 fantassins, de 300 artilleurs servant 12 pièces et de 2000 hommes d'intendance, ce contingent est confié à Ismaill, le fils de Méhémet Ali. La colonne est accompagnée de plusieurs savants occidentaux, dont le minéralogiste français Frédéric Cailliaud ${ }^{1}$ qui en a laissé une description vivante et remarquablement illustrée.

L'expédition remonte le Nil et rencontre peu de difficultés en pénétrant le Dongola, d'où elle chasse les derniers Mamelouks. Nombreux sont les potentats locaux qui offrent leur soumission: Berber, Shendi... Seuls les Arabes Chaykyés résistent avec panache, mais sans succès, à deux reprises, dans des combats en décembre 1820. Au départ, les Chaykyés avaient accepté de se soumettre au pacha d'Égypte et de lui payer un tribut, mais Ismail exigea la remise des armes et des chevaux, provoquant la rupture des négociations; l'armée massacra sans merci ceux qui tombèrent entre ses mains et dont les oreilles furent coupées, chaque paire étant payée 25 piastres turques par Ismaïl. Recevant plusieurs sacs de ces paires d'oreilles envoyées par son fils, Méhémet Ali s'empresse de le mettre en garde contre une telle conduite: 《KJ'ai bien reçu votre lettre en même temps que les oreilles des Chaykyés. Eh bien, cher fils, aucun gouvernement n'ignore cependant que c'est par la justice seule qu'on peut s'attacher les cœurs des populations [...] Il eût été préférable que vous eussiez cherché à gagner la population des Chaykyés par les ménagements et par la douceur [...]. \\ Ismail finit par former avec les Chaykyés un corps de cavalerie auxiliaire qui accompagne l'armée égyptienne dans le Sennar; à partir de cette époque, les Chaykyés deviennent les fidèles serviteurs du gouvernement égyptien au Soudan.

L'armée s'approche du royaume des Fundj au niveau de la ville d'Halfaya. Cailliaud raconte: 《L Depuis quelques jours, le melik ${ }^{2}$ de la province d'Halfaya avait fait annoncer à Ismail qu'il se rangeait sous son obéissance; il fut dès lors fait défense, sous les peines les plus rigoureuses, de faire le moindre tort aux habitants.

1 Frédéric Cailliaud: scientifique français (1787-1869); originaire de Nantes, il se forme en minéralogie et en géologie. Il va effectuer deux voyages en Égypte, le premier de 1815 à 1819, le second de 1819 à 1822 , où il explorera le désert égyptien, puis il découvrit les pyramides de Méroé.

2 Melik ou mek: chef. 
le Soudan

\section{4}

de 1820

à nos jours
Le 22 mai 1821, [...] quelques soldats s'amusèrent à mettre le feu à un village abandonné. L'incendie se propagea promptement à un autre qui était voisin et qui devint aussi la proie des flammes, à la vue des habitants éplorés qui poussaient des cris de désespoir. Cette atrocité gratuite demeura impunie, le pacha n'ayant pu découvrir les coupables.

La ville d'Halfaya, presque déserte, était bien moins considérable que celle de Shendi; beaucoup d'habitants avaient pris la fuite; les autres avaient caché leurs provisions, et, avec une feinte bonhomie, se disaient affligés d'une disette extrême. La politique d'Ismaïl étant de s'introduire dans le pays comme un libérateur, qui venait de mettre fin à l'oppression des Chaykyés; les égards avec lesquels il traitait les chefs de province, à qui il donnait des vêtements d'honneur et des armes; le soin qu'il avait de ne frapper d'autres contributions que celles qui étaient indispensables pour la subsistance de ses troupes; toutes ces considérations avaient fait croire à ces peuples que l'armée turque ne tarderait pas à rétrograder, si elle ne périssait pas entièrement dans le Sennar.

La population de Halfaya peut être estimée à trois ou quatre mille âmes; elle était de huit ou neuf mille âmes avant les invasions des Chaykyés. Les maisons, par groupes épars, sont entourées de grands enclos; ce qui fait qu'au total la ville occupe un emplacement qui n'a pas moins d'une lieue et demie de circonférence. Elle n'est coupée par aucune rue régulière. Les habitations, construites en argile, sont basses; deux ou trois seulement sont élevées d'un étage; ce sont celles des notables du lieu; elles sont surmontées de terrasses construites aussi en argile; des gouttières en troncs de dattier creusés servent à l'écoulement des eaux pluviales. Le pays, autrefois tributaire du Sennar, s'était rendu indépendant depuis cinquante ans environ.

Le 27 mai 1821, l'armée se mit en marche. Nous n'étions plus qu'à quelques heures de l'embouchure du fleuve Blanc: ce jour fut pour moi un des plus beaux de mon voyage. La route suit le bord du fleuve; il n'y a plus de terres cultivées: à l'ouest, le sol, plus élevé, était couvert de bois touffus d'acacias; les guides de l'armée me dirent qu'on y trouvait des girafes; [...]. L'hippopotame est commun dans cette partie du Nil. Après deux heures de marche, nous vîmes [...] l'île de Touti, de moyenne étendue au confluent du Bahr el-Azraq avec le Nil. L'armée campa sur le bord de ce dernier fleuve, en un lieu nommé Omdourmân [...]. Ici commence le royaume de Sennar. On m'apprit qu'il y avait, sur l'île de Touti, des ruines chrétiennes que je pus aller visiter. 
Nos guides me dirent que le fleuve Blanc s'élargit vers le sud et que cette branche est reconnue par les indigènes pour être plus considérable et plus étendue que l'Azraq ${ }^{1}$. Plus tard, l'expédition du prince ayant poussé jusqu'à Dinka ${ }^{2}$, je pus m'assurer de ce fait; telle était aussi l'opinion des auteurs anciens. On peut donc regarder aujourd'hui comme certain que les sources vues par Bruce en Abyssinie, et qu'il a prises pour les sources du Nil sont, en dernier résultat, celles du fleuve Bleu. En effet, selon les renseignements nombreux que j'ai obtenus sur le cours du fleuve Blanc, tous d'accord avec certaines des cartes des anciens et même avec celle de d'Anville ${ }^{3}$, il n'est pas douteux que son cours s'étend dans l'ouest, et non dans l'est comme Bruce l'a indiqué pour donner plus de vraisemblance à son assertion erronée. Le vrai Nil est le fleuve Blanc, dont le cours, très étendu, prend, suivant toute probabilité, son origine dans les montagnes de la Lune.

Ici, rebutés par des marches forcées et par les mauvais traitements des soldats, beaucoup de domestiques désertèrent; les nègres surtout, qui se rapprochaient de leur pays, le Kordofan et le Djebel-Nouba. Pour mon compte, je perdis un noir que j'avais acheté à Berber pour le prix modique de 75 francs; entraîné par ses camarades, il déserta.

Le 28 mai, dès que le pacha eut ordonné de traverser le fleuve Blanc pour se porter sur la presqu'̂̂le du Sennar, ce fleuve fut en un instant couvert de troupes. L'espoir de combattre bientôt, qu'on avait eu soin d'entretenir parmi les combattants; la perspective du pillage et d'un riche butin; la certitude de lutter avec avantage contre un ennemi qui n'aurait à opposer à leurs armes à feu que des lances et des sabres; l'expérience qu'ils avaient faite de cette supériorité incontestable, lorsqu'ils avaient eu à faire avec les Chaykyés; tout cela enflammait les âmes d'une ardeur poussée jusqu'à l'enthousiasme. Durant trois jours, sur une grande étendue, la surface du fleuve fut couverte de chameaux, de chevaux, de Turcs et d'Arabes qui se jetaient à la nage, les uns soutenus par des outres remplies d'air, ou montés sur des pièces de bois; les autres s'accrochant à la queue des chevaux ou grimpés sur les chameaux; c'est ainsi que passa l'armée, composée, avec les domestiques, de cinq mille cinq cents hommes et trois mille chameaux ou chevaux. On peindrait difficilement le tumulte, la confusion, le brouhaha, les cris des hommes et des animaux,

1 Le (bahr) Azraq (arabe) bleu; par extension, le Nil Bleu.

2 Comprendre: au pays des Dinkas (le Sud Soudan).

3 Jean Bourguignon d'Anville est cartographe du roi quand

il fait parâtre en 1727 ses cartes d'Afrique; son travail de cartographe

" de cabinet", s'avéra fort utile à différents explorateurs;

il fut le premier à cartographier avec précision le cours du Nil

jusqu’à Khartoum. (Voir cartes p. 545 et 546. ) 
le Soudan

\section{6}

de 1820

à nos jours le retentissement des coups dont on accablait ces pauvres bêtes pour les lancer à la nage et les faire avancer $[. .$.$] ce zèle coûta la vie à une trentaine d'hommes,$ et cent cinquante chameaux ou chevaux furent noyés.

Cette pointe de terre, qui forme l'extrémité de la presqu'île du Sennar, où l'armée campa entre les deux fleuves, se nomme Râs el-Gartoum ou el-Khartoum ${ }^{1}$. Je pus successivement observer le courant du fleuve Blanc et celui du fleuve Bleu; celui-ci a bien moins de rapidité, et est d'un tiers plus étroit que le premier.

L'expédition continue vers la capitale du royaume de Sennar, en proie à des luttes intestines qui lui permettent de l'occuper pacifiquement dès son entrée le 12 juin 1821. Le roi Badi IV offre sa soumission à Ismaïl Pacha qui, souhaitant briller aux yeux de son père, lance dans toutes les directions ses troupes à la chasse aux esclaves, organise des razzias continuelles parmi la population afin d'envoyer à Assouan les Africains destinés à former le noyau de l'armée nouvelle. De plus, Ismail impose les villages du royaume et, par ses violences, crée un mouvement d'émigration des populations qui cherchent à se soustraire à son autorité. L'insalubrité des lieux commence à décimer les troupes, qui ont de plus à faire face à une pénurie de vivres.

Heureusement pour les Égyptiens, le fils aîné du vice-roi, Ibrahim, était en route, à la tête d'une nouvelle expédition destinée à conquérir le Darfour. Une fois l'armée rétablie, Ismaïl conquiert le Fazogl ${ }^{2}$ et arrive jusqu'aux sables de Kamamyl, supposés riches en or; l'armée égyptienne a eu à subir lors de cette conquête des difficultés et des pertes conséquentes, car elle était obligée de lutter contre des tribus nombreuses et puissantes, bénéficiant de l'avantage d'un terrain montagneux et boisé. Pire, les sables de Kamamyl se révèlent pauvres en or, et Ismaïl, déçu dans ses espoirs de découvrir de riches mines d'or et des multitudes d'esclaves, redescend vers le Sennar après avoir atteint la limite de l'Abyssinie, en février 1822 .

Pendant ce temps, une troisième armée égyptienne, commandée par le defterdar ${ }^{3}$ Mohamed Bey Khusraw, engage en octobre 1821 la conquête du Kordofan. Quittant la province de Dongola pour entamer une marche de onze jours dans le désert, il rencontre l'armée du Kordofan, commandée

1 Rảs al-Khurțüm: «la pointe, le bout» (ra’s) de la "trompe (d'éléphant)» (Khurtūm). C'est la forme de la bande de terre, qui s'avance au milieu des deux Nils à leur confluent, qui explique cette dénomination.

2 Fazogl: région de l'État du Nil Bleu, située sur le fleuve entre Sennar et la frontière éthiopienne (ville de Famaka).

3 Defterdar (turc): intendant des finances tenant le registre des propriétés foncières, base de calcul des taxes. 
par le makdoum ${ }^{1}$ Musselim, roi ou gouverneur du pays. Les troupes du Kordofan, selon le Defterdar, s'élèvent à quinze cents cavaliers et à huit mille fantassins. À l'issue d'un combat sans merci, les soldats égyptiens soutiennent la lutte jusqu'au soir et remportent la victoire en infligeant à l'ennemi de lourdes pertes: le roi Musselim lui-même, deux cents cavaliers et plus de mille fantassins périssent. Dès ce moment, le royaume du Kordofan, vassal du Darfour, passe sous contrôle égyptien; les fusils turcs l'emportent sur la cavalerie Four, équipée de cottes de mailles, et ses alliés arabes.

Pour des raisons tant internes qu'externes, la conquête du Darfour est postposée. Méhémet Ali souhaite d'abord organiser la conquête dans le Halfaya-Sennar, le Fazogl et le Kordofan considérés comme trois provinces, un ensemble déjà malaisé à administrer en raison du faible nombre de troupes disponibles. À l'extérieur, la guerre de Morée (îles grecques) et des troubles dans l'Empire ottoman vont à ce moment focaliser l'attention de la Sublime Porte et de Méhémet Ali.

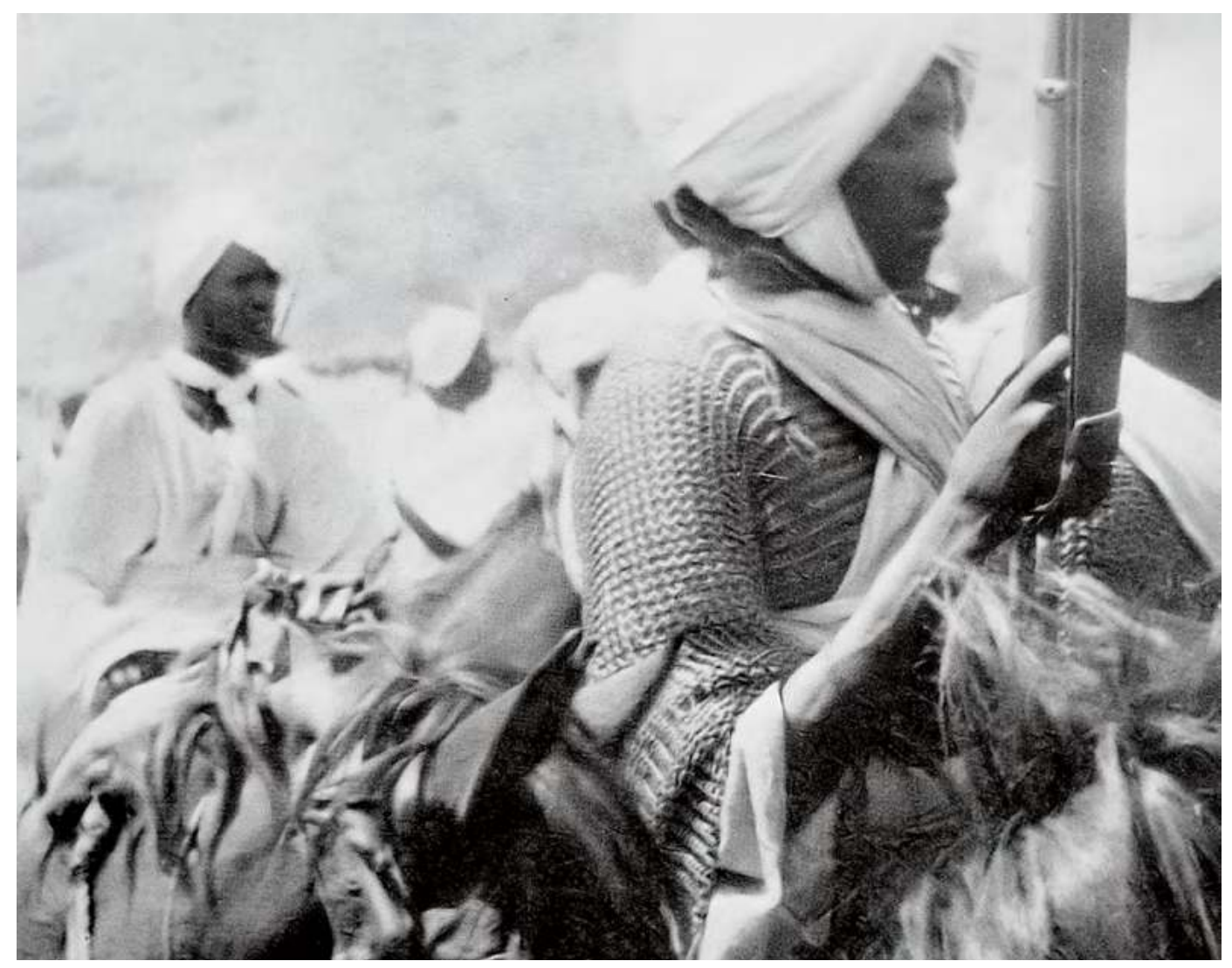

Arabes des Monts Nouba portant des cottes de mailles (1924).

1 Makdoum (arabe) : gouverneur. 
En 1822, en l'absence d'Ismail Pacha, les méthodes de collecte des taxes poussent la population du Sennar à la révolte. Après son retour et le rétablissement de l'ordre, Ismaïl quitte le Sennar en octobre 1822 et, passant par Shendi, réclame à son chef, le mek Nimr, une forte contribution en esclaves et en espèces. Ayant exprimé au pacha l'impossibilité de collecter cet impôt extraordinaire, Nimr se voit frappé, couvert d'insultes et de menaces. En s'unissant avec un mek voisin, il s'acquitte de cette contribution inattendue en ravalant sa rage. La nuit, il réussit à entourer de chaume la cabane où se trouvaient Ismaïl et ses compagnons à la veille de leur départ, et il y met le feu. La plupart meurent brûlés et ceux qui cherchent à échapper au feu sont transpercés par les lances de la troupe du mek Nimr. Ce fait de résistance, qui fait partie des thèmes clefs de l'identité soudanaise, est enseigné et joué encore aujourd'hui dans les écoles primaires.

Le Defterdar présent dans le Kordofan se dirige immédiatement vers le Sennar où il exécute plus de trente mille victimes. Cet événement restera gravé dans les mémoires soudanaises. Ainsi s'achève la première phase de la conquête du Soudan.

le Soudan

558

de 1820

à nos jours

\section{L'administration turco-égyptienne}

\section{et l'entrée du Soudan dans le monde moderne}

L'écrasement de la rébellion arabe qui suit la mort d'Ismaïl, orchestrée par le Defterdar avec force atrocités, va influencer l'attitude des Soudanais envers l'administration des "Turcs» jusqu'à la fin de leur présence. Le Defterdar est relevé en 1824, et finalement jugé non fiable par son beau-père, le vice-roi, qui le fait empoisonner en 1833 .

L'administration change peu avec la nomination du nouveau gouverneur pour les provinces de Sennar et de Berber, Othman Jakas al-Birniji, un Circassien ${ }^{1}$ de l'entourage du vice-roi. Sa politique fiscale oppressive brutale, visant à collecter des taxes excessives auprès des cultivateurs de la fertile vallée de la Gézireh, pousse ces derniers à fuir dans

1 Circassie: ancienne contrée de la Russie, située sur les deux versants

du Caucase, entre la mer Noire à l'ouest et la mer Caspienne.

Les habitants sont à l'est des Tchétchènes, à l'ouest des Tcherkesses.

Traditionnellement à la fois guerriers et pasteurs, et très attachés à leur indépendance, ils vivaient sous la loi de princes. Ils professent l'islam; ils étaient encore chrétiens à la fin du Xve siècle. La Circassie appartint aux Turcs, à qui les Russes l'enlevèrent au XviII ${ }^{\mathrm{e}}$ siècle, mais elle ne fut réellement soumise qu'en 1859 . 
le désert, où ils périssent de faim ou de maladies, et vaut à Othman Bey une mise en garde du vice-roi. En septembre 1824, il s'établit à Khartoum, au confluent des deux Nils.

La mort subite d'Othman Bey le fait remplacer par un Kurde, le mamelouk Mahu Bey Urfalu. Ce dernier accomplit un travail remarquable en une seule année de gouvernorat, pacifiant le pays, suspendant la collecte de l'impôt pour une durée de trois ans, décentralisant l'administration et restaurant la discipline des troupes. Avec Mahu Bey Urfalu fut initié pour le gouvernement du Soudan le principe d'association avec le cheikh Abdel Kader, une notoriété soudanaise qui sera consultée pendant plus de trente ans sur les affaires du pays, jusqu’à son décès en 1857 .

En 1826, Ali Khurchid Agha est nommé hikimdar ${ }^{1}$ du Soudan. Investi de larges pouvoirs, il découvre son nouveau domaine en ruines, après seulement cinq années sous hégémonie turco-égyptienne. Dès son arrivée, il réunit en conseil tous les chefs de service pour étudier les causes du mal et apporter les remèdes nécessaires; ces délibérations sont envoyées au vice-roi dès l'année de son installation. Le rapport révèle toutes les tares de l'administration initiale, l'oppression fiscale et la corruption des agents du pouvoir, la dépopulation du Sennar dont les habitants ont été décimés par la faim, la peste et l'émigration. Le rapport recommande la justice, la lutte contre la corruption, l'encouragement de l'agriculture et l'introduction de puits à roues (saqieh) pour arroser la terre, ainsi que l'établissement d'un système d'impôts adapté propice à ranimer la confiance générale et à inciter les émigrés à revenir. Dès 1826, 118 chefs et sous-chefs égyptiens sont envoyés pour initier les Soudanais à l'agriculture, ainsi que des contremaîtres pour introduire l'industrie, surtout la poterie et la construction de bateaux. Khurchid Pacha favorisa l'introduction de nouvelles cultures, le développement de celle du coton et la renaissance de la région de Gézireh. Il est le premier organisateur du Soudan égyptien et fait preuve de justice, de fermeté et de tact. Le gouvernement du hikimdar, qui se poursuit jusqu'en 1838, est marqué de nombreux progrès en termes de développement.

C'est aussi en 1826 que Méhémet Ali envoie en cadeau au roi de France Charles X une girafe provenant du sud-est du Soudan. Dès l'automne 1824, il en a ordonné la capture afin d'offrir un cadeau diplomatique destiné à mitiger la mauvaise image de l'Égypte d'alors en Europe. Capturé en amont du Nil Bleu en 1825, un couple de girafons est emmené d'abord par chameau jusqu'à Sennar, puis en felouque jusqu'à Khartoum, où il poursuit le voyage jusqu’au Caire puis Alexandrie. Le consul général

1 Hikimdar (arabe) : littéralement commissaire, terme utilisé pour le poste de gouverneur général du Soudan jusqu'en 1885. 


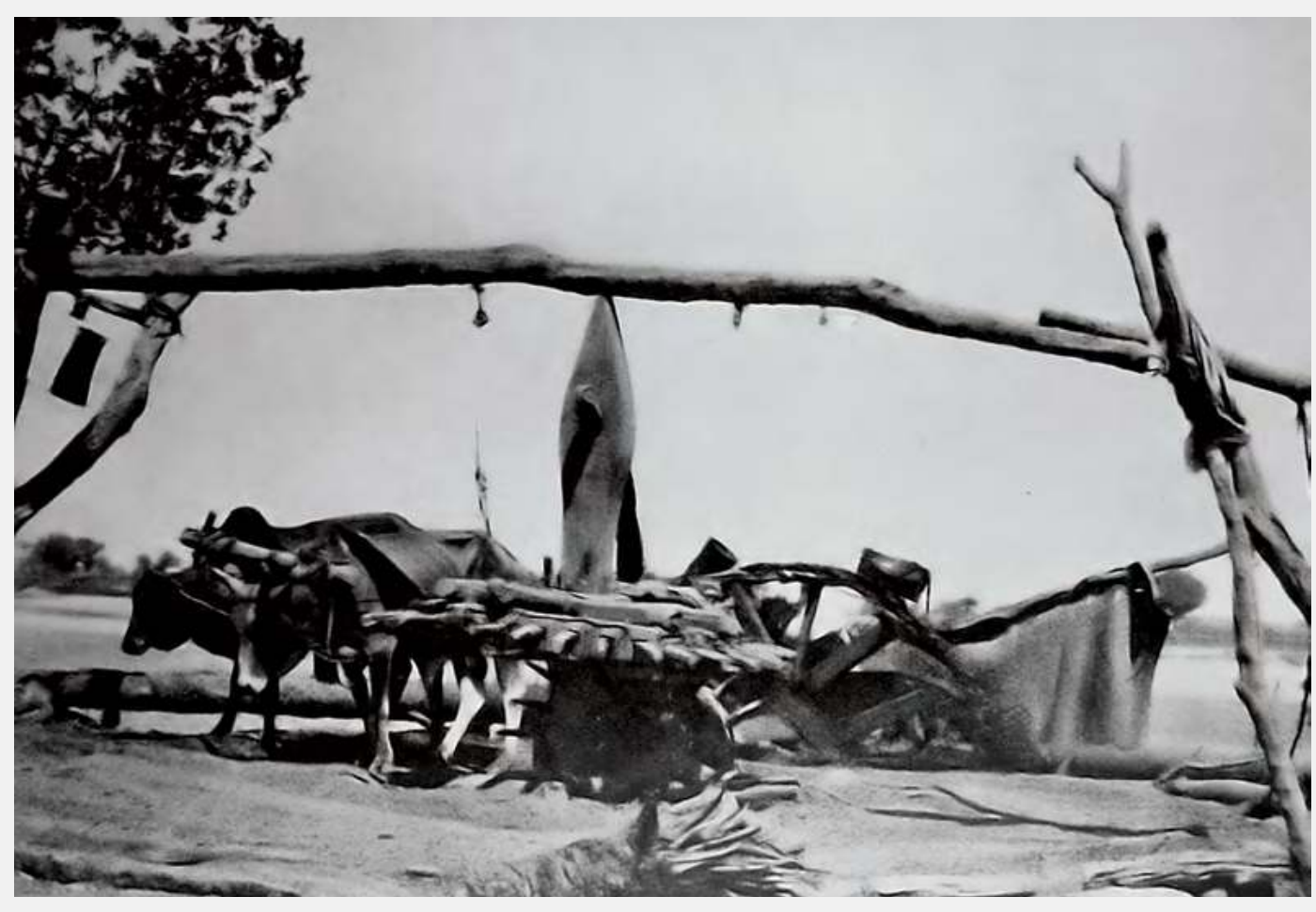

le Soudan

Sakiye au nord du Soudan (1929).

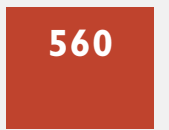

de 1820

à nos jours

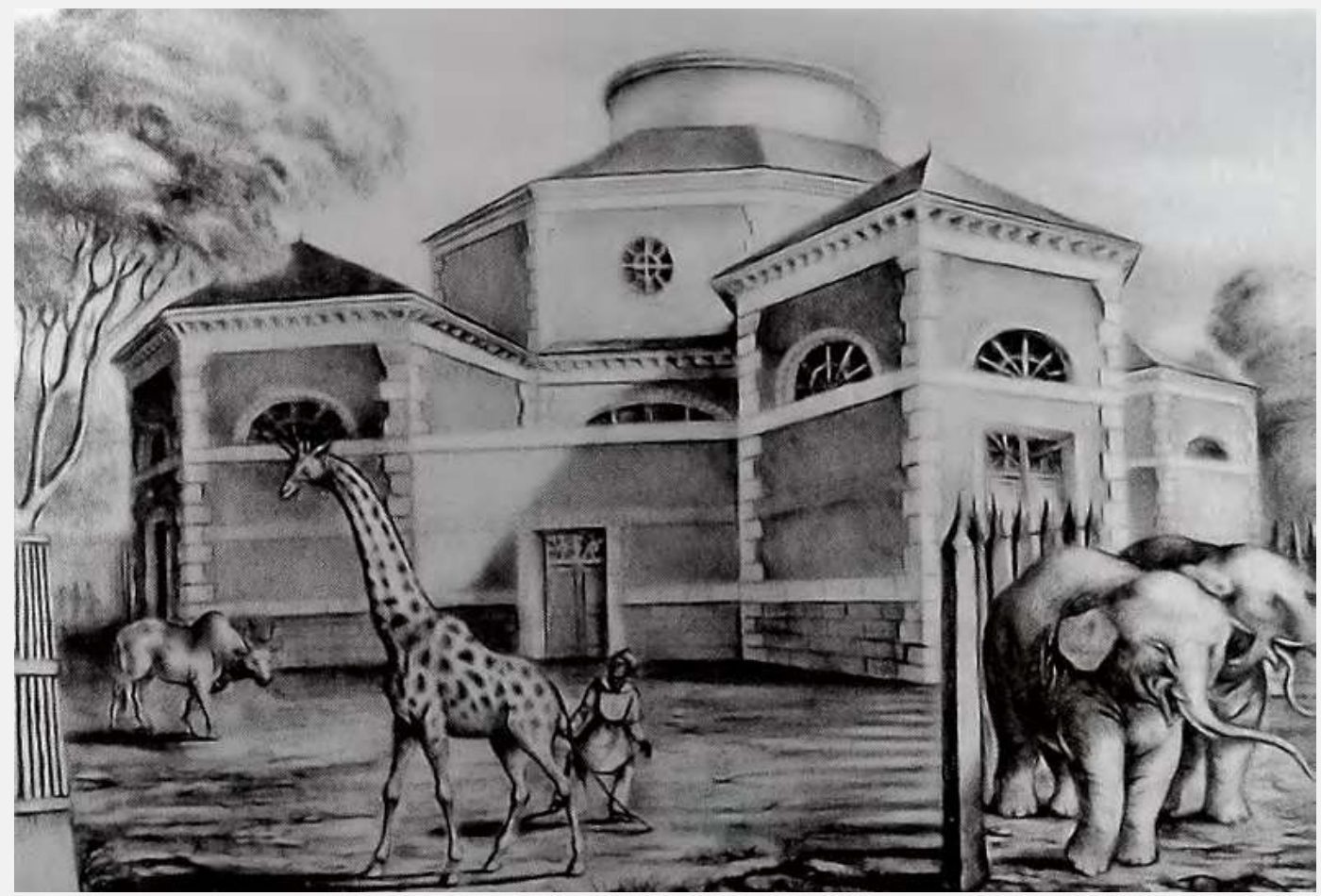

La girafe soudanaise de Charles $\mathrm{X}$. 
français Bernardino Drovetti, conseiller personnel de Méhémet Ali et expérimenté dans le commerce d'animaux pour l'Europe, joue un rôle majeur dans l'organisation du voyage. Les deux girafes arrivent à Marseille fin octobre 1826 avec leurs soigneurs, dont l'un, soudanais, les a suivies depuis le Sennar. La girafe de Charles X vécut au jardin des Plantes à Paris jusqu'en 1845 .

Khurchid Pacha développe aussi l'esclavage par de nombreux raids contre les Shillouks, les Dinkas et les Hadendowas, raids qui souvent rencontrent une forte résistance.

Méhémet Ali visite le Soudan en 1838, en descendant le Nil jusqu’à Khartoum, puis il rejoint Wad Madani, petite ville de 300 familles proprement logées, avec une caserne et des magasins, et traverse Roseires pour atteindre le Fazogl. Pendant ce séjour, il s'investit dans la promotion de l'agriculture, du commerce et de l'éducation. Il proclame aussi la liberté de commerce de l'indigo, produit en abondance à Dongola et Berber.

Le successeur de Khurchid Pacha est un ancien esclave d'origine circassienne, amené en Égypte où il fait une carrière militaire. Ahmed Pacha Abou Ahdan est gouverneur général du Soudan de 1839 à 1843. Il doit d'abord réprimer la révolte de la tribu des Hadendowas, partie des Bedja, à l'est, au cours d'une campagne de dix-huit mois. Reprenant Kassala après de durs combats, Ahmed Pacha poursuit sa progression dans la zone du Nil Bleu en quête d'esclaves pour l'armée de Méhémet Ali. Mais ses troupes, au nombre de cinq mille hommes accompagnés d'artillerie, sont mises en déroute par la population de Kurmuk (Nil Bleu) seulement armée de lances.

En 1840, des industriels européens fondent près de Khartoum, sous la protection du gouvernement égyptien, de vastes établissements industriels: savonnerie, indigoterie, sucrerie, distillerie. Ces fabriques sont longtemps prospères grâce au combustible bon marché et à la maind'œuvre payée à vil prix, grâce surtout au monopole dont jouissent les manufacturiers: les officiers et les soldats sont obligés de consommer les produits, payés d'office sur leur solde.

Ahmed Pacha favorise aussi la navigation en construisant de nombreux bateaux qui formèrent le noyau de la marine marchande du Soudan. Il innove en matière d'administration, supprimant le monopole sur l'ivoire en 1849 et combattant la corruption dans l'administration, spécialement celle des Coptes qui utilisaient leur savoir pour tromper leurs maîtres turcs. Il est extrêmement populaire auprès des troupes noires de l'armée égyptienne. Il interdit la chasse aux esclaves mais cette mesure demeura inappliquée. 
le Soudan

\section{2}

de 1820

à nos jours
En 1843, Méhémet Ali ordonne la constitution d'une puissante armée pour l'invasion du Darfour, mais l'opération est annulée en dernière minute car le vice-roi soupçonne Ahmed Pacha de trahison, tant sa popularité est grande. Quand Méhémet Ali prend connaissance des rumeurs selon lesquelles le gouverneur négocierait avec le sultan ottoman la séparation du Soudan et de l'Égypte, il le rappelle au Caire. Le gouverneur général préfere alors absorber une dose mortelle de poison mais, selon la rumeur publique, ce poison aurait été administré par les soins de l'envoyé de Méhémet Ali. La dépouille d'Ahmed Pacha est abritée dans la plus ancienne qubba ${ }^{1}$ de l'ensemble de tombes turques toujours visible au centre de Khartoum, sur Abbas avenue (voir infra p. 584 sq.).

En 1849, Abbas devient vice-roi d'Égypte. Les gouverneurs se succèdent et l'influence des Européens et de leurs consuls grandit régulièrement, ce qui se traduit par les renvois successifs des gouverneurs généraux de Khartoum. Par ailleurs, Abbas, d'humeur ombrageuse, utilise Khartoum et le Soudan comme lieu de déportation et y construit des prisons.

Abdel-Latif Pacha, gouverneur général de 1850 à 1854, cherche à corriger les abus commis durant les années 1846 à 1850 . Il rétablit la justice et la sécurité, et sait gagner le respect des populations. C'est à lui que l'on doit de nombreux édifices: le palais du gouvernement, les casernes, les magasins militaires et les poudrières; il créa à Khartoum une école gouvernementale dirigée par des maîtres réputés.

En 1854, Saïd, le nouveau vice-roi d'Égypte, renouvelle l'interdiction de l'esclavage; le marché de Khartoum est fermé mais le trafic clandestin continue. En 1857, le vice-roi, visitant le pays, constate sa misère et évoque la possibilité d'abandonner la gestion décentralisée au Soudan; les populations locales insistent auprès de lui pour que soit maintenue la souveraineté égyptienne. Saïd diminue les impôts et fait preuve de tolérance en chargeant du gouvernement un chrétien réputé pour son respect de la justice et ses talents administratifs, Arakeel Bey (1857-1859), qui agit au détriment des Coptes et des Juifs, ce qui déplut aux populations.

En 1861-1862, la persistance du trafic d'esclaves entraîne une révolte des Dinkas, et les gouverneurs du Sennar et du Nil Blanc sont sanctionnés pour ne pas les avoir protégés. En 1862, une digue est construite, afin de garantir Khartoum de l'inondation annuelle; la même année est créée une chambre de commerce. 
Moussa Pacha Hamdi (1862-1865), enterré dans la qubba occidentale du cimetière turc de Khartoum (voir infra p. 584), était un militaire d'origine circassienne. Esclave vendu au Caire à un Turc, Moussa Hamdi entra dans l'armée dont il gravit rapidement les échelons. Il mena une dure campagne de répression contre les Bedja révoltés à l'est. Son action demeure controversée: selon les sources anglaises, il augmente le montant des impôts jusqu'à des sommets jamais égalés et permet au commerce des esclaves de se développer sans entrave. Il entre en conflit avec les armées privées des trafiquants d'esclaves dans le Sud. Samuel Baker le considérait comme la caricature de l'autorité turque.

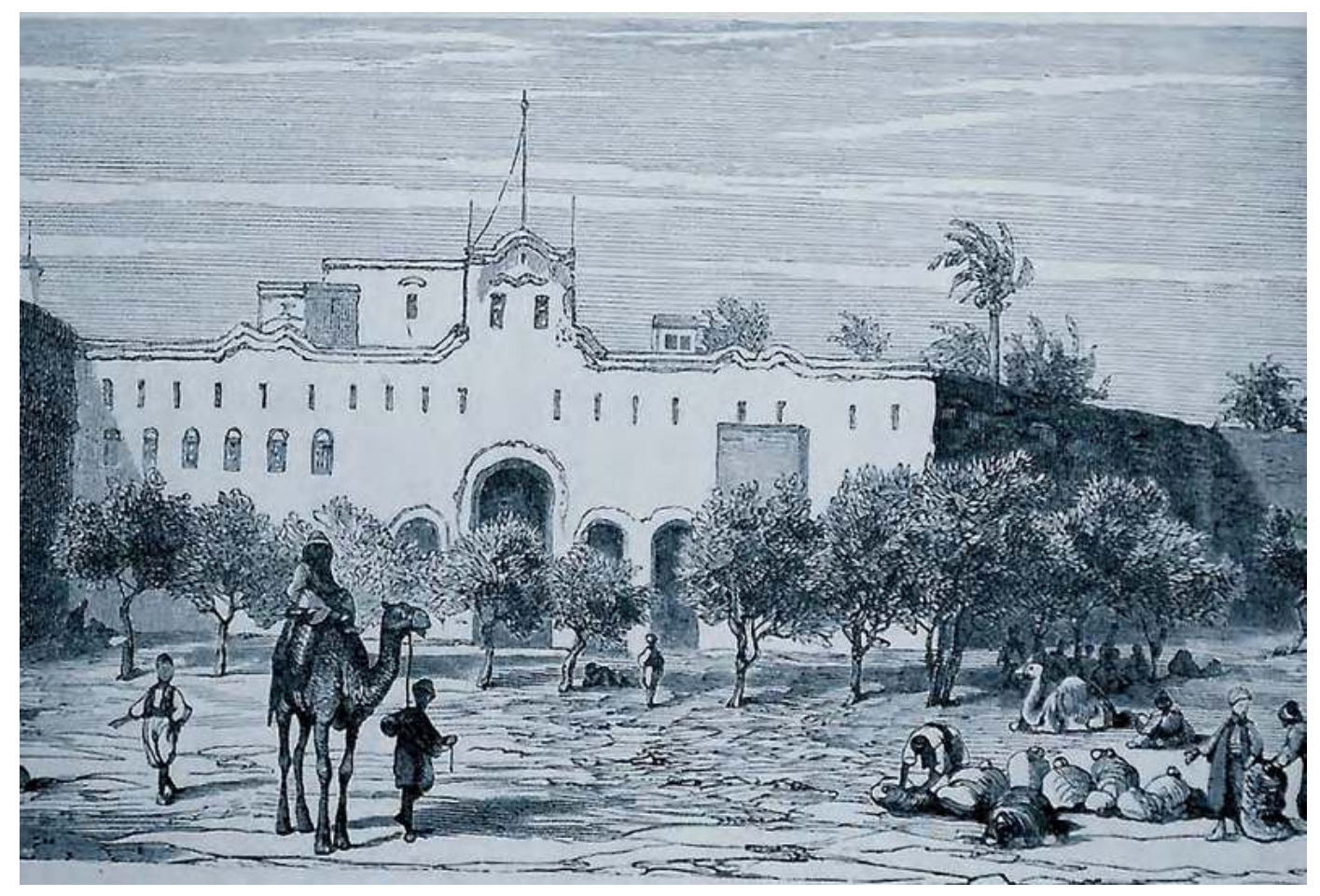

La mudirie de Khartoum dans les années 1860.

De 1865 à 1871, Jaffar Mahzar Pacha organise le corps des Oulémas dont la présidence est confiée à un Soudanais, tout comme le gouvernorat de Khartoum. Des efforts de rigueur budgétaire et dans le domaine de la santé publique sont menés.

En 1866, les ports de Souakin et de Massaoua, dépendants de l'Égypte depuis 1846, passent sous le contrôle du Soudan, pour mieux lutter contre le trafic des esclaves. 
le Soudan

\section{4}

de 1820

à nos jours
À partir de 1869, le khédive Ismail initie une politique d'administration mixte (Égyptiens-Européens), d'abord au Sud (gouverneurs de la province d'Équatoria: Samuel Baker en 1869 puis Gordon en 1874) puis au niveau du Soudan (Gordon 1877-1879), et cette politique créera un terrain favorable à l'insurrection mahdiste.

La mission confiée à Samuel Baker est double: étendre les limites du Soudan jusqu'aux Grands Lacs, dont il est un des découvreurs, et lutter contre l'esclavage.

En 1871, le télégraphe relie Khartoum au Caire. Le réseau sera renforcé et étendu aux provinces sous la direction de Giegler Pacha (qui résidera à Khartoum de 1873 à 1883). Celui-ci commence à son arrivée par déplacer dans la ville le terminal, qui est installé au niveau de l'actuel Khartoum Nord, de l'autre côté du Nil Bleu, afin d'être plus facilement accessible. En 188o, un travail important a été réalisé, et le réseau couvre plusieurs provinces et villes importantes. Giegler en a laissé une carte impressionnante. À l'ouest, Khartoum est relié à el-Obeïd, et une ligne est en projet pour atteindre el-Fasher au Darfour. L'est est bien desservi: Kassala, Gedaref, Fazogl, Sennar, ainsi que Massaoua et Souakin sont reliées à Khartoum. Au sud, le télégraphe relie Fachoda à Khartoum, et, au nord, la ligne unissant Khartoum au Caire dessert sur son passage les villes de Shendi, Berber, Dongola et Wadi Halfa.

À la même époque, une réforme (de portée éphémère) supprime le niveau administratif couvrant l'ensemble du Soudan égyptien ainsi que le poste de gouverneur général, et plusieurs provinces autonomes sont créées, les gouverneurs ayant à répondre directement au Caire. La province joignant Dongola et Berber est gouvernée par Hussein Bey Khalifa; la province de Khartoum, à laquelle sont joints le Sennar, le Kordofan et Fachoda, est dirigée par Ismaïl Ayyub Pacha, basé à Khartoum; les provinces de l'est, Kassala, Souakin et Massaoua sur la mer Rouge, sont sous le commandement de Munzinger Bey ${ }^{1}$, qui réside à Massaoua.

1 Werne Munzinger (1832-1875) est un administrateur et explorateur suisse, qui a également fait œuvre d'ethnologue;

il collabore avec Heuglin dans l'exploration de l'Afrique centrale;

il est consul britannique, puis consul de France à Massaoua [port de l'actuelle Érythrée].

En 1871, il est nommé gouverneur de Massaoua par le khédive Ismaill Pacha, et, en 1874, gouverneur du Soudan oriental. Il meurt à la tête des troupes égyptiennes lors d'une attaque contre l'Éthiopie en 1875 . 
En 1874, le puissant marchand d'esclaves al-Zubayr Rahmat Mansur ${ }^{1}$, devenu un potentat disposant de son armée privée, conquiert le Darfour dont le sultan est tué, et il remet la province à l'administration égyptienne, mais sans obtenir toutefois le poste de gouverneur du Darfour qu'il convoitait.

Malgré les dépenses engendrées par l'œuvre d'organisation, la période de 1870 à 1874 correspond à une période de grande prospérité: le Soudan est alors un pays riche, populeux, grand producteur de blé, n'ayant aucune dette à supporter; après le paiement des dépenses du Darfour et de l'expédition vers les grands lacs, il verse au Trésor égyptien, selon les statistiques officielles, un tribu considérable de 150 ooo livres.

Ismail Ayyub Pacha, circassien, gouverneur de 1875 à 1877, était apprécié par Samuel Baker pour les améliorations qu'il avait apportées à Khartoum: l'achèvement de l'hôpital du gouvernement, la transformation des terrains vagues en jardins publics où il était possible d'entendre tous les soirs de la musique militaire et la création de nouvelles avenues qui rendent la ville plus agréable et plus salubre. S. Baker décrit aussi les travaux entrepris pour développer, avec la technologie à vapeur de l'époque, l'irrigation pour la culture du coton. Il mentionne encore la création d'une école pour l'éducation des plus intelligents parmi les jeunes Noirs qui pourraient être enlevés aux chasseurs d'esclaves. Baker salue enfin la création des provinces qui permet une administration de proximité plus facile à mettre en œuvre qu'à partir de Khartoum.

Les mémoires de C.C. Giegler sont probablement les seuls à mentionner la création d'une académie militaire à Khartoum en 1875 . L'objectif en est de remplacer progressivement les soldats égyptiens par des Soudanais.

Charles Gordon arrive en mars 1874 à Khartoum pour succéder à Samuel Baker comme gouverneur de la province d'Équatoria, avec mission de poursuivre la lutte contre l'esclavage. Il rétablit les monopoles d'État sur le commerce de l'ivoire, interdit la constitution de milices privées ainsi que l'accès au Sud, préfigurant la politique du closed district qui sera reprise après la Première Guerre mondiale pour "protéger» les populations du Sud. La limite méridionale du Soudan est fixée au lac Albert.

1 Zubayr (Zubeir): Arabe Djaalin né en 1830, il se lance dans la traite des esclaves et de l'ivoire à partir de 1856; au faite de sa puissance, il possède une trentaine de comptoirs (zéribas); il sera retenu au Caire pendant plusieurs années à partir de 1878; de 1885 à 1887, il sera emprisonné par les Anglais à Gibraltar, car soupçonné de soutien au Mahdi. 
le Soudan

\section{6}

de 1820

à nos jours

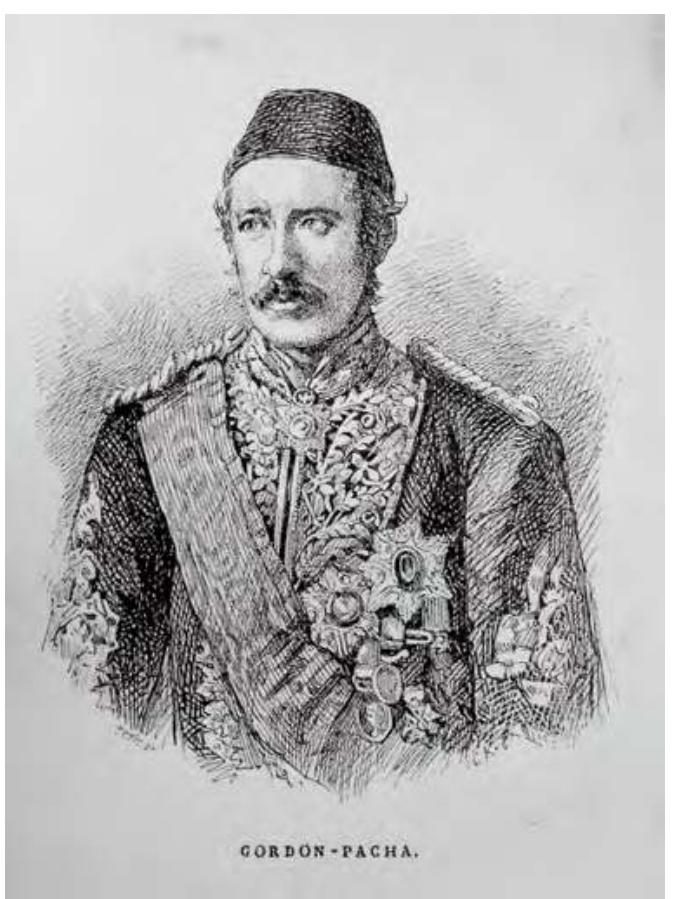

Gordon Pacha.

En 1876, Gordon est nommé gouverneur général du Soudan. L'année suivante, le khédive signe avec les Anglais une convention contre l'esclavage. Gordon engage en 1878 une répression méthodique de la traite, arrêtant près de 700 trafiquants en deux mois, en même temps qu'il épure l'administration des éléments complices. La lutte sera coûteuse en hommes et en munitions, et modifie les équilibres tribaux car Gordon a joué de certains groupes arabes (Baggara, Rizeigat...) contre d'autres (les Jallaba). Gordon quitte son poste en 188o. Comme le dit Chaillé-Long, officier américain au service du khédive: 《Gordon avait trouvé le Soudan en paix et pleine prospérité; lorsqu'il le quitte, le tribut avait disparu, une dette énorme avait été créée, et partout régnaient la terreur et la misère. \\Malgré les efforts de son successeur Reouf Pacha, le Soudan égyptien ne va pas se relever; le terrain était favorable à la croissance du mouvement mahdiste, qui était d'abord une révolte contre l'oppression.

En mai 1881, Muhammad Ahmad ibn Abd Allah, qui se proclame le $\mathrm{Mahdi}^{1}$, prend les armes contre le pouvoir; il entend restaurer la pureté de l'islam authentique et lutter contre les "Turcs», c'est-à-dire les Égyptiens.

1 Mahdi (arabe) : le Messie, personne guidée par Dieu, celle qui montre le chemin. 
La période $1882-1885$ est marquée par une succession de revers militaires sanglants pour l'armée égyptienne. L'importance des défaites va aller crescendo, et va renforcer l'aura du Mahdi, de plus en plus considéré comme doté de pouvoirs surnaturels. Cette montée en puissance aboutit à la chute de Khartoum en janvier 1885 - malgré le retour de Gordon en 1884 avec la mission limitée de rapatrier l'armée égyptienne. Ce dernier se rend compte très vite qu'il n'est pas possible de négocier avec le Mahdi qui repousse toute offre, ni d'évacuer Khartoum sans les renforts militaires qui lui seront refusés par le cabinet Gladston, jusqu’à une tardive inflexion sous l'influence de l'opinion publique. Le corps expéditionnaire, dont la préparation aura été très longue et qui comprenait un bataillon canadien (expert en navigation difficile afin d'assurer le passage dans les cataractes du Nil), arrivera quelques jours trop tard: la bannière du Mahdi flotte sur Khartoum et Gordon est mort.

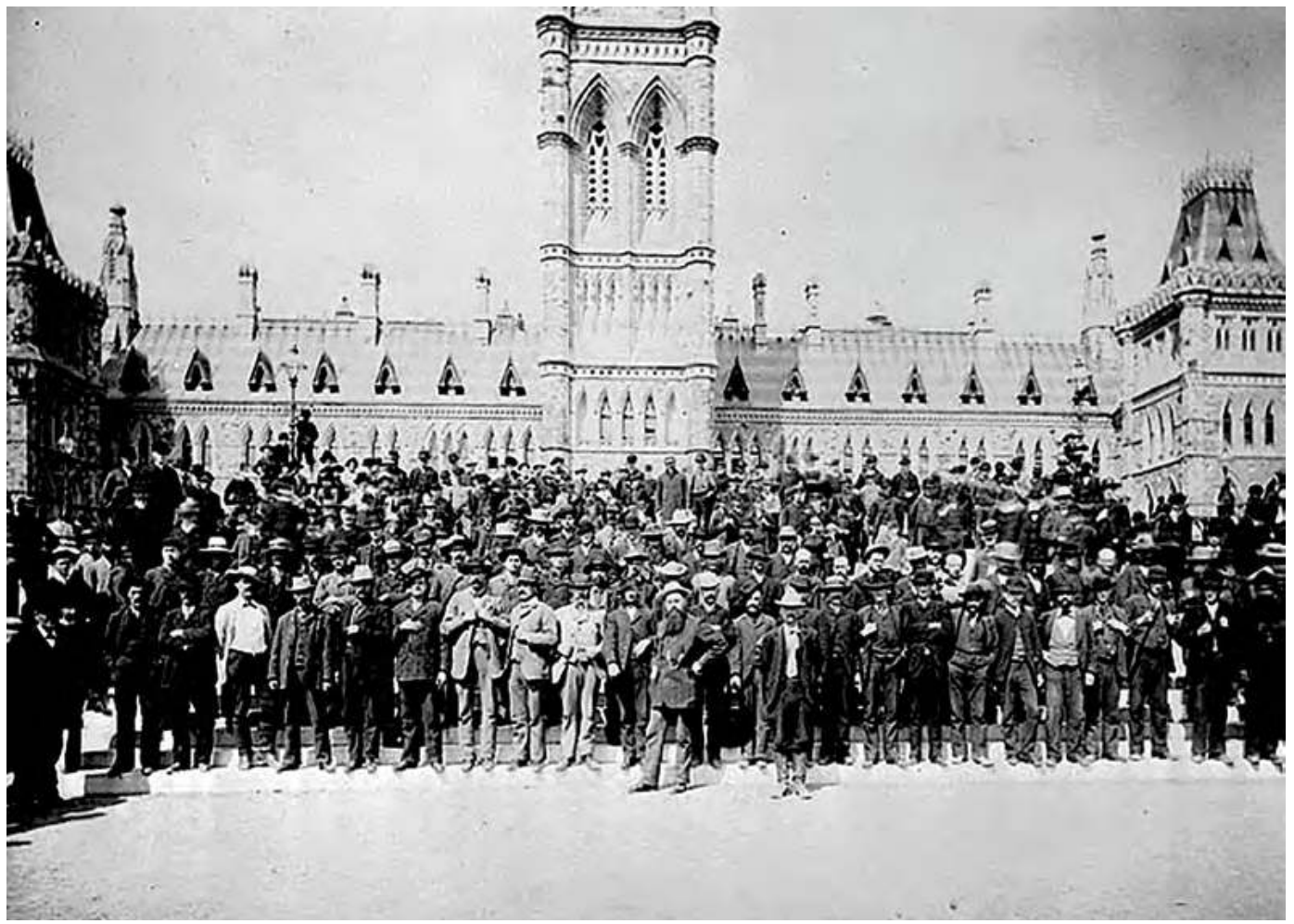

Canadiens de l'expédition de secours (1884). 


\section{L'extension du Soudan turco-égyptien vers la mer Rouge le port de Souakin}

Le port de Souakin et celui de Massaoua sont témoins au XVI ${ }^{\mathrm{e}}$ siècle de la lutte entre l'Empire ottoman, allié à Venise, et les Portugais, qui vont bloquer la route des épices venant d'Orient. Souakin sert de base arrière aux troupes de la Porte quand elles prennent le contrôle d'Aden, ce qui porte un coup sérieux au blocus portugais. Ultérieurement, Souakin va dépendre du pacha de Djeddah.

Au début du XIx siècle, Souakin dispose de fortifications et d'une garnison d'une quarantaine de soldats. La forteresse est armée de six canons de gros calibre et de dix-huit autres plus petits. Le gouverneur est nommé chaque année par le pacha de Djeddah. Les droits de douane sont fixés à $10 \%$ de la valeur de tous les produits qui entrent dans le port. Parmi ces derniers, on trouve de la magnésite, du sel de mer, de la poudre d'or venant de l'intérieur des terres et des perles pêchées par des plongeurs. Le maïs et le millet de Tokar, au Sud, fournissent deux récoltes par an.

Quatre forts équipés de canons protègent l'île, qui ne possède pas

le Soudan

\section{8}

de 1820

à nos jours de mur d'enceinte. On y trouve alors deux mosquées et sept écoles. À cette
époque déjà, l'état des maisons, construites en pierre corallienne friable, semble poser des problèmes. En 1814, un visiteur estime leur nombre à 600 sur l'île mais il précise que les deux tiers sont en ruine.

Environ 3000 personnes vivent alors sur l'île et 5000 à l'extérieur. La principale communauté est constituée par les descendants des natifs de l'Hadramaout (Yémen), en particulier de la ville de Shahher. D'où le nom donné aux habitants: les Hadherebe, les étrangers. Ces derniers se distinguent des tribus locales, telles que les Hadendowas, ainsi que des Turcs et des Arabes, tous rassemblés sous le nom de Souakiny.

En 1846, le port de Souakin et celui de Massaoua, dans l'Érythrée actuelle, passent sous le contrôle direct de l'Égypte. Les deux villes vont bénéficier de ce changement de tutelle. C'est le passage d'un caïmacan ${ }^{1}$ sans autorité à une administration relativement ferme et organisée. Des deux villes, Souakin est la mieux placée car la plus proche de Djeddah, la traversée de la mer Rouge, trajet d'au moins trente heures, étant alors entrepris par de très nombreux boutres.

1 Cä̈macan (du turc: Kaymakam): dignitaire de l'Empire ottoman. Cette fonction correspondait à l'origine à celle d'un «lieutenant» d'un sultan ou d'un grand vizir. Au XIX ${ }^{e}$ siècle, c'est le titre des gouverneurs de provinces. 


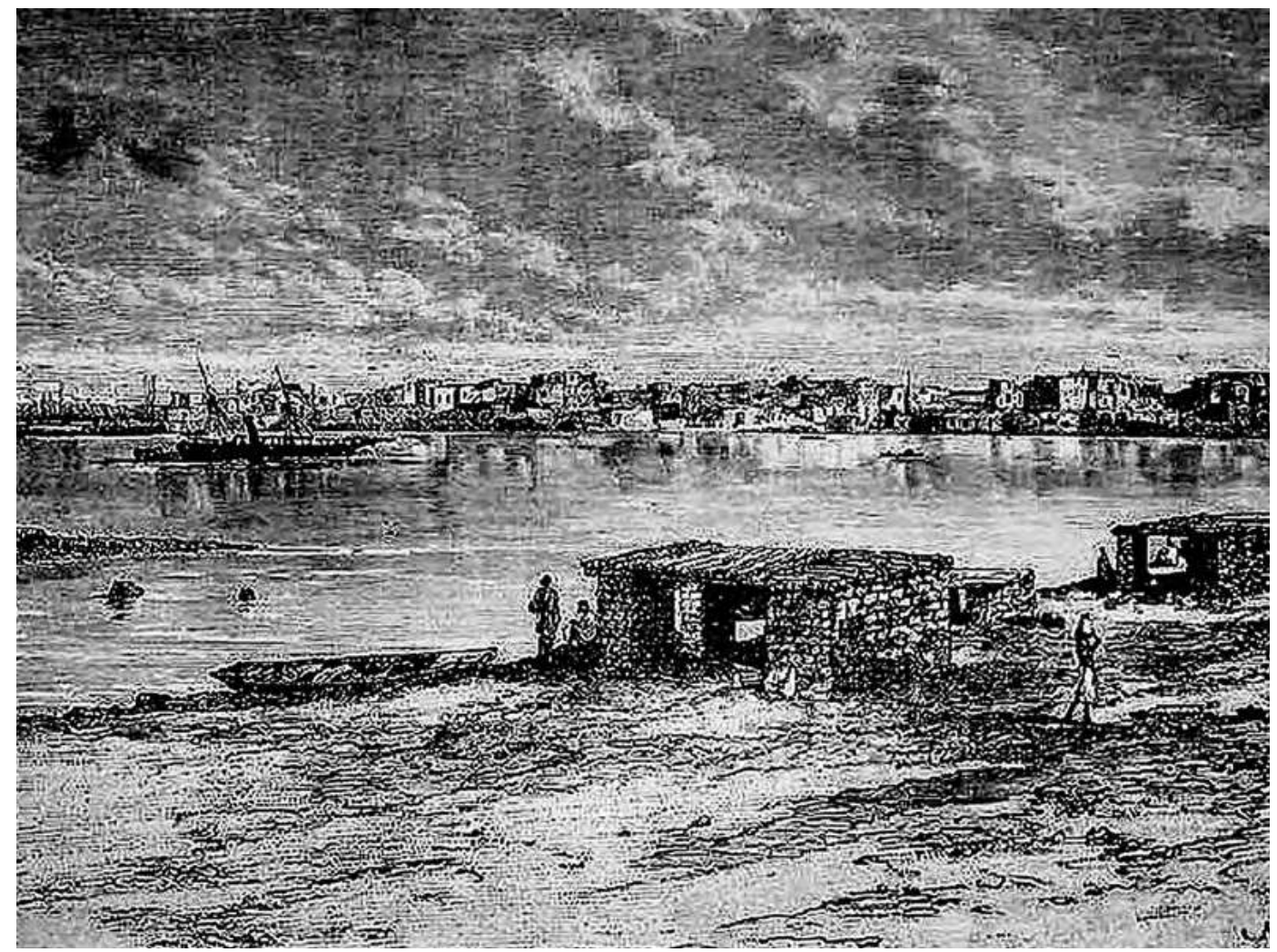

Souakin (gravure de la seconde moitié du XIxe siècle).

Malgré l'absence de télégraphe et de steamers, en juin 1858 la nouvelle du massacre des consuls français et anglais à Djeddah avait atteint Souakin avec une rapidité surprenante.

Vingt ans plus tard, les deux ports sont transférés à l'administration soudanaise, en vue d'améliorer la lutte contre le trafic des esclaves, sous la pression principalement de l'Angleterre.

Souakin va tirer profit de la fermeture des marchés d'esclaves en Égypte en 1870 . Le trafic s'oriente alors vers la mer Rouge. Simultanément, le flux des pèlerins se rendant à La Mecque augmente au fil de l'islamisation de l'Afrique de l'Ouest. Un nouvel élan est donné aux échanges commerciaux par la construction de chemins de fer. L'ouverture de la ligne Alexandrie-Suez et celle du canal de Suez, en 1869, relancent le commerce sur la mer Rouge. Les bateaux à vapeur égyptiens assurent une liaison régulière entre Souakin et Suez. La ville se développe sous l'impulsion de l'énergique pacha Ahmed Mumtaz (1865-1872). Un bâtiment des douanes et un quai sont construits sur l'île et une plantation de coton est établie à Tokar. La récolte ainsi que celle provenant de Kassala sont traitées dans la filature construite à Souakin en 1870 par une compagnie syrienne. 


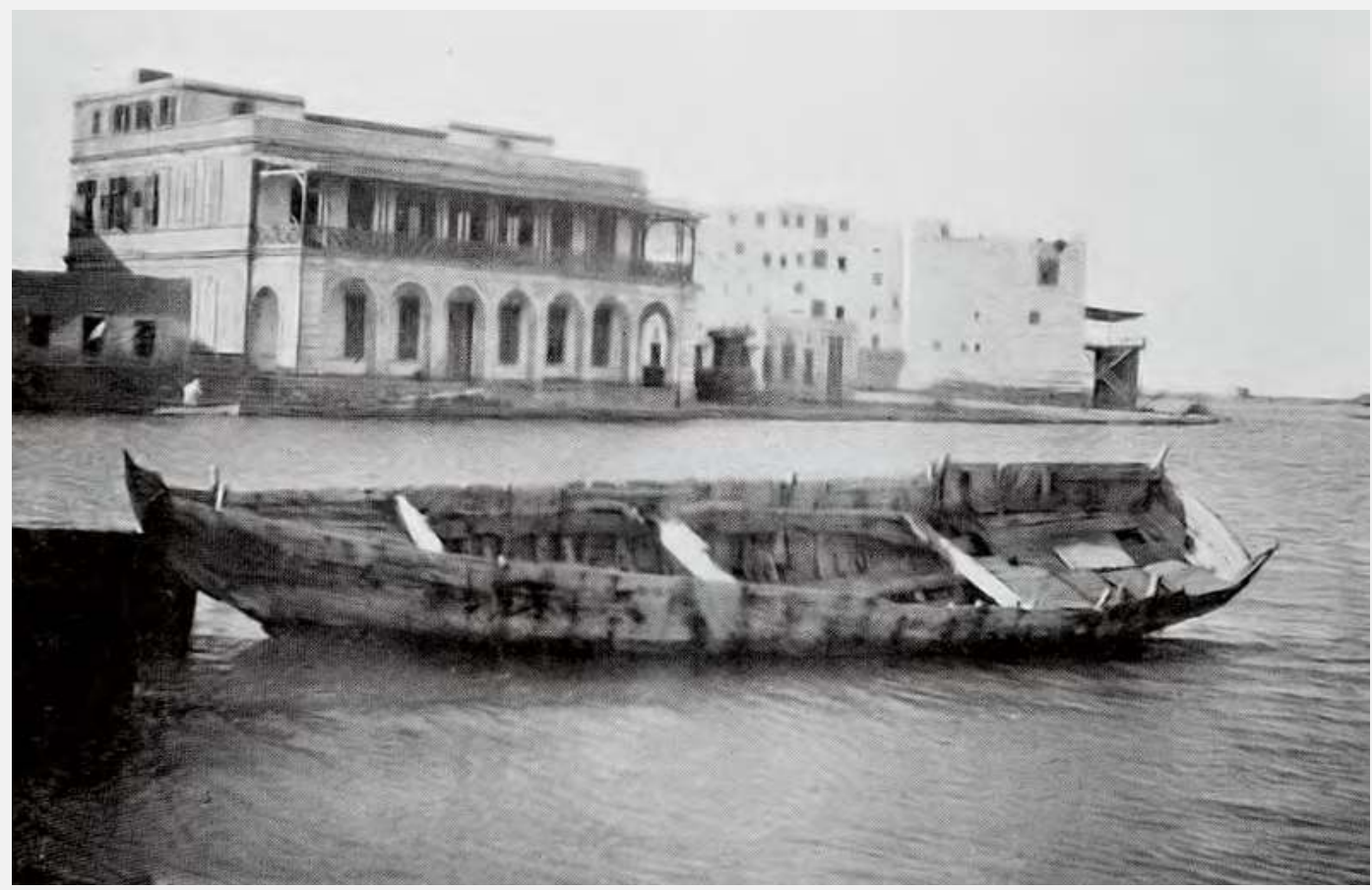

le Soudan

570

de 1820

à nos jours

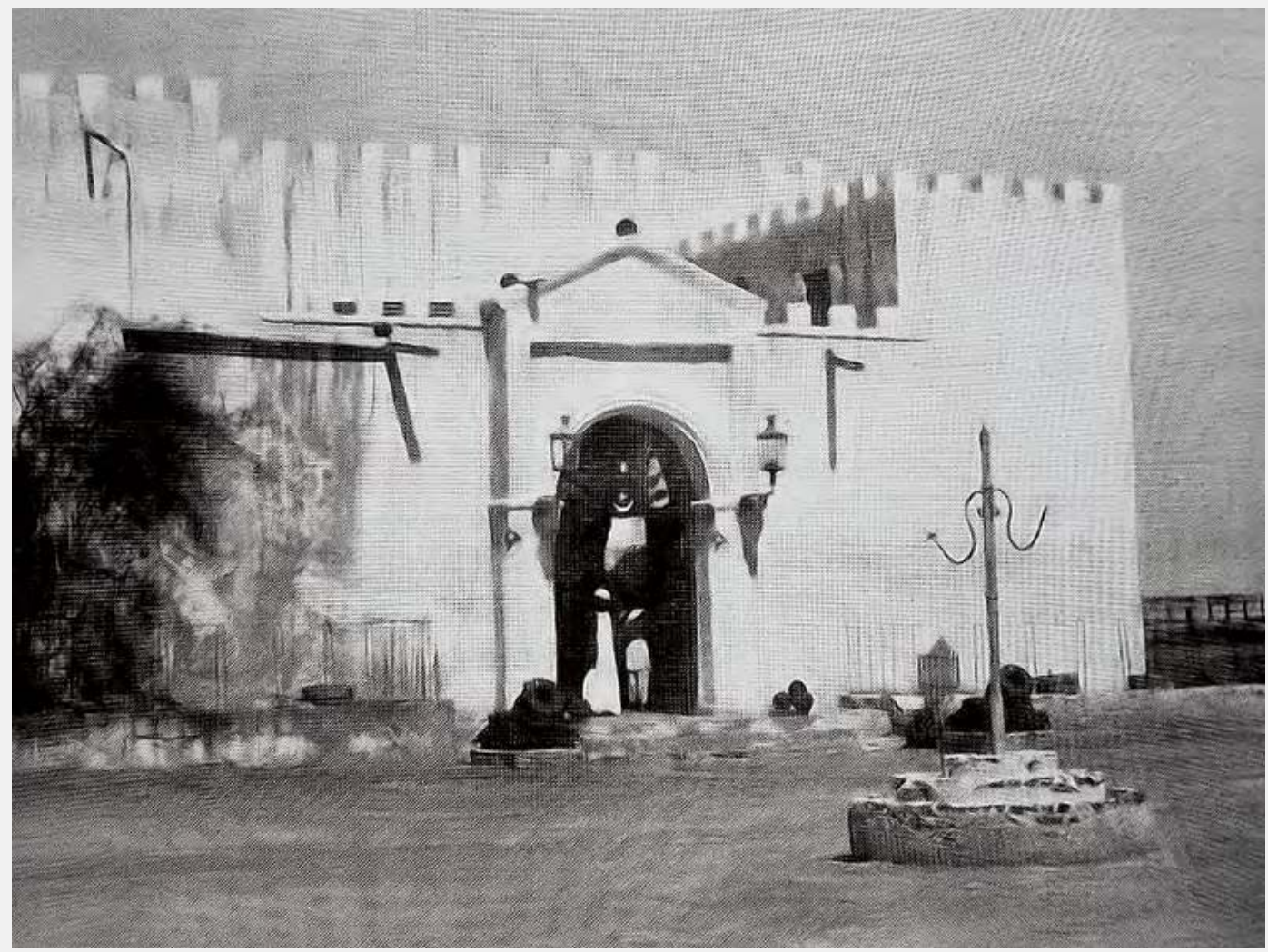

Souakin en 1912. 

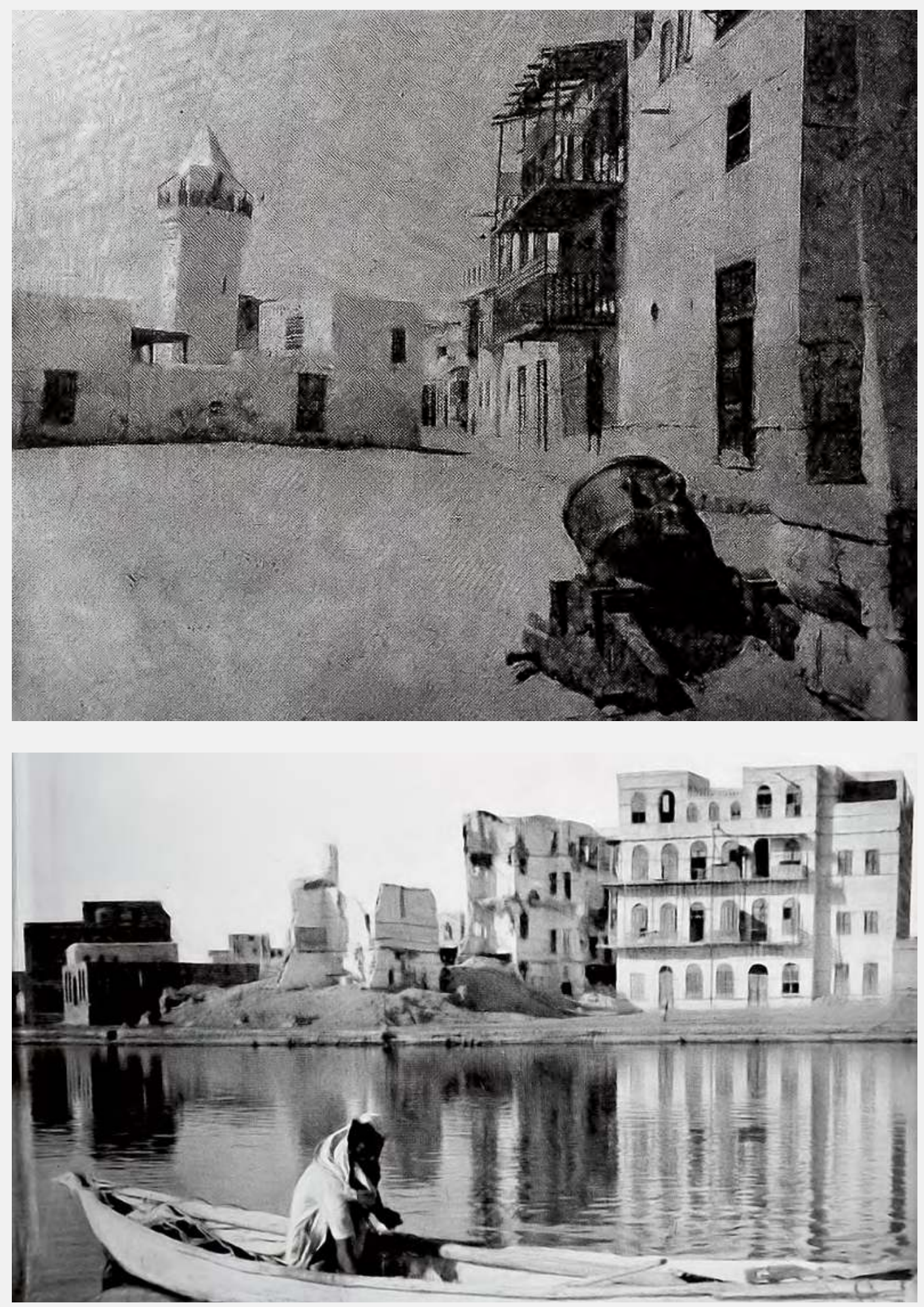

la création du Soudan moderne 1820-1885 Souakin en 1942 et en 1950. 
le Soudan

\section{2}

de 1820

à nos jours
Malgré cette expansion, Souakin peine à devenir un port international majeur. Ses marchands ne sont souvent que des agents de compagnies installées à Djeddah. En 1882, son trafic est inférieur de $40 \%$ à celui de Massaoua, le port africain le plus proche. Déjà, Souakin est pénalisé par le faible tirant d'eau du port et son accès délicat par des canaux de plus en plus obstrués par la croissance corallienne.

À son apogée, Souakin, qui ne peut prétendre accueillir les grands navires transocéaniques, doit se contenter des bateaux côtiers, tels que les boutres reliant Djeddah et Massaoua et les navires à vapeur égyptiens qui acheminent les produits soudanais à Suez et Aden, où ils sont transbordés pour être envoyés en Europe et en Inde. Le port est relié à l'intérieur des terres par des caravanes de chameaux suivant deux routes: vers Berber et la vallée du Nil vers l'ouest, vers Kassala, Gedaref et l'Érythrée au sud-ouest.

Casati décrit Souakin où il arrive le 23 janvier 1880 : \ La ville donne accès au Soudan par deux voies distinctes; l'une se dirigeant par le plateau de Kokreb sur Berber et Khartoum, l'autre gagnant le Sennar et le Nil Bleu par Kassala. C'est une petite ville de 4000 âmes dont la plupart des habitations sont des cabanes, aux formes variées, construites et couvertes en paille. Bon nombre de Grecs y sont à demeure, beaucoup d'autres y affluent à des époques déterminées et y font un séjour temporaire nécessité par les affaires. M. Albert Marquet ${ }^{1}$, un homme fort aimable, $y$ possède un comptoir [...]. Je fus on ne peut mieux accueilli par un Grec du nom de Demetrio Mosconas, on ne pleut plus fêté par Paoletti, un vieux compatriote qui est chargé du service postal et du service sanitaire. Souakim est administrée par un gouverneur et dispose d'un service postal et télégraphique.

Dans les années 1880, des caravanes de 500 à 1000 chameaux partent ainsi de Souakin tous les mois, chargées de laine de mouton, d'épices, de parfums et de soie provenant des Indes. Elles reviennent avec du café d'Abyssinie, de la gomme arabique, des plumes d'autruches, du séné, du sésame, du coton, des peaux, du bétail vivant ainsi que de l'ivoire et des esclaves noirs. C'est la tribu nomade des Hadendowas qui fournit les chameaux, acteurs essentiels de ce commerce. Une pénurie de ces derniers conduit à envisager une liaison ferroviaire avec le Nil. 
Le développement du commerce va permetre aux marchands de Souakin de restaurer les maisons de l'île et de construire de nouveaux bâtiments de style égyptien et européen. Les espaces libérés par les maisons détruites sont occupés par des tentes et des huttes, et le centre de lî̀le est peuplé par des commerçants grecs, égyptiens et originaires de Djeddah. Un caravansérail est construit en 1881, peu après la liaison de l'île à la côte par une digue édifiée en 1878 .

Le khédive Ismaïl obtint de Constantinople la remise de l'administration de la Côte des Somalis, où les Ottomans bénéficiaient depuis longtemps de points d'appui. En 1875, il reçut les villes de Zayla et Berbera mais échouera à plusieurs reprises à conquérir l'Éthiopie.

\section{L'extension vers le sud}

N'étaient quelques rares contacts établis depuis la côte est-africaine, le sud du Soudan a vécu coupé du monde occidental, jusqu'à l'expédition organisée par Méhémet Ali en 1841. Durant l'antiquité, les explorateurs égyptiens et romains (sous Néron, voir p. 271 sq.) avaient été bloqués par le Sudd ${ }^{1}$, ces immenses marécages qui couvrent des milliers d'hectares et entravent l'écoulement du Nil Blanc vers le nord de Bor, jusqu'au niveau de Malakal.

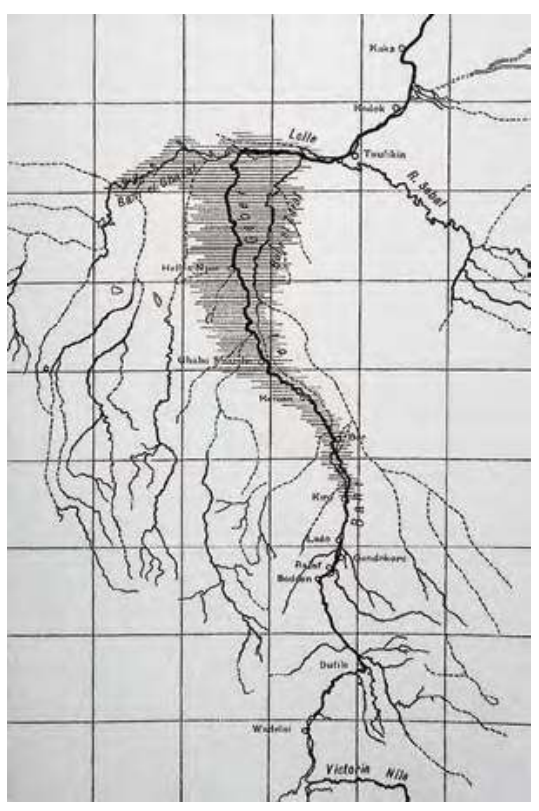

Le Sudd, sur le Nil Blanc.

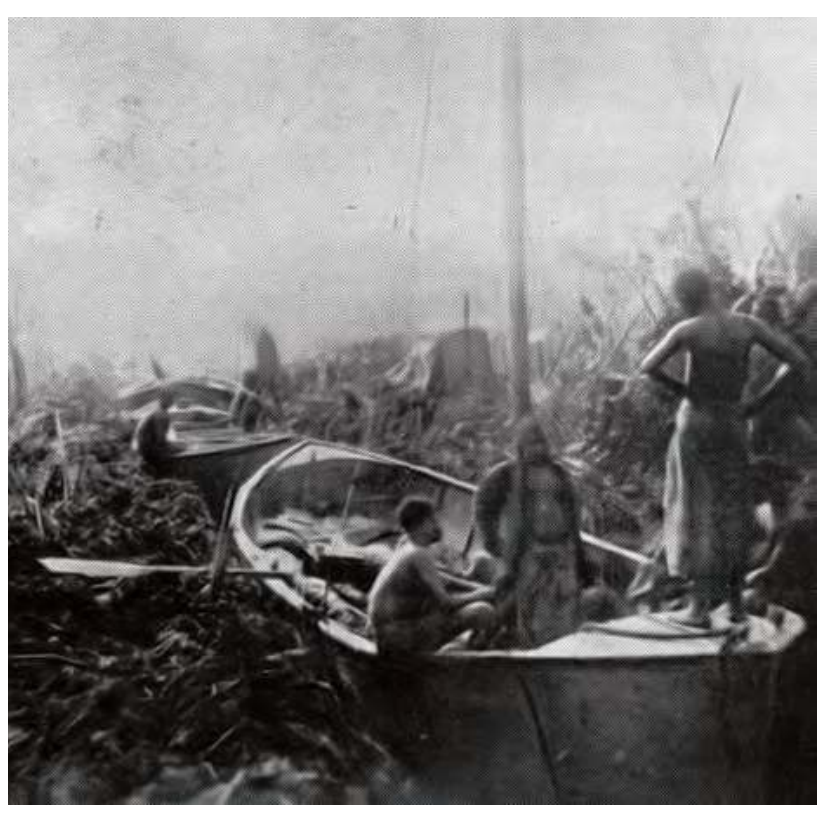

Passage du Sudd par une expédition européenne.

1 Sudd (arabe): obstacle. 
de 1820

à nos jours
Bahr el-Ghazal : village de Dem Souleyman en 1883.

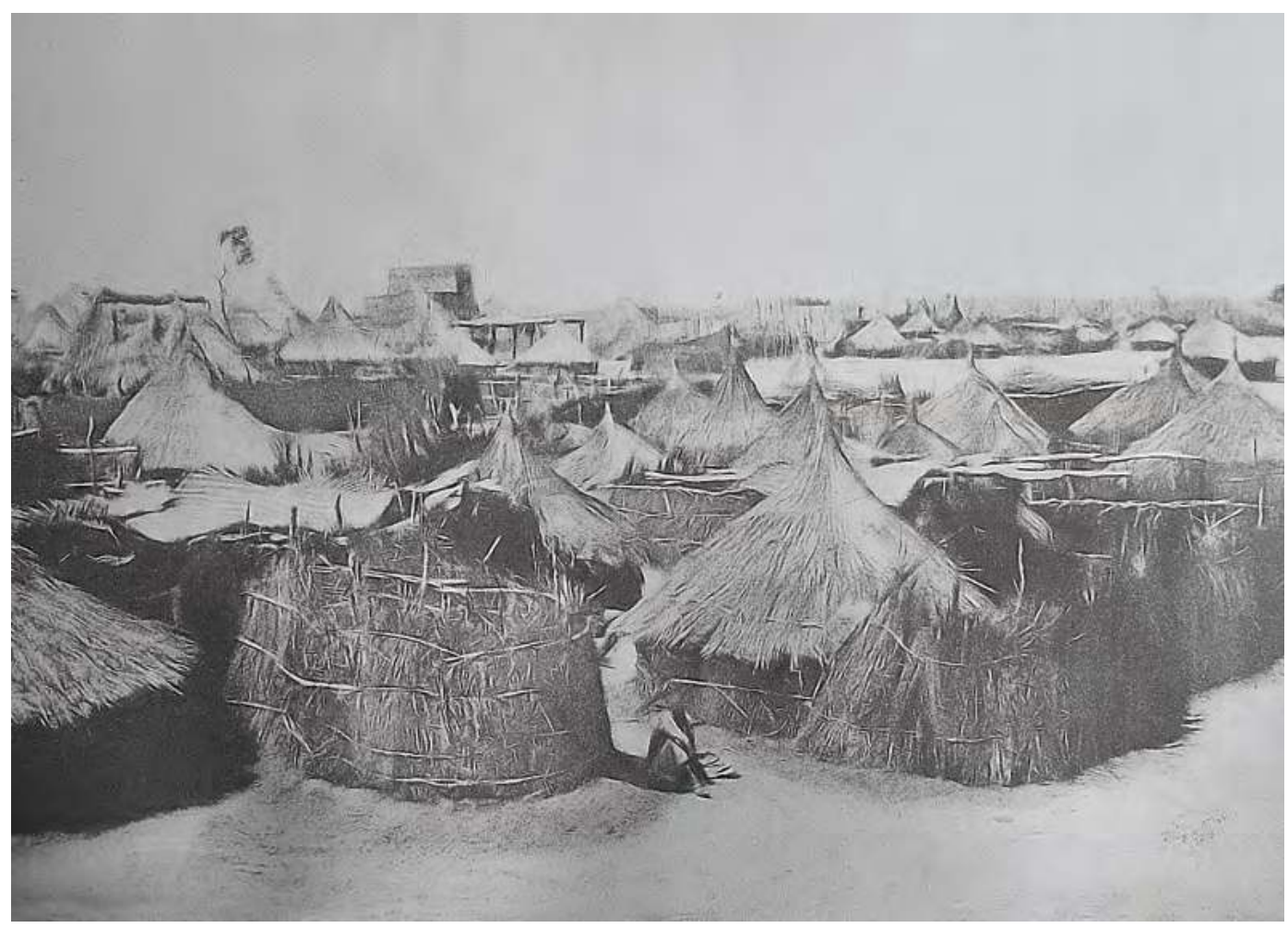

C'est la plus vaste cuvette marécageuse du monde, avec une masse de papyrus, de roseaux et de plantes aquatiques qui, emportés par les crues du Nil de mai à décembre, dérivent pour former des îlots de végétation dans le fleuve où ils s'enracinent à nouveau. En 1841, le vice-roi d'Égypte lança l'expédition dirigée par le capitaine Selim Gapudan et sa flottille de dix navires réussit à franchir cette muraille de végétation.

Des trafiquants européens et arabes, en quête d'ivoire et d'esclaves, s'installent à Khartoum dans les années 1840, suivis par des missionnaires et des explorateurs partis à la recherche des sources du Nil. Un des premiers traitants sera le savoyard Jacques Antoine Brun Rollet; installé à Khartoum dès 1831, il crée une succursale en pays Bari à Gondokoro en $1845^{1}$. Charles Didier ${ }^{2}$ évoque les premiers contacts avec les populations du Sud (1858) : 《Les premiers Turcs et les premiers Européens qui parurent sur le Fleuve Blanc furent pris pour des magiciens par les riverains,

1 Gondokoro: site devenu de nos jours un quartier périphérique de la ville de Juba, capitale du Soudan du Sud.

2 Charles Didier (1805-1864), romancier français d'origine suisse, publia en 1857 et 1858 deux livres « à sensation " tirés de son journal (voir p. 581 sq. et p. 592 sq.). 

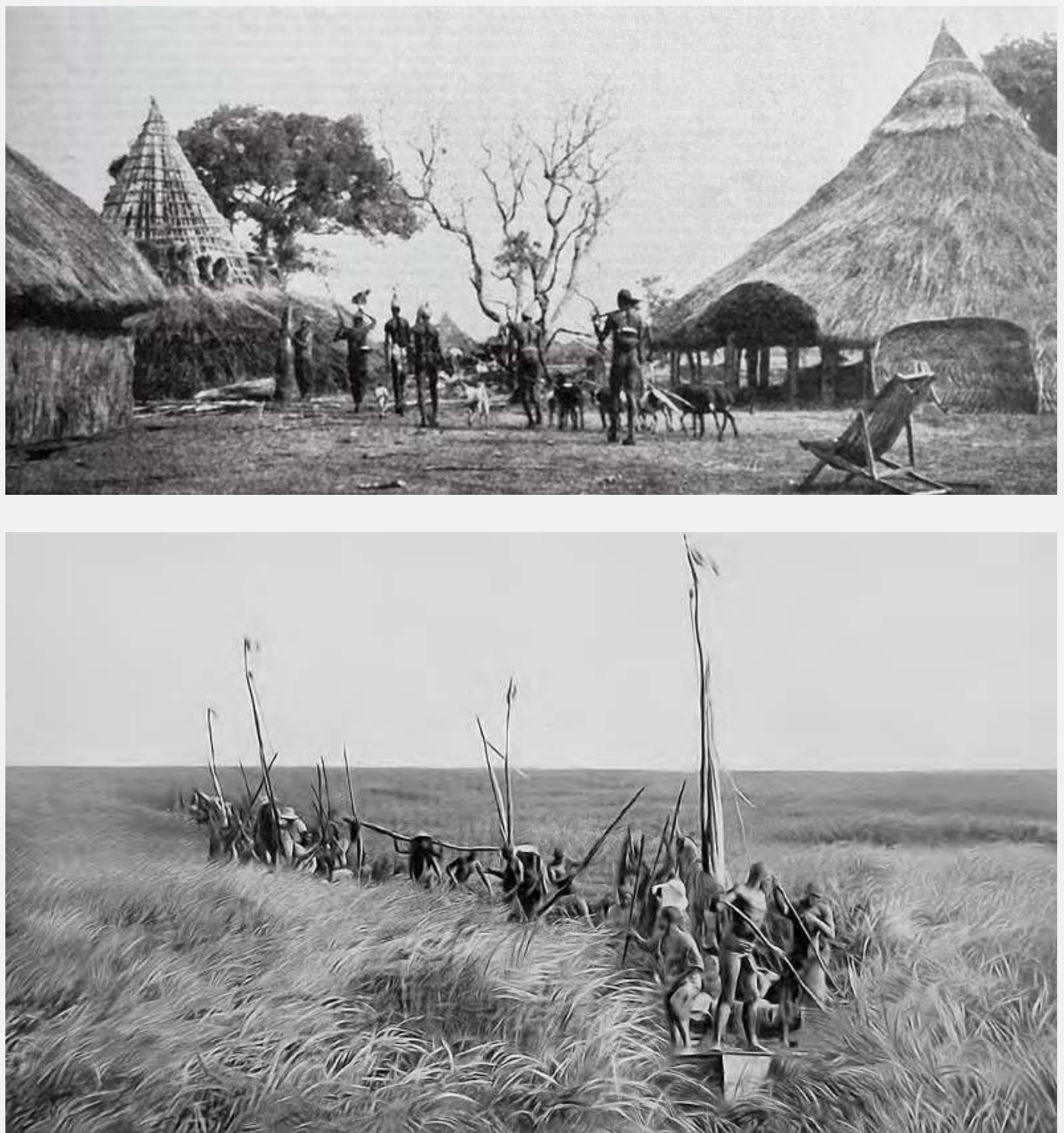

la création du Soudan moderne 1820-1885

Bahr el-Ghazal : village de Fort-Desaix en 1898.

La mission "Marchand » dans le Sudd. 


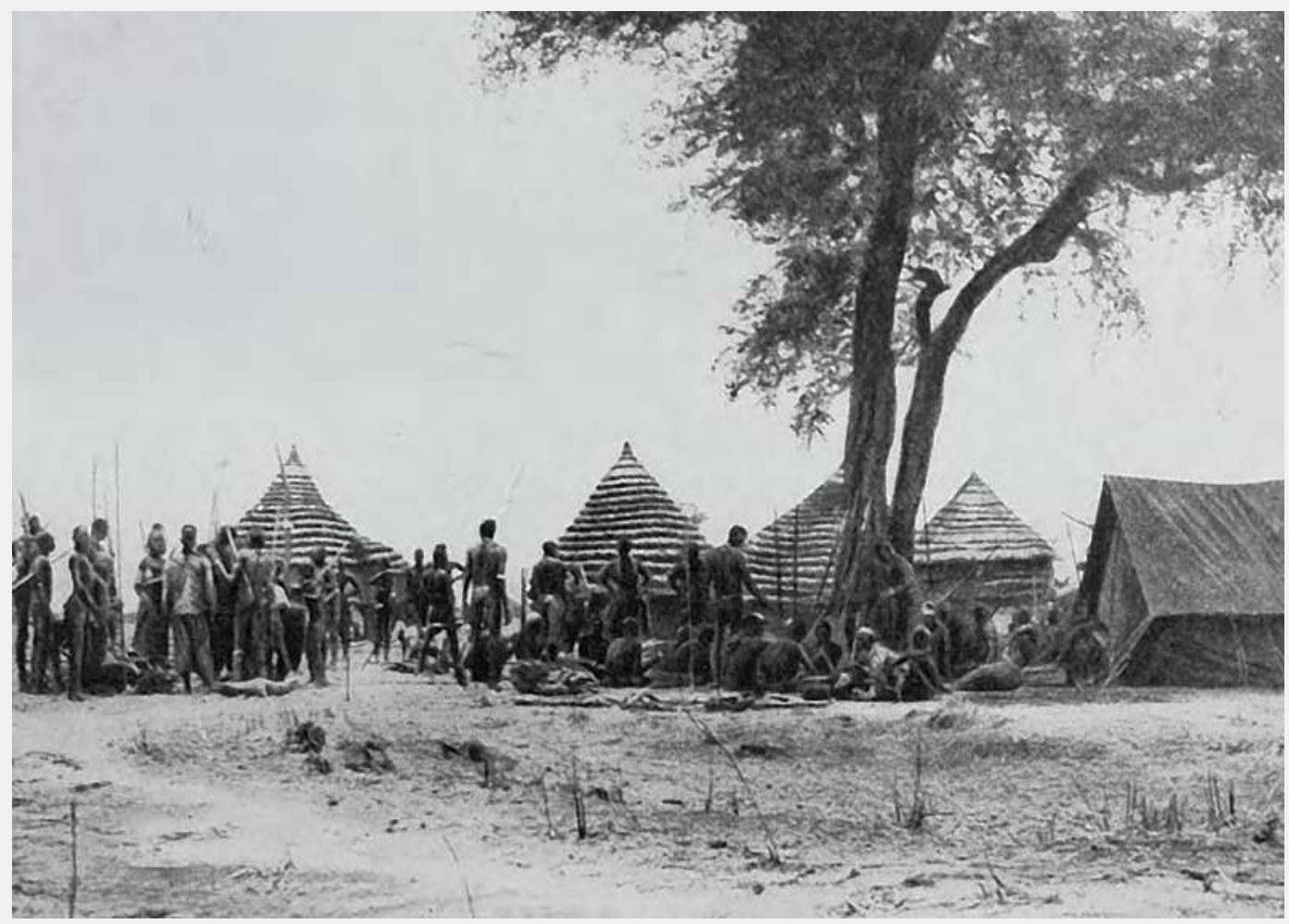

\section{6}

de 1820

à nos jours

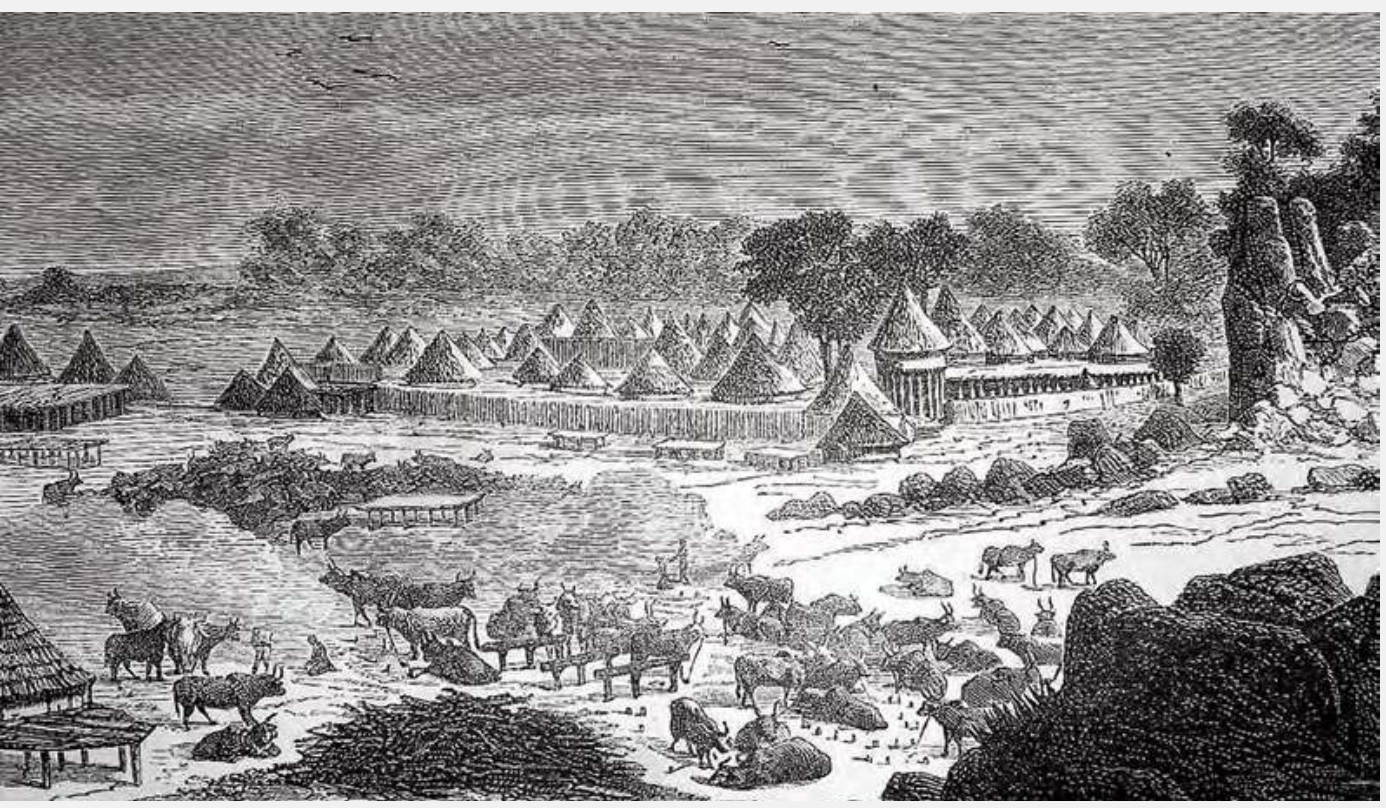

Bahr el-Ghazal : village de Makouetch Équatoria en 1899

La zériba des frères Poncet. 
à cause de leur peau blanche, et accueillis comme des êtres supérieurs. Il y a un siècle environ qu'une caravane de blancs partis de Zanzibar, des Portugais sans doute, venait par terre tous les deux ou trois ans acheter de l'ivoire chez les tribus supérieures du Nil Blanc. Une nuit, les naturels massacrèrent ces étrangers: or, à l'apparition des premiers étrangers dans ces mêmes tribus, les fils des meurtriers s'imaginèrent que c'étaient les victimes de leurs pères qui revenaient pour se venger, et ils furent frappés à leur vue d'une terreur superstitieuse. Ils étaient d'autant plus autorisés à le croire, que les premières expéditions turques et même européennes furent de véritables tueries, et ceux qu'on ne tuait pas étaient, hommes, femmes et enfants, trainés en esclavage.

Les naturels, si cruellement traités au début, et si souvent trompés depuis par les marchands, sont devenus très défiants à leur égard, très soupçonneux, beaucoup plus exigeants en fait de conterie [en matière financière] et plus prompts à mettre les armes à la main. Un de leurs kodjours, errant dans les forêts du pays de Dim, ne cesse de leur répéter encore à cette heure, et en cela il n'a pas tort, que c'en est fait à jamais de leur liberté s'ils entrent en communication avec les blancs; que les blancs, de quelque côté qu'ils viennent, ne sont que des messagers de servitude et de mort. Le prophète est vraiment prophète en cette circonstance; l'avenir qu'il prédit à son peuple est infaillible: les naturels du Fleuve Blanc ne peuvent manquer d'avoir quelque jour le sort des Indiens du Nouveau Monde.

L'administration est faiblement implantée dans le Bahr el-Ghazal où les expéditions "commerciales» vont se multiplier et constituer leurs réseaux de zéribas ${ }^{1}$, campements fortifiés (voir page ci-contre) d'où seront tissés les liens d'affaires avec les chefs locaux. Chaque traitant développe son propre réseau et en assure la défense avec de petites armées privées. Les expéditions sont organisées sur une base annuelle. Certains traitants font fortune de leur trafic, comme l'Autrichien Franz Binder. D'autres deviennent de véritables potentats locaux, comme Zubair Pacha, disposant d'une véritable armée privée.

1 Zériba (arabe) : enclos, palissade; par extension, campements fortifiés installés par les traitants au sud du Soudan, protégés par des buissons épineux, où étaient stockés les marchandises d'échanges et le bétail, où étaient retenus les esclaves. Ces zéribas vont créer des marchés et ont donné ultérieurement naissance à certaines villes. Sur ces sites, dont l'un est protégé par les autorités au niveau de la ville de Rumbek (centre du Soudan du Sud), on retrouve enfoui superficiellement dans le sol les restes des perles de verre utilisées jusqu'au début du Xxe siècle pour le troc avec les populations locales (voir les récits de Stanley par exemple: de nombreux sacs de perles faisaient partie des matériels d'expédition). 
le Soudan

\section{8}

de 1820

à nos jours
Après 1840, le nombre d'expéditions scientifiques remontant le Nil Blanc va considérablement augmenter; à l'exception de celle de Burton et Speke qui choisit Zanzibar, les autres partiront de Khartoum. La quête des sources du Nil passionne les opinions publiques occidentales, jusqu'à ce que le mystère soit levé en 1863 par Speke et Grant.

Sous Ismaïl Pacha, un grand nombre d'explorations sont menées afin de découvrir les derniers territoires inconnus de l'intérieur des terres, aux confins de l'actuel Tchad, de la Centrafrique et de la République Démocratique du Congo, et ce jusque dans les années 1880.

En 1871, l'Égypte annexe le Sud du Soudan; auparavant, la région portait le nom de Bahr el-Ghazal; elle est divisée en deux provinces: le Bahr el-Ghazal et la province d'Équatoria, limitée au sud par le lac Albert et le lac Victoria (aujourd'hui en Ouganda).

Le développement des missions religieuses au Sud commence lorsque le jésuite polonais Maximilien Ryllo et le chanoine maltais Aneto Casolani arrivent à la même conclusion: 《LLà-bas (au Sud) les Nègres sont totalement païens mais prêts pour la civilisation et le christianisme... \\ Le pape Grégoire XVI se laisse convaincre en 1846 de créer le vicariat apostolique de l'Afrique centrale, qui s'étend en théorie du sud de l'Égypte jusqu'au fleuve Zambèze. Trois autres missionnaires atteignent Khartoum en 1848. La mission s'y installe, mais rapidement le vicaire Casolani démissionne devant l'ampleur de la tâche et le pro-vicaire Ryllo meurt peu après son arrivée à Khartoum. Le père Knoblecher, nommé vicaire, décide en 1849 de descendre au Sud, accompagné de deux missionnaires italiens. Ils s'arrêtent au village de Gondokoro, point ultime de la remontée du Nil à l'époque. Si le Vatican a des soucis prioritaires avec Garibaldi, l'évangélisation du Soudan devient un sujet en vogue dans les salons viennois. L'Autriche ouvre alors un consulat à Khartoum dans les bâtiments de l'évêché et soutient celui-ci.

Deux missions sont créées, en 1852 à Gondokoro et en 1854 à Heilige Kreutz. Mais les missionnaires meurent en grand nombre: sur dix-neuf prêtres envoyés entre 1848 et 1854, dix sont morts fin 1855 , tandis que deux sont renvoyés malades en Europe. Knoblecher meurt en 1858. Le vicariat est alors repris par les pères du Sacré-Cour de Vérone, qui vont eux aussi payer un lourd tribut à l'évangélisation. En 1860, la décision est prise de fermer ces missions, et il faudra plus de quarante ans avant de revoir des missionnaires dans la région. 


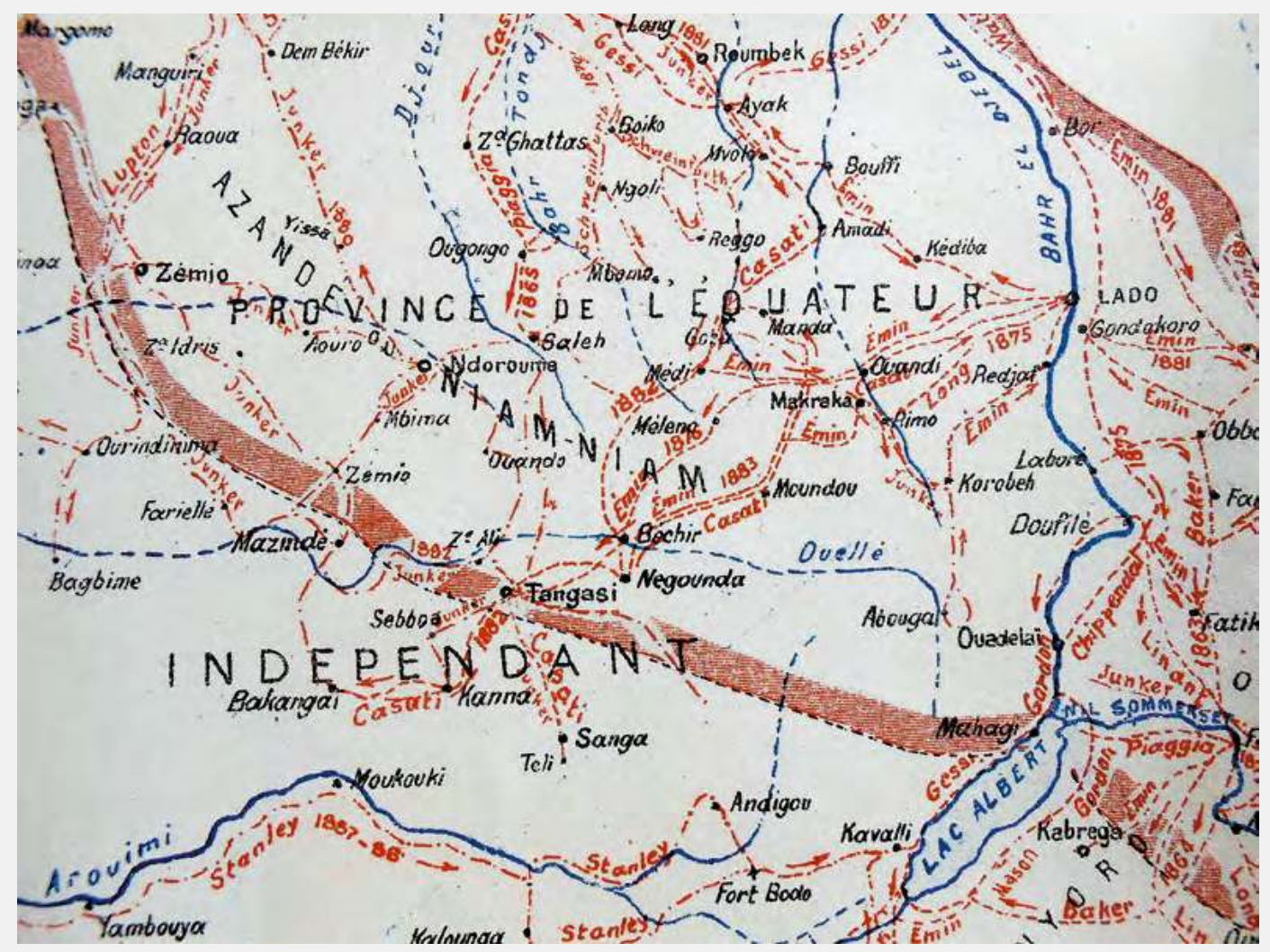

Carte des explorations du Sud Soudan sous le règne du khédive Ismaïl.

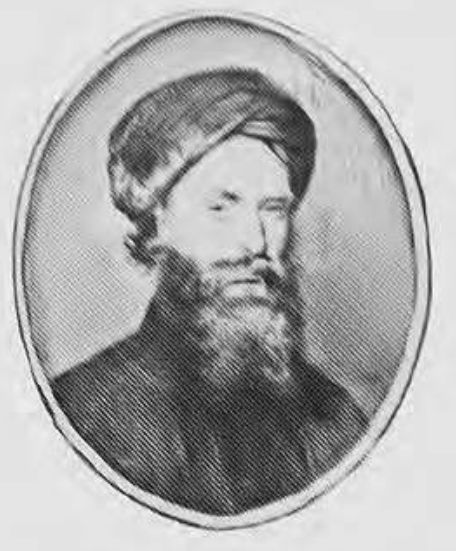

Le père Knoblecher.

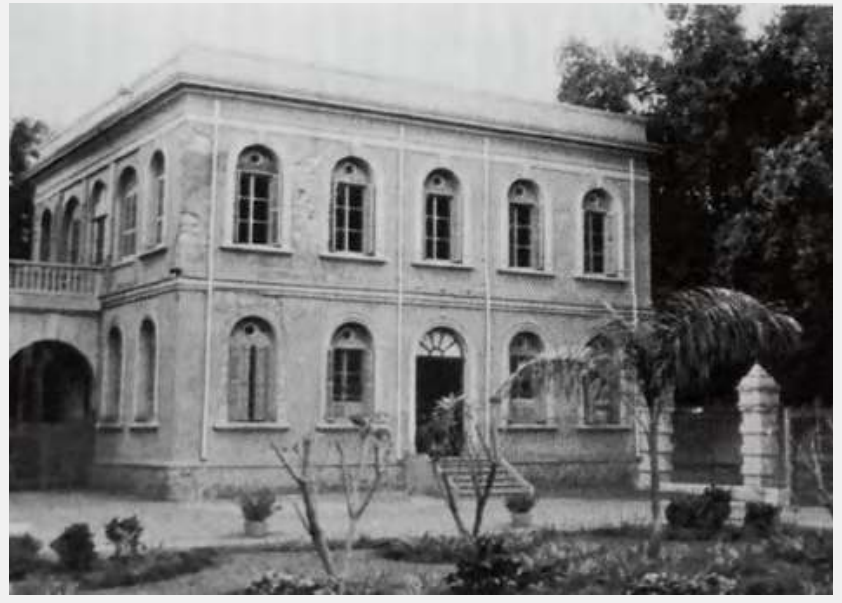

La mission autrichienne. la création du Soudan moderne 1820-1885 


\section{Le développement de Khartoum}

Othman Bey avait établi sa résidence à Khartoum en septembre 1824, mais ce fut sous Khurchid Pacha que la ville devint la capitale du Soudan. Sur son emplacement, il n'y avait que quelques cabanes de pêcheurs; le gouvernement y établit le centre de l'administration, y éleva des casernes, un arsenal, des édifices publics bâtis en briques cuites, y aménagea des jardins et des potagers, y attira des habitants et les encouragea à construire, pour la première fois, des maisons en briques d'argile séchées au soleil, alors qu'ils ne connaissaient jusque-là que des constructions faites avec de la paille, des roseaux et des peaux de vache.

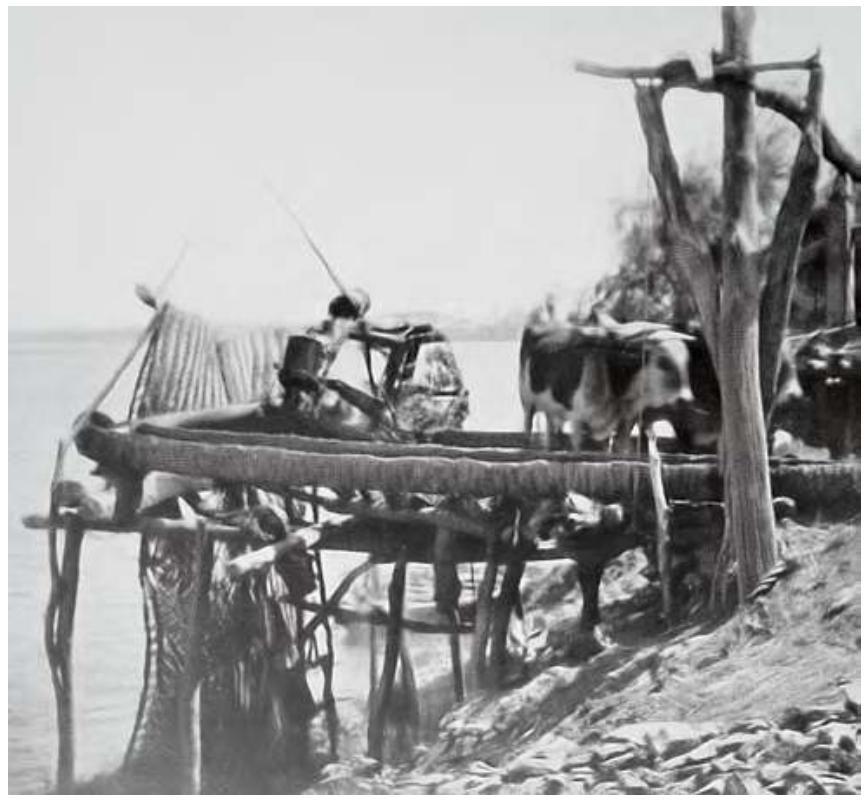

Saqieh à Khartoum en 1924.

Méhémet Ali visite Khartoum lors de son passage au Soudan en 1838. Le journal officiel du 21 avril 1839 décrit ainsi la ville: \$Il y a quinze ans à peine, ce n'était qu'une réunion de dix toukouls ${ }^{1}$. Khurchid Pacha [...] poussa plusieurs familles du Sennar et quelques Arabes à y construire leurs habitations. Aujourd'hui, c'est une ville composée de cinq cents maisons, régulièrement bâties, ayant de vastes casernes, un hôpital bien tenu, des magasins considérables, de nombreux jardins où croissent et mûrissent en hiver des figues et des raisins [...]. $\\rangle$

1 Toukoul: case en terre, surmontée d'un toit de paille. 
En 1848, la population est estimée à 30 ooo âmes par Pierre Trémaux. George Melly, voyageur britannique, séjourne durant quelques semaines à Khartoum en 1850. La ville comprend alors environ trois mille maisons en terre séchée.

Il décrit aussi les habitants, dont il estime également le nombre à 30000 , en comptant la garnison. 《IIls sont divisés en musulmans, chrétiens et juifs; les premiers font l'immense majorité de la population, et prient dans leurs mosquées - elles sont particulièrement peu éclairées, et leurs prêtres pas beaucoup plus. Les chrétiens sont environ cinquante, comprenant toute la communauté attachée à la mission catholique romaine, où il $\mathrm{y}$ a trois prêtres, une chapelle ainsi qu'une école pour la préparation des convertis et l'instruction du nombre croissant de fidèles. Les juifs sont une douzaine.

En 1852, on estime le nombre des Européens à vingt ou trente, tous liés au commerce de traite avec le Sud. Et ces quelques Européens se font parfois une guerre sans merci, comme le consul de Sardaigne Vaudey et le traitant Malte-Brun, qui s'accusent mutuellement de malversations ou de trafic d'esclaves devant des tribunaux en Europe.

Le voyageur franco-suisse Charles Didier décrit la ville en 1855:

Grâce à son heureuse situation, au concours des caravanes et au mouvement du commerce, la ville de Khartoum a pris un développement rapide: elle compte aujourd'hui de trente à trente-cinq mille habitants, Turcs, Arabes, nègres indigènes, sans parler des juifs, des Grecs en assez grand nombre, et des coptes, ces derniers formant une petite église chrétienne au milieu des infidèles. [...] La ville n'est ni fortifiée ni même fermée. Sa garnison, de trois mille hommes environ, est formée de Nubiens esclaves et de Bachibouzouks ${ }^{1}$. Elle couvre un grand espace à cause des jardins intérieurs qui y sont très vastes et très nombreux. Les rues et les places sont poudreuses, irrégulières et percées au hasard sans aucun plan; chacun a bâti comme il l'a voulu et quand il l'a voulu: aussi le désordre et la confusion règnent-ils dans les constructions. À l'exception d'un certain nombre de maisons assez spacieuses et pourvues de larges cours, toutes les autres sont misérables. Bâties en terre et de forme carrée, sans autre jour que la porte, elles n'ont, pour la plupart, qu'une seule pièce, laquelle est au niveau du sol,

1 Bachibouzouks: du turc başıbozuk, littéralement «tête non standardisée», est utilisé pour dénommer les troupes de cavalerie irrégulière de mercenaires indisciplinés appuyant l'armée ottomane et disposant d'un armement léger. Ces cavaliers ne portaient pas tous le même chapeau, d'où la dénomination de "têtes non standardisées". 
le Soudan

\section{2}

de 1820

à nos jours accessible à tous les reptiles, et sert à la famille entière. [...] Au temps des pluies, les rues, et surtout les places, se transforment en mares où des myriades de grenouilles coassent le jour et la nuit...

Les deux principaux édifices publics sont le divan, ou palais du gouverneur (voir illustration p. 563), et la prison, tous les deux au bord du fleuve, et les premiers qui aient été construits. Je ne dis rien des mosquées, aucune ne m'ayant frappé. Je crois même qu'il n'y en a qu'une; ce qui ne prouve pas un zèle religieux bien fervent. Les hôpitaux ne sont pas si mal tenus qu'on pourrait le croire, grâce aux médecins européens; mais en revanche les casernes sont des chenils, de véritables porcheries. La poudrière est beaucoup mieux bâtie. Les briques de l'ancienne cité de Soba ${ }^{1}$ ont servi, m'a-t-on dit, à plusieurs constructions de la cité moderne. Par une précaution rare en terre musulmane, on a relégué les abattoirs à une certaine distance de la ville; ce qui ne les empêche pas de corrompre l'air environnant. Les oiseaux de proie planent sans cesse sur ces charniers infects [...].

À si bas prix que soit la viande, le mouton par exemple à 10 ou 12 centimes la livre, la masse des habitants est si pauvre qu'ils n'en mangent que dans les grandes circonstances, aux mariages, aux circoncisions, aux enterrements, aux fêtes du Beiram² ${ }^{2}$. Il leur faut si peu pour subsister, et leurs besoins sont si bornés, qu'une famille entière, même assez nombreuse, et l'on comprend qu'elles le soient dans un pays où les filles se marient à 13 ans et les garçons à 15 , vit fort à l'aise avec 40 centimes par jour, soit 12 francs par mois.

Khartoum n'est point une belle ville et n'a rien de remarquable, rien qui soit digne de fixer l'attention. Cette métropole du désert n'a pour elle que sa position au cœur de l'Afrique, au confluent des deux plus grands fleuves de cet immense continent. Que ne deviendrait-elle pas entre des mains intelligentes et vraiment civilisatrices! Mais qu'espérer des Turcs qui la possèdent? [...] Si quelques pointes ont été poussées au Sud, soit par le Nil Blanc, soit par le Nil Bleu, c'est aux Européens qu'on en est redevable; et pourtant quels Européens! Des marchands avides dont l'esprit et le cœur sont fermés à toute autre préoccupation, à tout autre intérêt

1 Soba: capitale de l'ancien royaume nubien chrétien d'Alodia (les auteurs arabes appellent "al-Abwab» la province septentrionale proche du confluent de l'Atbara et du Nil) dont les vestiges étaient encore visibles au début du XIX ${ }^{\mathrm{e}}$ siècle, dans le quartier qui porte toujours le nom de Soba, aujourd'hui intégré dans la moderne Khartoum.

2 Bayram, en turc: la fête, ici celle du sacrifice. 
que leur négoce, et prêts à tout pour augmenter leur lucre. Mais, quoiqu'en des mains indignes, le commerce est, ainsi que la guerre, par la force même des choses, un instrument de civilisation...

Le plus grand, le seul charme de Khartoum est dans les jardins qui l'environnent, surtout du côté du Fleuve Bleu, dont la rive gauche est couverte entièrement. Quelques-uns sont vraiment délicieux; il est impossible de voir de plus beaux ombrages, et quel prix n'ont-ils pas sous un climat si brûlant! On y recueille d'excellents fruits, du raisin, des limons, des bananes, bien d'autres encore, et une espèce d'ananas. Les melons et les pastèques abondent, principalement sur quelques petites îles, et où l'on cultive aussi le tabac.

Khartoum était la résidence d'un gouverneur général qui avait sous ses ordres le Soudan égyptien tout entier et la Nubie jusqu’à la seconde cataracte. Ce vaste territoire était subdivisé en cinq gouvernements particuliers, ou mudiries, qui relevaient de Khartoum, et n'avaient de relations avec le gouvernement central que par la filière administrative du pacha résidant dans cette ville. Ces cinq mudiries étaient l'ancien royaume du Sennar, Kassala ou Taka, le Kordofan, Dongola et Berber. Le gouverneur général, nommé par le vice-roi, était donc un grand personnage, et, grâce à son énorme éloignement du Caire, il jouissait d'une autorité quasi illimitée. Il tenait dans sa main tous les fils de l'administration, et commandait à une armée de quinze mille noirs. [...] Un service de poste aux lettres, qui existait déjà depuis longtemps, mais à l'état rudimentaire, a été perfectionné, afin de faciliter, de hâter surtout les communications.

D'après Casati, en 1880, la population s'élève à 60000 habitants, parmi lesquels nombre de négociants étrangers, surtout des Grecs et des Syriens. 《La vieille ville se compose en majeure partie de maisons construites en boue et en briques séchées au soleil; des constructions récentes se font en briques cuites, mais le manque de chaux rend assez onéreux un semblable luxe.

Il faut mentionner, parmi les créations de l'État, l'arsenal, l'imprimerie et l'école militaire - ces deux dernières fondées par Gordon. Au nombre des édifices qui se distinguent par leur solidité et leur élégance, je mentionnerai la mission catholique, le palais du gouvernement et les habitations de quelques riches négociants; l'unique mosquée n'a aucune valeur artistique. Il y a encore un vaste jardin public appartenant à l'État, bien planté et bien entretenu, où un corps de musique, formé presque entièrement de nègres soudanais, donne de temps en temps des concerts qui sont seuls à rompre la monotonie de la vie quotidienne à Khartoum. 


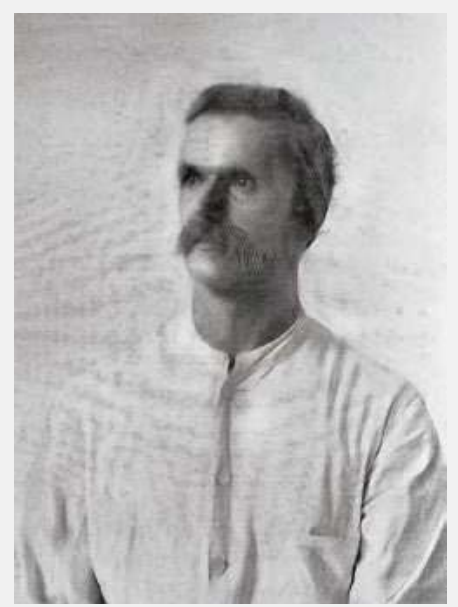

Gaetano Casati.

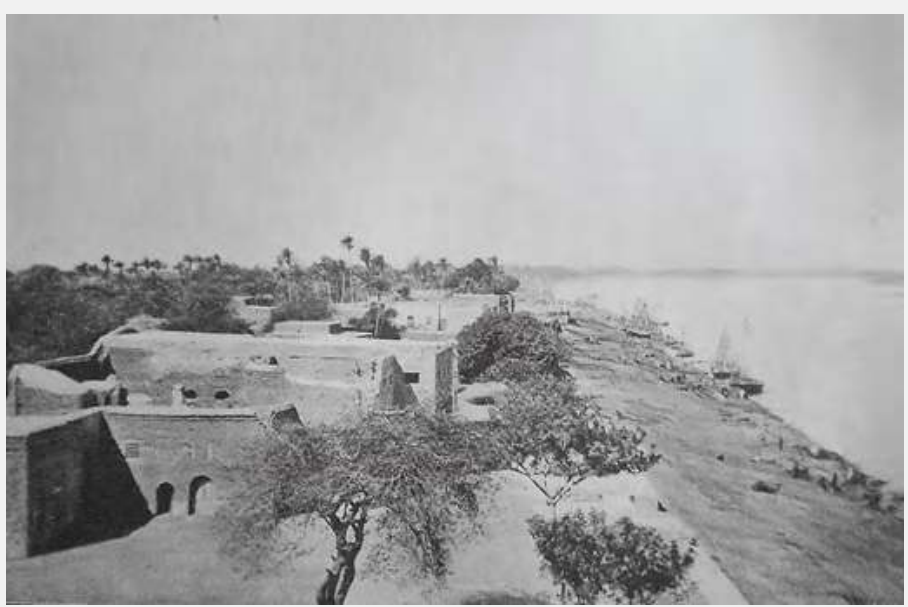

Khartoum au bord du Nil Bleu en 1881.

le Soudan

\section{4}

de 1820

à nos jours

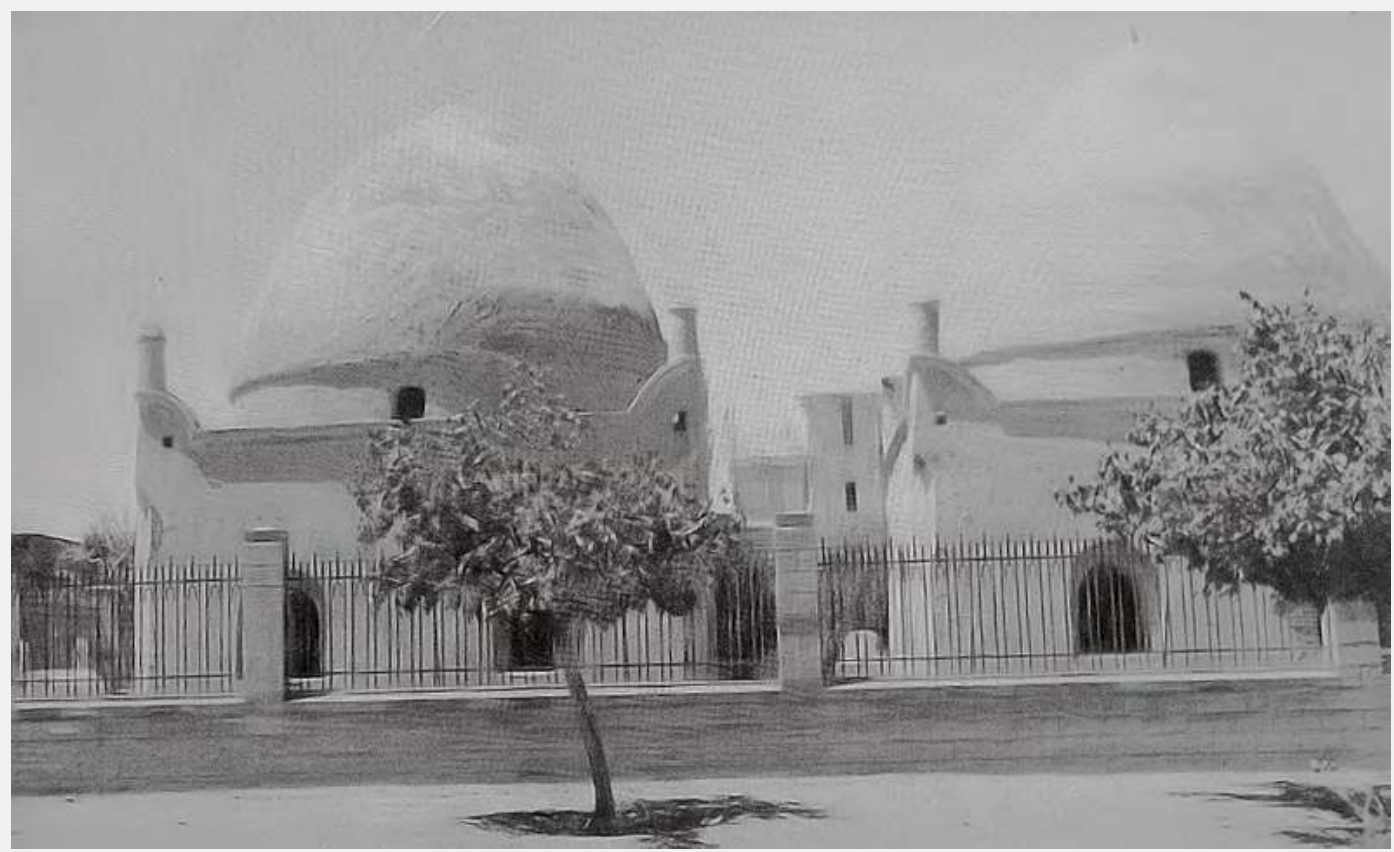

Les qubbas. 


\section{Les qubbas d'Abbas avenue à Khartoum vestiges de la Turkiyya}

Ces tombes couvertes de dômes, qui ont été épargnées lors de la Mahdiyya, ont la forme des tombeaux des saints, tel celle du Mahdi, que l'on retrouve dans toute la vallée du Nil. Y sont enterrés non pas des saints mais des personnalités importantes de la Turkiyya. On y trouve les tombeaux de deux gouverneurs généraux du Soudan au service des vice-rois d'Égypte et d'origine circassienne. Comme il est de tradition, les tombeaux des saints sont entourés de tombes plus modestes de leurs disciples ou de ceux qui, des générations plus tard, veulent bénéficier de la baraka ${ }^{1}$ des shaykh ${ }^{2}$ enterrés. Mimant cette coutume, les qubbas séculières d'Abbas avenue sont aussi entourées des tombes d'officiers de l'armée égyptienne mais d'origine soudanaise.

Le premier tombeau est celui d'Ahmed Pacha Abou Adhan, gouverneur général du Soudan de 1839 à 1843 . Amené comme esclave en Égypte, il fit une carrière militaire dans l'armée égyptienne. Il s'illustre sous le fils de Méhémet Ali dans les campagnes militaires d'Arabie, de Grèce et de Syrie. $\mathrm{Au}$ Soudan on lui doit la répression d'une rébellion des Hadendowas ${ }^{3}$ (Bedja) ${ }^{4}$ dans l'est et la prise de Kassala. En 1843, il prépare l'invasion du Darfour, mais des rumeurs de trahison poussent Méhémet Ali à interrompre l'opération, le gouverneur général étant devenu très populaire: la rumeur courait que ce dernier négociait la séparation du Soudan de l'Égypte. Le gouverneur général fut rappelé, mais il semble qu'il préféra plutôt absorber une dose fatale de poison, à moins qu'il n'y ait été forcé par le message du vice-roi.

La seconde qubba principale abrite la dépouille de Moussa Pacha

Hamdi, gouverneur de 1862 à 1865 . Lui aussi vendu comme esclave au marché du Caire, il gravit rapidement les échelons de la carrière militaire où il acquit une réputation de brutalité. Alors que ses prédécesseurs avaient tenté de limiter le trafic d'esclaves, il laissa ce celui-ci repartir sans entrave.

1 Baraka (arabe): pouvoir spirituel du shaykh.

2 Shaykh (arabe): maitre, directeur spirituel ; dans la péninsule arabe, le terme désigne aussi un chef de tribu.

3 Hadendowas : une des tribus constituant le peuple des Béjas, avec les Bicharins, les Beni Amer, les Ababde, les Amarar...

4 Les Bedja sont un peuple qu'on retrouve dans les États soudanais actuels de River Nile, Red Sea, Kassala et Gedaref, ainsi qu'en Érythrée et au sud-est de l'Égypte. Certains sont nomades.

Ils sont connus depuis les pharaons; ils furent dénommés «Blemmyes» par les Romains, et «Fuzzie-Wuzzie» par Kipling, qui désignait ainsi les soldats, issus du clan des Hadendowas, ayant lutté contre les Britanniques durant la Mahdiyya. 
Pour financer l'entretien d'une armée considérable et sous-utilisée, il la prêta même, moyennant finances, aux trafiquants d'esclaves opérant dans le Sud. Il fut emporté par la variole.

Parmi les qubbas secondaires, on trouve la tombe de Muhamad Bey Almas qui commença en 1834 sa carrière comme simple soldat et finit officier. L'aventure mexicaine de l'empereur Napoléon III entraîna celle, inattendue, d'un régiment de soldats soudanais qui partirent en 1862 sous le commandement de Muhamad Almas. Ils se révélèrent de remarquables combattants, très populaires auprès de leurs alliés français. Almas fut décoré par l'archiduc Maximilien de l'ordre de Notre-Dame de la Guadeloupe. Les survivants repartirent en 1867 , et furent passés en revue par Napoléon III à Paris. Almas reçut la croix de la Légion d'honneur. Ces vétérans du Mexique furent considérés comme les troupes les plus fiables, et certains vécurent assez pour défendre Khartoum encerclée sous le commandement de Gordon.

Un autre militaire soudanais est enterré sur ce site, Adham Pacha al-'Arifi, originaire du Sud Kordofan, probablement Nuba, qui fut l'un des premiers Soudanais noirs à bénéficier d'une formation militaire en Égypte et qui participa à la campagne de Syrie et à la guerre de Crimée dans le corps expéditionnaire ottoman. Il rentra ensuite au Soudan où on le retrouve à Kassala chargé de réprimer une mutinerie des troupes qui refusaient d'aller rejoindre le contingent déjà présent au Mexique. Il convainquit les mutins de se rendre, mais ceux-ci furent exécutés malgré ses protestations. Son rôle lui valut le poste de gouverneur général adjoint.

On trouve encore la tombe de l'épouse de Mari Bey, un aventurier corse qui prétendait avoir servi comme colonel sous Napoléon, ce que la rumeur contestait, le bruit courant qu'il y avait été simple tambour. Il servit de préfet de police au Caire en 1853, puis il perdit les faveurs d'Abbas ${ }^{\text {er }}$ et fut envoyé en exil à Khartoum, où son épouse mourut.

\section{La vie quotidienne à Khartoum avant la Mahdiyya}

George Melly arrive à Khartoum à la fin de 1850. \$ Khartoum, vu du fleuve, est un long mur de terre, avec de nombreuses maisons qui apparaissent pardessus, les bâtiments les plus visibles sont la résidence du gouverneur et ses bureaux, l'ancien siège du gouvernement, et la chapelle de la mission catholique. Nous allâmes aux bureaux du gouverneur, par un vaste train sur lequel deux compagnies militaires, les mieux habillées et équipées que j’aie vues depuis l'Europe, procédaient à la relève de la garde, chaque compagnie menée par un soldat portant un fanion sur sa baïonnette. Nous arrivâmes dans une cour, où se trouvaient plusieurs canons de bronze, et entrâmes dans un local spacieux rempli de divans turcs et de chaises européennes. C’était le Divan. 
À une extrémité était assis Latif Pacha, général de l'armée, amiral de la flotte, et gouverneur du Soudan, de Philae jusqu'aux plus lointaines possessions du pacha d'Égypte. Il apparaît comme un homme capable d'être tout cela et même plus, avec son visage fin, une bonne figure, avenante, une moustache magnifiquement taillée et une barbe d'un noir de jais. Il portait les plus beaux vêtements orientaux que j'aie jamais vus - un costume de drap bleu, richement brodé, un gilet rouge et or, des bas de soie, une superbe écharpe autour de la taille, un tarbouche, une étoile de diamant, et de nombreuses chaînes en or. À sa droite était assis Ali Bey Hassib, le gouverneur de Berber, et quelques autres dignitaires en costume d'apparat.

Sa réception fut très courtoise à notre égard: pendant quelques minutes, il conversa avec le gouverneur de Berber; ensuite il nous consacra toute son attention, examinant firmans ${ }^{1}$, passeports et lettres d'introduction. La conversation se déroula en italien, dont il avait une maitrise limitée; on nous avait dit cependant qu'il était familier de l'anglais et du français. Nous lui demandâmes où il lui serait agréable que nous plantions nos tentes; il nous proposa une maison dans la capitale. Il nous proposa aussi d'utiliser son propre bateau. Il nous promit aussi 30 chameaux. Pour l'acheminement de notre courrier, il proposa d'envoyer un messager spécial par chameau jusqu’à Assouan, où les lettres seraient transmises par voie de courrier pédestre jusqu’au Caire, et par la suite de la façon habituelle. En résumé, il nous promit tout ce que nous souhaitions, nous donna café et pipes, après quoi nous prîmes congé de lui.

Il y avait une foule considérable de janissaires ${ }^{2}$, d'esclaves, de cawas ${ }^{3}$, et un grand nombre d'officiels dans le hall; comme les oiseaux, leurs costumes semblaient plus brillants sous ces latitudes plus méridionales; le bleu et le jaune, avec les manteaux et les pantalons blancs, se voyaient plus pimpants que le brun sobre et le beige habituels au Caire. Le porteur de pipe du gouverneur, un Français qui avait accompagné Ibrahim Pacha en Angleterre, nous montra la ville. Il nous accompagna d'abord à la maison mise à notre disposition: nous la trouvâmes fort bien située, entre des orangers, des bananiers et des grenadiers dans un jardin, sur une haute berge, à côté du harem du pacha.

1 Firman : mot d'origine perse utilisé dans l'Empire ottoman pour désigner toute permission écrite délivrée par une personnalité officielle, par exemple la permission de traverser un pays.

2 Janissaires : mot d'origine turque (« nouvelle armée ») désignant des troupes d'élite de fantassins, créées au XIv siècle, composées d'esclaves chrétiens formés et islamisés. Ils deviennent rapidement une garde prétorienne. Leur statut va évoluer et le recrutement va s'ouvrir aux Turcs.

3 Cawas (français du XIX ${ }^{e}$ siècle) : policiers, dans les pays du Proche-Orient. 
Après quoi nous allâmes flâner au bazar, où nous apprîmes que le pacha était parti, et nous le trouvâmes à la principale boutique. Une foule bloquait tout le marché, mais on nous laissa passer, en partie par crainte de notre origine inconnue, et aussi parce qu'un personnage à l'aspect effrayant, vêtu d'une veste rouge, de bottes et muni de nombreux pistolets, nous ouvrit la route manu militari. Ayant assuré le gouverneur que tout ce qu'il avait fait pour nous était parfait, nous allâmes visiter le pharmacien-chef, qui nous reçut avec hospitalité; un par un arrivèrent tous les Européens de Khartoum, parmi lesquels un respectable cercle de Français et d'Italiens, qui étaient très accueillants. Au retour au fleuve, le bateau du pacha nous attendait, et nous ramena rapidement à nos tentes dans un style parfait. La comparaison entre le gouverneur et de hautes personnalités en Angleterre, dans leur façon d'accueillir des étrangers, était sans contexte en faveur du gouverneur.

On nous avait promis des chasses prodigieuses; aussi, très excités le lendemain matin nous prîmes le bateau du pacha pour aller sur le Nil Blanc. On vit des nuées de canards, d'oies, d'ibis, de pélicans, de pluviers, ainsi que quatre crocodiles se chauffant au soleil.

À notre retour, nous trouvâmes nos effets déménagés dans notre maison, comme si le gouverneur ne voulait pas que nous nous installions sur le bateau, et avec l'aide qu'il nous fournit l'endroit devint rapidement extrêmement confortable. L'édifice était de bonne taille, même si bâti de matériaux non durables comme la terre. Il était placé au milieu d'une délicieuse orangerie; malheureusement à proximité d'une saqieh grinçante. La maison était faite d'un grand salon, auquel on accédait par un petit escalier, et qui donnait sur trois chambres garnies de divans de terre crue et de fenêtres largement ouvertes sur la rafraichissante perspective des orangers, des grenadiers et des cannes à sucre. Quel contraste avec notre tente fermée, dans le désert!

Nous avons fait connaissance avec tous les Européens, qui venaient nous voir. Parmi eux, le pharmacien et le médecin responsable du service médical, un bel homme agréable des environs de Genève. Dans la cour de Mr. R. que l'on partit visiter ensuite, se trouvait une jeune girafe de neuf ou dix pieds de haut, et une antilope aussi volumineuse qu' un âne, avec deux cornes d'au moins un yard de long (soit $91,44 \mathrm{~cm}$ ). Notre ami avait le plus beau jardin de Khartoum, avec des allées couvertes d'une treille faite de vigne, qui donne toute l'année. Il nous reçut avec les civilités d'usage dans un large salon, où il faisait des affaires avec des marchands locaux portant djellabas blanches, turbans et écharpes. Après vint un Turc très clairvoyant, habillé de belle manière, et portant au cou une étoile de diamants, qui parlait couramment le français. Comme Latif Pacha et beaucoup d'autres ici, il était banni, privé de la compagnie de ses femmes et de sa famille. 
Après avoir fait circuler des rafraîchissements, notre hôte montra ses curiosités, comme des cornes de rhinocéros, des dents d'hippopotame, et de nombreux objets fabriqués par les locaux. Je pus admirer une paire de pinces et une javeline réalisées en fer, avec des instruments tellement primitifs qu'une pierre comme enclume et qu'un morceau de rocher comme marteau. Des tambours, des arcs, des lances, des flèches avec leurs carquois, des gourdins, et de curieuses matraques en fer faisaient partie de sa collection, avec des pipes pouvant engloutir trois livres de tabac, et des cuillers à thé comme des louches. Il nous offrit toute la collection, comme il l'avait déjà fait pour le musée de Vienne.

Nous visitâmes les bazars, avec quelque embarras car les locaux étaient très curieux de voir ma mère et ma sœur, une vague de curiosité inhabituelle de leur part. En passant devant une boutique encombrée de janissaires et d'administratifs, je fus appelé par le gouverneur de Berber qui offrit fort civilement de nous accompagner jusqu'à Berber et de nous montrer les choses remarquables au long de la route. Après nous avoir promis maison, chameaux... il promit sa visite pour le lendemain.

Un autre de nos nouveaux amis disposait d'un établissement considérable. Soixante-dix esclaves, des chèvres, des vaches, et environ cinq acres de terrain, qu'il avait obtenus en achetant dix tickets de cent piastres à une loterie. Cependant il souhaite vendre son domaine pour soixante livres. Il était employé depuis quinze ans par Mr. - , un marchand parisien qui ne vendait aucune marchandise britannique sans un profit de cent pour cent. Il a également acheté un grand établissement au Kordofan, pour une somme dérisoire.

Lors d'un retour d'une promenade au bazar, nous rencontrâmes Bayoumi Effendi, un homme très distingué qui avait fait partie des trente étudiants envoyés par Méhémet Ali à l'école polytechnique de Paris. Il resta treize ans à Paris, et a traduit deux livres par an durant de nombreuses années. Le sultan lui offrit un poste, avec le rang de colonel et de bey s'il s'établissait à Constantinople, et le pacha d'Égypte lui proposa les mêmes avantages s'il venait se mettre à son service. Il hésita longtemps et à la fin, mal inspiré, il choisit l'Égypte, où il est devenu en réalité un esclave.

Au départ, il fut nommé responsable de l'instruction à Boulak, près du Caire. Ensuite, brutalement, il lui fut ordonné de créer une école à Khartoum, avec douze de ses professeurs les plus capables. Aucun bâtiment n’a été construit, et il est absolument impossible d'en créer une, comme les parents nomadisent et vivent en toute indépendance dans le désert, plutôt que d'envoyer les enfants à l'école. Et même s'il y avait des écoles, son assistance n'aurait pu être utile qu'après de nombreuses années, comme les enfants ne savent ni lire ni écrire, alors que Bayoumi Effendi est un des professeurs européens les plus performants en mathématique et en ingénierie, plutôt que d'être un instituteur d'arabe. 
Il se plaignait amèrement d'avoir été privé de ses femmes et de ses enfants, et d'avoir été forcé de quitter Le Caire dans les douze heures; malgré tout, il pensait que le pacha était moins à blâmer que ses conseillers, qui ne lui permirent pas d'accéder à Méhémet Ali, alors qu'il n'aurait bien sûr pu l'offenser. En effet, il était si confiant dans son sens de la justice qu'il était sûr que s'il arrivait à présenter son cas, les décisions correctrices auraient été prises immédiatement. Il attribuait sa malchance à la malice des traducteurs, certains de ses élèves.

Les écoles sont ici naturellement une fumisterie. Les professeurs sont peu éduqués, et sans doute interferent moins avec les actions du viceroi. Il serait absurde, pour tout voyageur passant trop rapidement dans un pays inconnu, de tenter de poser un jugement sur la politique qui y est menée; on ne peut néanmoins passer sous silence ces prisonniers, même s'ils n'en portent pas le nom, qui sont gouverneurs de villes importantes ou de provinces, ou présidant aux destinées d'écoles imaginaires à Khartoum.

Il est évident que ces gens se sont rendus désagréables au pacha, en partie peut-être parce qu'ils le dépassaient, ou ayant dispensé des conseils non demandés, ou pour être à tort ou à raison considérés comme des partisans de la Porte. Le résultat de tous ces bannissements est que les provinces sont très correctement gouvernées: Khartoum, Berber, Dongola, Fazogl... sous la direction d'hommes intelligents, qui ont beaucoup voyagé et ont été des observateurs attentifs.

Je n'ai jamais vu un pays aussi propre. Cependant les vêtements des gens sont très pauvres. Les Bédouins se contentent d'un vêtement autour des reins durant la chaleur du jour; les filles et les enfants souvent n'ont même pas ce minimum, mais ils sont si pudiques que personne ne perçoit leur nudité. La parure des femmes plus âgées est classique, à ravir les dessinateurs.

La ville comprend environ trois mille maisons, ressemblant à celles déjà décrites. L'architecture étant tellement primitive dans ces régions qu'on ne peut s'attendre à beaucoup d'urbanisme; il n'y a pas d'artères spacieuses; il y a ici et là des espaces qu'on peut difficilement prendre même pour un modeste square européen. Les maisons les plus belles appartiennent soit aux officiels du gouvernement soit aux résidents européens. Dans certaines, on approche du luxe, dans d'autres, du confort. En effet, il faut reconnaitre qu'avec les jardins délicieux, et un climat plaisant, il n'est pas difficile de se réconcilier avec une maison en terre séchée.

Dans le voisinage, l'activité la plus fréquente est la construction de bateaux; les barques construites sont surtout de longues embarcations non pontées pour naviguer sur le Nil, faites en bois de palmier, mais aussi d'autres essences. 
Le principal commerce concerne la production des jardins et des champs, qui sont très productifs. Les marchés sont organisés autour de quatre rues couvertes et quatre non couvertes. Les rues couvertes hébergent les magasins les plus beaux, remplis de marchandises diverses, où figurent imprimés de Manchester, couteaux et ciseaux de Sheffield, et poteries du Staffordshire; les rues découvertes présentent surtout des étals où se vendent du séné, des lichens, des herbes et des légumes variés. Les marchands exportent ici la gomme arabique, des peaux non traitées et de grandes quantités d'ivoire par chameau vers Korosko, après descendant le Nil jusqu’à Berber.

[...] Les gens les plus modestes se contentent d'une seule femme, qui donne à son époux de nombreux enfants. Les plus riches ne sont pas aussi aisément satisfaits; et ils ont jusqu’à quatre femmes.

La partie la plus déplaisante de l'année est la saison des pluies; et les précipitations sont si importantes que les rues deviennent impraticables. Les orages arrivent si soudainement qu'une personne peut rester bloquée trois ou quatre jours dans la demeure d'un ami, jusqu'à la descente des eaux. Personne n'essaie de quitter sa maison pendant les pluies; et la ville peut donner pour cette raison l'impression d'émerger tout juste du déluge.

Les pratiques superstitieuses sont répandues. Les mercredis sont considérés comme néfastes, particulièrement le dernier mercredi du mois, mais c'est surtout le dernier mercredi de l'année qui est le pire, car c'est le jour où Moïse fit saigner les eaux. Ainsi la veille, avant 15 heures, tout un chacun fait provision d'eau pour deux jours. Le pacha n'est pas insensible à ces superstitions; et Riffa Bey, qui a bénéficié d'une double éducation persane et parisienne, et en plus très versé en magie, doit expliquer les rêves de Son Excellence chaque jour.

Les forces militaires comportent une infanterie de dix mille hommes et deux milliers de cavaliers. Dans la cour du palais du gouvernement, j'avais pu voir de nombreuses pièces de canons de bronze, de quatre à dix livres; il y avait aussi des obusiers et des bombes. Il y a au Soudan une infanterie de vingt mille hommes et douze mille hommes de cavalerie, avec trente-six pièces d'artillerie, sous le commandement de Latif pacha, qui a le rang de général.

Quoique les femmes nubiennes ne correspondent pas à ce que nous considérons comme de belles femmes, elles sont presque toujours d'harmonieuses proportions; elles mesurent en général cinq pieds six pouces (environ 1,70 mètre), avec des membres bien faits, un cou et des épaules bien dessinées, et un teint agréable. Pour contrebalancer ces avantages, elles ont de larges lèvres teintes en bleu, des sourcils passés au henné, et les cheveux tombant en petites tresses autour de la tête, peu familières du peigne ou de la brosse, emmêlés et graisseux. Les yeux sont grands, fins et expriment 
le Soudan

\section{2}

de 1820

à nos jours

la douceur, noirs en général mais aussi souvent bleus. Chaque mouvement révèle une grâce et une élégance naturelle auxquelles n'atteignent pas toutes les belles Européennes, en particulier les jeunes filles qui sont très souvent séduisantes, l'épaisseur des lèvres n'étant pas complètement développée, et leurs yeux bleus brillent d'un éclat plus intense que chez leurs aînées. Elles se marient avant douze ou treize ans, et sont déjà vieilles à vingt. Leur apparence n'est pas servie par la coutume de porter sept ou huit scarifications sur le haut des joues, coutume également prégnante chez les hommes qui portent en plus les mêmes scarifications sur la poitrine.

$\mathrm{Ma}$ mère et ma sœur demandèrent à rencontrer Madame Latif Pacha, qui les reçut très joliment dans sa nouvelle résidence voisine de notre jardin. Elle est jolie et très grande dame; elle était vêtue d'une veste grecque très ajustée, couverte de dentelle dorée, et portait des pantalons de soie bleu intense. Elle leur montra toute la maison, la seule vraiment bien construite du pays, leur offrit le café dans les habituelles coupes filigranées d'or, qu'elles admirèrent autant que les nappes, napperons brodés, et travaux de velours qu'elle avait réalisés elle-même. Elle ne paraissait pas très jeune - environ vingt ans, petite et espiègle. Tout ce qui se raconte sur ces beautés emprisonnées se ressemble, et tend à faire croire que si ces dames étaient éduquées et traitées comme leurs sœurs européennes, elles se comporteraient de façon respectable en société.

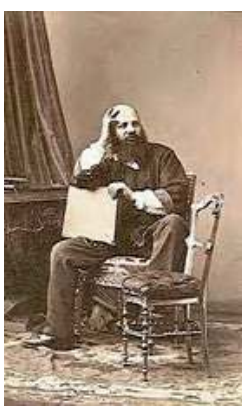

Charles Didier.

Charles Didier à Khartoum, 1855. 《 Pendant mon séjour à Khartoum,... le poste de gouverneur général était vacant... l'intérim était assuré par le moudîr ${ }^{1}$ du Kordofan, venu d'el-Obeïd à Khartoum à cet effet. Abdel-Kader Bey... était un Grec musulman de l'archipel... dont les mœurs douces, les manières courtoises, accusaient une éducation bien supérieure à celle de

1 Mudir: littéralement "directeur»; terme utilisé pour nommer le gouverneur d'une province, à partir de 1833 . 
tous les Turcs du pays... Il avait l'habitude de faire tous les vendredis une longue station au bazar; c'était pour lui le moyen de tuer le temps et de tromper l'ennui du vendredi qui, comme chacun sait, est le dimanche des musulmans, que l'on passe comme l'on peut, affaires publiques et affaires privées, tout étant suspendu: il ne reste pour distraction que la prière et la mosquée. Cependant, par une contradiction assez étrange et que je ne m'explique pas, c'était précisément ce jour-là que les transactions du bazar étaient les plus animées. Arrivés au bazar, où nous nous étions rendus sans aucune suite, nous nous établîmes dans une boutique vide, sans autres meubles que des angarebs ${ }^{1}$ pour s'asseoir... les marchands lui offraient, avec une politesse peu désintéressée, les prémices de leurs marchandises, tantôt un fusil réputé précieux, tantôt un dromadaire soi-disant de prix, ou une esclave abyssinienne dont chacun pouvait, sans les réclames du djellab, apprécier les beaux yeux et les dents blanches. Tout cela se vendait à l'encan, et la chose restait au plus offrant. La dernière de ces marchandises, je veux dire la jeune fille, fixa particulièrement mon attention, et je la suivais avec intérêt, lorsqu'on la promenait plus qu'à demi-nue d'un bout du bazar à l'autre, afin que chacun pût la voir à son aise, miser et surenchérir. On n'en donnait pas grand-chose. Elle était pourtant jolie, et fort bien faite, et c'était une sedassi, c'est-à-dire qu'elle avait de onze à quinze ans, âge auquel les esclaves sont le plus estimées. [...] Si jeune et si belle que fût cette esclave, son air, j'en dois convenir, n'était pas très doux. Ce qui me frappait surtout en elle, c'était son impassibilité. On eût dit qu'elle n'était point en cause et qu'il s'agissait de toute autre qu'elle... J'ignore à qui elle échut par le droit de la force et de l'argent.

Les autres objets du marché ne sont pas dignes de mention: c'étaient des légumes du pays, quelques fruits, quelques épiceries, de grossiers ustensiles à l'usage des Bédouins, des vêtements non moins grossiers, des sandales, des bâts, rien qui fût propre à tenter ma convoitise ou même à éveiller ma curiosité, si ce n'est pourtant des brides de dromadaire en cuir artistement tressées et ornées de glands en verroterie.

Une machine sans nom, sorte d'abattoir humain destiné aux exécutions, s'élève au beau milieu du marché, pour l'exemple sans doute; mais les habitants ne s'en émeuvent pas le moins du monde, et même quand fonctionne la machine sanglante, les affaires vont bon train comme si de rien n'était.

1 Angareb: lit traditionnel composé de quatre pieds de bois soutenant un cadre tendu de cordes, tel qu'on peut en voir dans les tombes de l'Égypte antique, et toujours en usage en zone rurale au Soudan, au Tchad... 
Sous le rapport ethnologique, le bazar de Khartoum offre un piquant intérêt. On y voit réunis des individus de chacune des races qui peuplent cette partie du monde, et tous sont reconnaissables à la couleur plus ou moins foncée de la peau. Les Turcs, les Grecs se distinguent par la blancheur; les Arabes nomades, venus originairement du Hedjaz, sont d'un brun déjà beaucoup plus foncé, et se nomment asfar; viennent ensuite les cuivrés, les roux, les bleus, azrak, les verts akhdar, et enfin les noirs ou nuba, descendus des montagnes du Sud, notamment du Takel qui forme la frontière méridionale du Kordofan.

Les habitants de Khartoum sont de bonnes gens au fond, comme le sont en général tous les Soudaniens dans leur état naturel. [...] On ne peut mieux les définir qu'en disant que ce sont des enfants, enfants par l'imprévoyance et par la mobilité. Leurs passions s'éteignent aussi vite qu'elles s'allument. Ils sont fidèles à leur parole et respectent religieusement un dépôt. Leur hospitalité est sans bornes; un hôte est sacré pour eux et ils se ruinent pour le bien traiter. [...] Cette vertu est si grande qu'ils la pratiquent au-delà même du tombeau. Quelqu'un cherche-t-il asile dans un cimetière, il n'a qu'à s'étendre sur une tombe; le mort qui l'habite le protégera, et à ce propos ils racontent qu'un étranger n'ayant pas pris cette précaution, et s'étant couché par terre, son sommeil fut troublé toute la nuit par les morts qui se le disputaient, chacun voulant être son protecteur; légende charmante, dont pourraient s'enorgueillir des nations plus raffinées.

La ville de Khartoum était, du vivant d'Abbas Pacha, un lieu de déportation, où sa défiance $[. .$.$] reléguait tous ceux qui lui étaient suspects,$ à n'importe quel titre.

Le médecin-chef de la province est le docteur Peney, au service de l'Égypte, et fixé dans le pays depuis de longues années. Il a épousé une Abyssinienne dont il a des enfants café au lait. M. Heuglin, consul ou vice-consul d'Autriche, capitaine d'artillerie, [...] composait à lui seul tout le corps consulaire. L'agent anglais était absent, ainsi que celui de Sardaigne, M. Vaudey, qui précisément dans ce temps-là tombait sous les flèches d'une tribu du Nil Blanc. Ces trois puissances, l'Autriche, la Grande-Bretagne et la Sardaigne, sont les seules qui aient des représentants à Khartoum.

M. Heuglin arrivait d'un voyage scientifique en Abyssinie... Il succédait dans ses fonctions de consul au docteur Reitz, l'un des premiers explorateurs du Soudan oriental, qui était mort tout récemment des suites de ses voyages, à l'âge de trente-trois ans. Je pourrais citer d'autres Européens, des Français même, établis à Khartoum, tels, par exemple, que le pharmacien en chef de la province, un Marseillais devenu musulman, 
qui avait déjà épousé, puis répudié, une cinquantaine de femmes, sans compter celles qu'il a eues depuis et qu'il aura encore. Khartoum est le vestibule de la barbarie, le point intermédiaire entre la vie sauvage et la civilisation, dont il marque de ce côté la limite extrême; mais quelle civilisation! À peu d'exceptions près, elle n'y est connue que par le ravissement de ses vices, et l'Europe n'est représentée là en général que par l'écume de ses populations. Des marchands avides y vont chercher des dents d'éléphant qu'ils échangent contre des verroteries avec les riverains du Fleuve-Blanc, et se croient tout permis dans ces régions lointaines. Aussi, que d'abus, que d'excès de tout genre, que de crimes impunis! Ainsi par exemple un marchand français était accusé par un autre de faire la traite des noirs, crime puni par les lois françaises. M. Vaudey lui-même, tout consul de Sardaigne qu'il soit, venait, au moment de sa mort, d'être appelé à Turin sur la dénonciation d'un de ses compatriotes qui ne l'accusait de rien moins que d'avoir tué un de ses domestiques... la vie sauvage, avec toutes ses superstitions, toutes ses ignorances, n'est-elle pas préférable encore à une civilisation ainsi représentée? Et quelle idée les indigènes doivent-ils se faire de l'Europe, à la vue de tels Européens?

Il règne à Khartoum une liberté de mœurs qui sent fort la vie sauvage. Les Européens s'en accommodent parfaitement, ou l'exagèrent encore, bien loin de la réprimer. Les Turcs et les Arabes cachent et clôturent leurs femmes au fond des harems, et les eunuques commis à leur garde répondent de leur fidélité. Quant aux indigènes, c'est pis encore: ils croient si peu à la vertu féminine qu'ils ont adopté l'infibulation, usage barbare que le gouvernement égyptien essaie en vain de combattre et qui résiste à toutes ses prescriptions. Cette industrie est l'apanage des matrones du pays.

Je ne cite que pour mémoire des touristes américains qui commencent à paraître de temps en temps dans ces régions lointaines, et des officiers anglais qui viennent de Bombay, d'Aden et même de Londres, chasser pendant leurs congés l'hippopotame et le lion.

Dès le soir de mon arrivée, il y eut une grande fantasia en plein air, devant la maison de $\mathrm{R}^{*}$. Les chants et les danses étaient entremêlés de feux d'artifice. Ces chants et ces danses étaient exécutés par des femmes égyptiennes ou abyssiniennes. Toutes avaient le visage découvert, contrairement à la loi du Coran, et je ne pouvais que m'en féliciter, vu qu'elles étaient toutes d'une beauté accomplie et dans la fleur de la jeunesse. Vêtues de robes de soie à couleur voyante, où le rouge et le jaune se mariaient au vert clair et au bleu de ciel, elles avaient les bras et les pieds nus. Une bande de gaze couvrait à demi leur poitrine, et leurs cheveux noirs flottant en arrière étaient ornés jusqu'à l'extrémité de petites monnaies d'or passées 
dans un fil. Elles s'accompagnent pour danser du tar ou tambour de basque, et de castagnettes de cuivre en formes de cymbales, appelées en arabe sadjat ou saganet, dont elles jouent avec une dextérité merveilleuse. Leurs danses et une partie de leurs costumes sont absolument les mêmes que l'on voit représentés dans les peintures des anciens hypogées, et je n'en doute pas qu'ils se soient conservés par tradition.

Les almées, a'oualem ou danseuses, forment en Égypte une caste à part, comme elles devaient en former au temps des Pharaons. Elles sont beaucoup plus cultivées que les autres femmes de l'Orient, savent lire, écrire, et beaucoup sont poètes. Vivant en dehors de la loi commune, elles ne se marient point, ignorent par conséquent la claustration, la servitude du harem, et aussi indépendantes par nature que par profession, elles jouissent d'une liberté sans bornes. Appelées dans toutes les fêtes publiques ou privées, il n'y en a pas sans elles; aussi mettent-elles souvent à très haut prix leur présence, et ne les a pas qui veut. Abbas Pacha, excité par sa mère, une dévote intolérante à la façon des dévotes européennes, avait exilé du Caire toutes les almées et les avait reléguées dans la Haute-Égypte.

La fête se renouvela le lendemain devant la maison du consul d'Autriche. Des torches de résine portées par des domestiques ou des esclaves convertis en candélabres éclairaient la scène, et les gens du consul faisaient circuler du sorbet. Les almées étaient pour moi toute la fête. Leur chant monotone, singulièrement primitif et absolument étranger à toutes les notions musicales de nos pays, avait je ne sais quel charme indéfinissable; sa monotonie même faisait sa puissance et, quoiqu'il sentît d'une lieue ses pharaons, il plongeait l'âme à la longue et la berçait mélancoliquement dans une rêverie profonde. Les danses sont beaucoup plus variées; elles étaient exécutées avec une grâce, une légèreté et une ardeur extraordinaires. Nos ballets, ni rien de ce qu'on voit dans nos salons, n'en pourraient donner l'idée. Les danses espagnoles seules s'en rapprochent un peu, avec cette différence que ces dernières s'exécutent par couple, tandis que les almées dansent toujours seules; nul homme ne danse jamais avec elles.

Une des almées se mit à exécuter la danse du sabre, danse d'un grand caractère, qui exige beaucoup d'agilité et encore de souplesse. Tantôt le sabre tourbillonne sur la tête de ma danseuse en jetant des éclairs; tantôt elle le rabaisse et le tient fixé près du sol, comme pour frapper un ennemi terrassé.

Une autre danse célèbre dans le pays et fort goûtée des Turcs est celle de l'abeille. La danseuse suppose qu'elle a une abeille sous les habits, et pour la chercher, s'en dépouille les uns après les autres avec des mouvements, des gestes qui expriment tour à tour la crainte d'être piquée et l'espoir d'être délivrée de son ennemi. Mais comme ce petit drame est un peu vif, 
surtout au dénouement, on ne se le permet guère que dans le particulier. On ne l'oserait sur la place publique. Je dois convenir que toutes les danses qui se succédèrent étaient relativement fort décentes, quoique la volupté, sinon la passion, soit l'âme de presque toutes, et qu'à peu d'exceptions près, elles n'aient d'autre but que d'éveiller les sens. Dans les entr'actes, les almées allaient s'asseoir familièrement auprès des spectateurs dont elles désiraient capter la faveur ou piquer la générosité.

Il me restait à faire connaissance avec les danseuses du Soudan. La nuit étant venue, on alluma des torches, et je vis arriver une troupe de femmes enveloppées de la tête aux pieds dans leur ferdah, large pièce de toile blanche bordée de franges aux deux bouts. Elles vinrent nous baiser la main respectueusement l'une après l'autre, puis s'accroupirent en groupe sur les nattes qu'on leur avait préparées.

La première à se dévoiler fut une grande femme d'un certain âge, quelque chose comme trente ans, dont le visage assez régulier était d'un beau noir, et dont la coiffure toute isiaque me frappa singulièrement pour en avoir vu de semblables dans des figures de l'Égypte et de l'Éthiopie anciennes. Cette femme était une impresaria; les jeunes filles qui lui servaient à défrayer son industrie étaient des esclaves achetées par elle, sa propriété par conséquent.

Enfin le ballet commença; ballet étrange, et qui n'a rien de commun avec tout ce que j'avais vu jusqu'alors. Sur un signe de la maîtresse, qui resta accroupie à l'écart et enveloppée de son voile, les esclaves, au nombre de six ou sept, se levèrent et, se dépouillant du leur, demeurèrent absolument nues, au raat près qui leur ceignait le bas des reins. Toutes étaient de la première jeunesse, faites à ravir, et, quoique parfaitement noires, elles avaient le nez aussi droit, les lèvres aussi minces et l'ovale du visage aussi pur que les plus jolies femmes de Paris.

Elles n'avaient ni tambour de basque ni castagnettes, elles dansent à la voix, l'une après l'autre, et celles dont ce n'est pas le tour battent la mesure dans leurs mains. À mesure que la danse s'anime, le chant s'anime aussi et dégénère en hurlements. Pendant ce temps, la danseuse, seule au milieu du cercle comme une statue d'ébène, paraît plongée dans une profonde extase. La tête renversée en arrière, la poitrine tendue, les bras roidis, elle paraît soutenir une lutte intérieure et combattre une force invincible. Puis bientôt sa poitrine s'enfle, tout son corps est agité de frémissements nerveux, elle s'avance à petits pas mais en cadence, et comme poussée toujours malgré elle vers un spectateur qu' elle a choisi ou qu'on lui a désigné, celui d'ordinaire à qui la fête est destinée; elle arrive devant lui, elle s'arrête en palpitant, elle tombe, et, pour peu qu'il soit poli, il la reçoit dans ses bras. 
le Soudan

\section{8}

de 1820

à nos jours
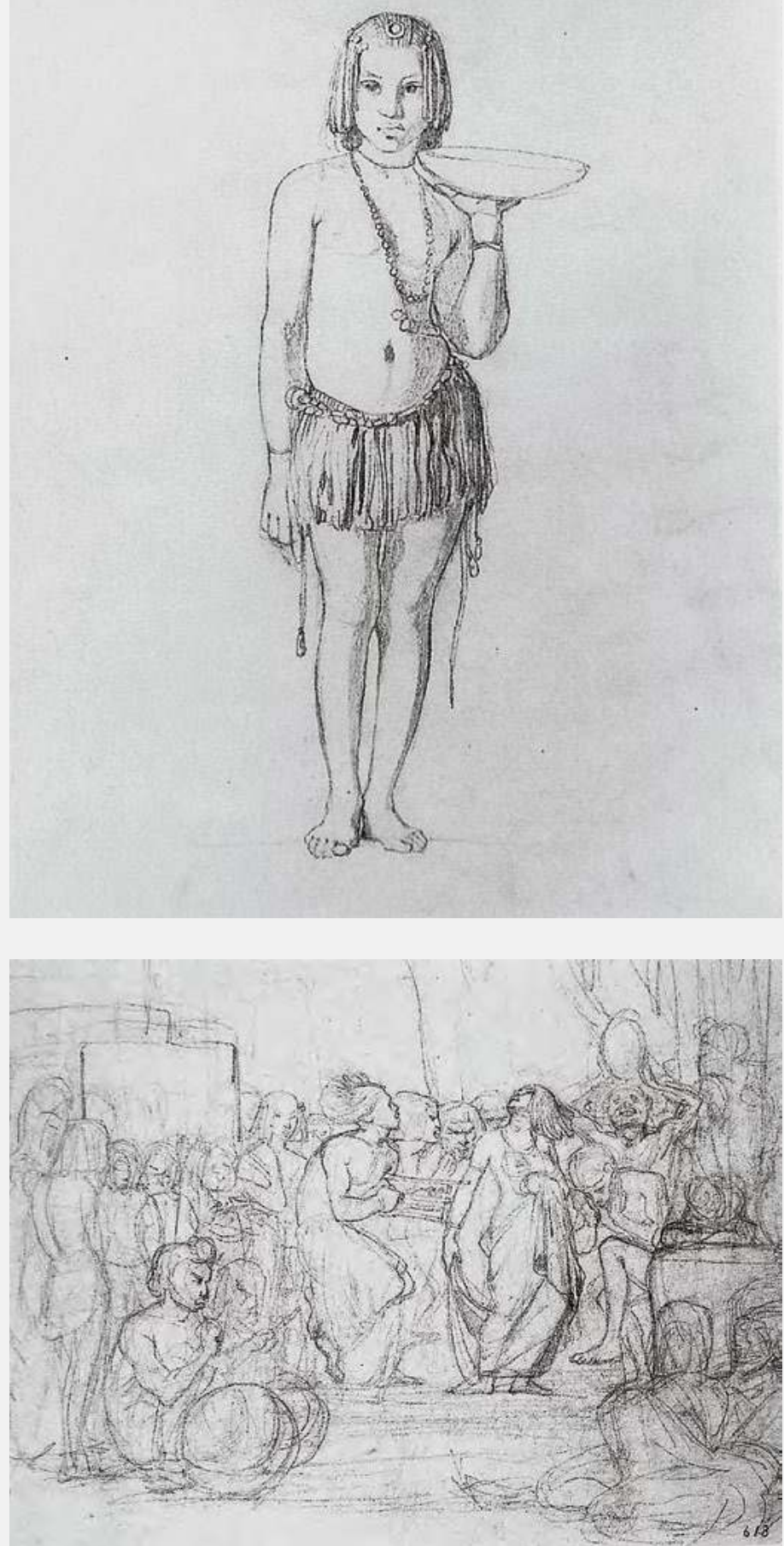

Esclave portant un raat.

Les almées. 
Voilà toute la danse des Soudaniennes; et le drame qu'elles figurent est assez clair, assez diaphane pour être compris, sans avoir besoin de commentaire. Cette danse est commune à toutes les femmes du Fleuve-Blanc. Un touriste américain qui y fit en 1853 un voyage d'agrément raconte une fantasia célébrée en son honneur par une tribu... et où les choses se passèrent absolument de la même façon.

Les chants remplissent l'intervalle des danses, et celui-là est encore plus primitif, plus monotone que celui des almées. Il se compose de deux ou trois notes tout au plus, qui reviennent toujours les mêmes, avec la même intonation; et non moins élémentaire, l'accompagnement de ces cantilènes consiste comme pour la danse à frapper les mains l'une dans l'autre. Les chanteuses improvisent d'ordinaire les paroles qui leur servent de libretto, et ne font pas pour cela de grands frais d'imagination. Ce soir-là, le libretto était naturellement en l'honneur du consul qui payait la fête. \\

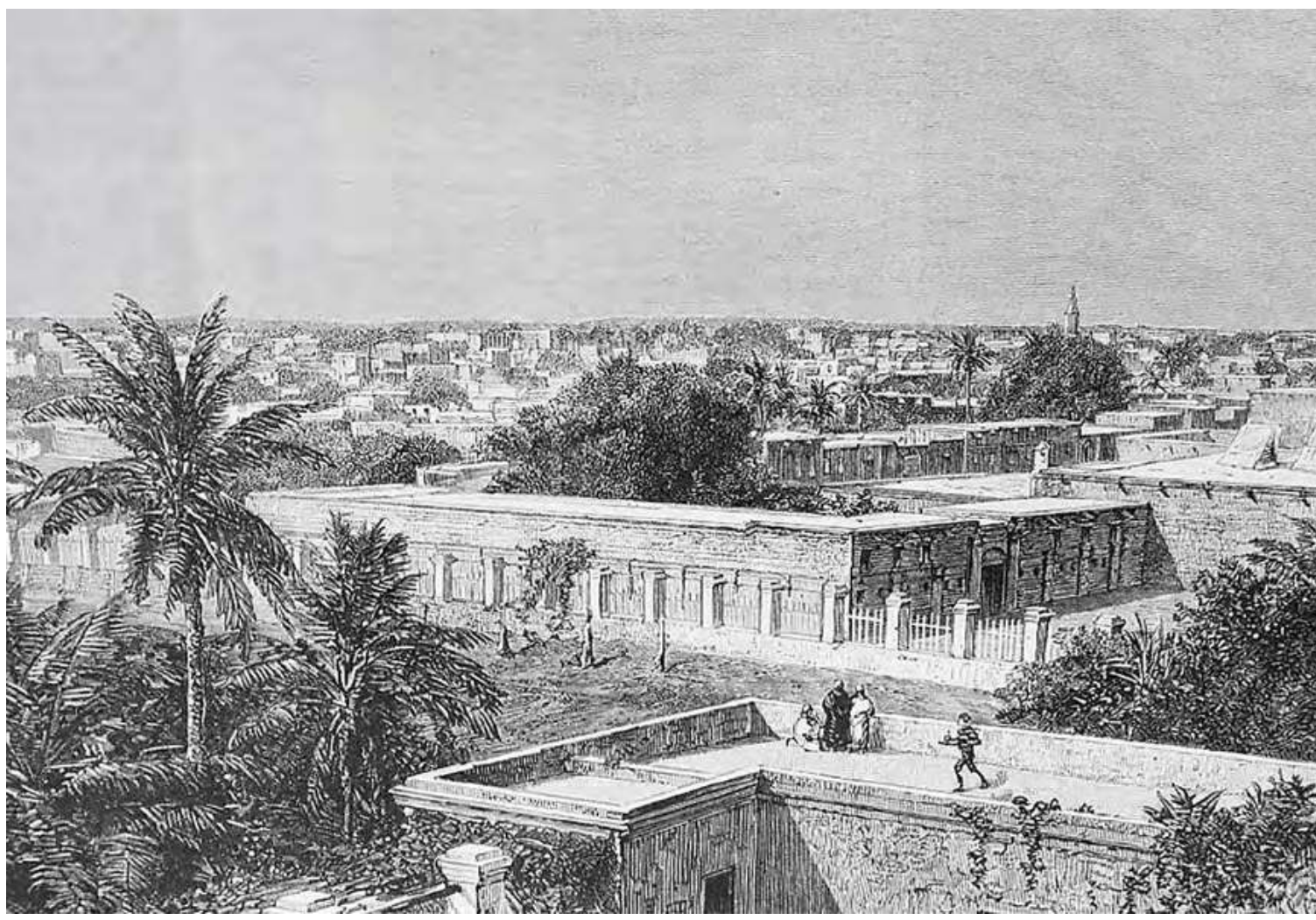


le Soudan

\section{0}

de 1820

à nos jours
Carl Giegler Pacha, qui sert dans l'administration égyptienne à Khartoum de 1873 à 1883, raconte par le menu la vie quotidienne. Cette vie, relativement simple, est rythmée par le passage des étrangers, qu'il s'agisse des techniciens au service de l'administration égyptienne, d'explorateurs, de grands voyageurs, d'aventuriers ou d'officiels en visite... Les décès y sont fréquents. Khartoum est aussi le point de départ des expéditions militaires, et l'on y fête les victoires.

Ainsi, le futur Slatin Pacha, arrivé avec une caravane de marchands, dit préférer la vie "libre et facile au Soudan» à un retour difficile dans son Autriche natale, lorsqu'il y est rappelé pour effectuer son service militaire. Et les maisons des expatriés sont décrites comme plaisantes.

Le rythme de la vie à Khartoum dépend aussi de la présence du gouverneur général: quand Gordon part en mission, celle-ci et le travail de l'administration s'apaisent.

Même la musique "moderne» atteint le Soudan égyptien: c'est au Darfour, invité par le commandant militaire récemment installé à el-Fasher, le circassien Hassan Pacha Hilmi, que Carl Christian Giegler entend pour la première fois, en 1876, la marche d'Aïda de Verdi, jouée par la fanfare militaire!

Les festivités pour le retour d'Ismaïl Ayyub Pacha qui rentre victorieux du Darfour en 1876 vont durer plusieurs semaines. "Chaque jour était organisée une nouvelle "azouma" ${ }^{1}$ Ces fêtes sont données en l'honneur du pacha par les hauts fonctionnaires et les marchands aisés. Une azouma se déroule de 17 heures à minuit. De cinq à sept, les convives discutent entre eux, au son de la fanfare militaire. À sept heures, le repas est servi, sur trois tables; les officiels et les notables sont placés à la table du pacha; aux autres tables les convives sont placés selon leur importance et leur rang social. Le repas consiste habituellement en une quarantaine de plats, tous préparés parfaitement. Le plat principal est un mouton entier grillé et farci de riz. On mange avec ses doigts selon la coutume locale. Il y a des règles à respecter, et la bonne éducation est jugée en fonction. Quand les premiers invités ont mangé, d'autres les remplacent, jusqu'à ce que tout le monde ait été rassasié, même le plus modeste ânier, ce qui peut prendre des heures. Pendant ce temps des danseurs présentent des numéros, des bouffons détendent l'atmosphère jusqu'après minuit, où les invités rentrent chez eux. 
De nombreux techniciens étrangers ont été engagés par Gordon ou par le chef d'état-major égyptien le général Stone, ancien officier américain au service des États confédérés, qui va recruter d'autres Américains (colonels Campbell, Colston, Grant, Chaillé-Long, Purdy, Prout...) dont plusieurs sont également issus de l'armée confédérée et qui vont réaliser un travail cartographique considérable.

Le Soudan attire des aventuriers: Gordon était fort sollicité par des Anglais qui recherchaient plus l'expatriation ou la possibilité de pratiquer le big game qu'un travail dans l'administration. Eduard Schnitzer, médecin juif allemand, plus connu sous le nom d'Emin Pacha, arrive sans le sou à Khartoum en 1875 après avoir exercé de longues années dans l'Empire ottoman, et devra être assisté par la communauté expatriée de Khartoum pour installer son cabinet, avant d'être engagé par Gordon en Équatoria.

Certaines biographies sont étonnantes, comme celle de Romolo Gessi, né de père italien et de mère arménienne, qui travaille comme secrétaire au consulat britannique de Bucarest avant de servir comme interprète lors de la guerre de Crimée. Quelques années plus tard, il participe aux combats pour la libération de l'Italie avec Garibaldi. Alors qu'il s'occupe de commerce en Roumanie, Gordon l'appelle pour lui confier le poste de gouverneur général de la province d'Équatoria, lors du départ de Samuel Baker. Il participe à l'exploration du lac Albert, puis démissionne. Il revient au Soudan comme accompagnant d'une expédition italienne dans le bassin du Nil Bleu; à son retour à Khartoum, il réintègre l'administration khédiviale, et Gordon le nomme gouverneur du Bahr el-Ghazal; lors d'une campagne contre les trafiquants d'esclaves, il tue le fils de Zuber Pacha. Il est démissionné par le successeur de Gordon, après une expédition calamiteuse: sa flottille restera piégée dans le Sudd pendant plusieurs semaines, ce qui entraînera une disette fatale à beaucoup; lui-même sera atteint par les fièvres et mourra à Suez, sur le chemin du retour vers l'Égypte.

Un certain De Witt, qui décède en 1875, engagé par Gordon, est un avocat allemand qui avait fui la ville de Brême pour échapper à des poursuites pénales.

Des voyageurs passent par Khartoum. Ainsi du capitaine Burnaby, célébrité de l'époque, journaliste, écrivain, voyageur et grand sportif (premier à gagner en ballon la France depuis l'Angleterre), qui sera tué à la bataille d'Abou Klea ${ }^{1}$ en 1885, et deviendra un symbole de héros britannique célébré par les poètes.

1 Abou Klea: bataille survenue du 16 au 18 janvier 1885 entre les insurgés mahdistes et l'armée de secours qui arrivait trop tard pour sauver Khartoum et le général Gordon; [.../...] 
le Soudan

602

de 1820

à nos jours

Il faut citer aussi Mademoiselle Tinné (1839-1869) exploratrice hollandaise qui, accompagnée de sa mère et de sa tante, de deux servantes hollandaises et de l'explorateur T. von Heuglin, part explorer le Haut Nil Blanc début 1863. L'expédition qui a joint Gondokoro rentre sur Khartoum car la tante est sérieusement atteinte par les fièvres dont elle décède rapidement. L'expédition repart explorer les régions de la Sobat et du Bahr el-Ghazal et atteint le territoire Azandé. La mère de Melle Tinné et les deux servantes vont à leur tour succomber aux fièvres à Wau', avec d'autres membres de l'expédition. On meurt beaucoup au XIX ${ }^{\mathrm{e}}$ siècle au Soudan, de fièvre souvent, de mort violente parfois. Et Khartoum représente un havre de salubrité par rapport aux territoires du Sud où la malaria fait des ravages dans les gens des expatriés.

Les couples mixtes, des Européens mariés à des femmes africaines, soit Éthiopiennes (Abyssiniennes)..., soit Soudanaises, existent, même si les discours racistes sont habituels chez les Européens de l'époque, et si le problème du métissage et du sort à réserver aux métis est un sujet de débat.

Ainsi l'Autrichien Marno Bey était marié à une femme Dinka christianisée, Caterina Zaynab, dont il a un fils qui sera baptisé par le religieux catholique italien Daniele Comboni, fondateur de la congrégation du même nom.

Lupton Bey, le dernier gouverneur du Bahr el-Ghazal nommé par le successeur de Gordon, était marié à une Abyssinienne, Zaynuba, dont il avait deux filles; son épouse était une ancienne esclave de Rosset Pacha, commerçant puis officiel, vice-consul intérimaire de France et de Grande-Bretagne à Khartoum en 1874-1876.

Madame Lafargue était une personnalité connue de Khartoum. «Madame Miriam» était la femme d'un marchand français ayant fait fortune au Nil Blanc et qui «ne pouvait rentrer en France comme il ne pouvait y emmener sa femme» (dixit C. C. Giegler). Il s'était donc installé à Berber dans une vaste maison confortable et, à sa mort, laissa tous ses biens à sa femme. Sa veuve recevait non voilée les Européens importants. Malgré sa quarantaine, elle restait une belle et délicate personne. Elle avait accru sa fortune grâce à une importante flottille de navires pour le commerce du maïs avec l'Égypte.

\footnotetext{
la bataille est remportée par les mahdistes, au prix de lourdes pertes dans leurs rangs ( 71 Européens sont tués sur un effectif de 1100 hommes, et environ un millier de mahdistes sur un effectif de 13000 combattants).

1 Wau: ville du Sud Soudan, capitale du Western Bahr el-Ghazal.
} 
La vie sociale, celle d'une petite communauté vivant à l'étranger, dans des conditions tropicales, avec un approvisionnement difficile en denrées européennes, est importante.

Voici le récit d'une veillée de Noël à Khartoum en décembre 1875 : 《Nous avons passé la veillée de Noël chez les Hansal. Emin jouait du piano et nous autres, Slatin, Rosset et son frère récemment arrivé à Khartoum, nous avons chanté des cantiques allemands. Il y avait aussi des femmes noires. C'étaient les femmes d'un charpentier italien et d'un assistant de Hansal, élevées à la mission. Ces femmes avaient été en Italie et en Autriche quand elles étaient jeunes filles. Toutes deux parlaient l'italien à la perfection, et l'une d'entre elles, Joséphine, s'exprimait aussi dans un allemand parfait. Quand la fête battit son plein nous avons même dansé avec les Africaines qui s'avérèrent d'excellentes danseuses. Le lendemain, quand les prêtres de la mission eurent vent de la fête, il y eut un mini-scandale parce qu'elles avaient dansé avec moi, un protestant. Elles eurent même à faire pénitence, ce que me dit Slatin... \\En 1881, dans une atmosphère apaisée après le départ de Gordon, le baccarat est beaucoup pratiqué. Le gouverneur Rả uf Pacha était un homme sociable, qui s'invitait chez beaucoup de gens et ces rencontres improvisées étaient appréciées.

Louis Vossion, vice-consul de France à Khartoum, photographie en 1882 les personnalités de la ville et son album (conservé à la Bibliothèque nationale de France) conserve la mémoire des notables européens : le consul de Grèce Aristidis Leondidi, le conseiller Hansal, consul de l'empereur d'Autriche, l'agent consulaire du roi d'Italie, Calixto Lagnani, l'agent consulaire de la Perse à Khartoum, Boutros Boulos. Parmi les autres figures, on retrouve le Dr Peney, médecin-chef du Soudan, marié avec une Abyssinienne dont il a trois enfants, Edward Harden, agent d'une maison de commerce allemande de Hambourg, le Dr Xinoudaki, médecin d'Athènes établi à Khartoum, Albert Marquet, Français chef de la plus importante maison de commerce européenne au Soudan, les missionnaires américains Ladd et Snow de l'American Mission Society, Ibrahim Effendi Khalil, le chef de la colonie copte de Khartoum, Onorato Moussy, maltais et ses enfants malto-abyssins, le Rp. Léon Henriot, alsacien, Giegler Pacha, ancien directeur des lignes télégraphiques, et ses serviteurs allemands d'origine. Sont aussi photographiés les employés du vice-consulat de France: le drogman ${ }^{1}$, les cawas. De nombreuses familles posent avec les nourrices, et les domestiques, abyssins ou anciens esclaves Dinkas ou Darfouris.

1 Drogman: français du XIX ${ }^{e}$ siècle (de l'arabe tardjiman), utilisé pour nommer le traducteur dans certains pays du Proche-Orient. 


\section{La lutte contre I'esclavage : Baker et Gordon}

L'esclavage était une réalité de la vie quotidienne au Soudan depuis des temps immémoriaux. Il était toléré et réglementé par l'islam, qui considérait l'esclave comme un bien mobilier. Un des motifs de la conquête du Soudan tint d'ailleurs à la nécessité qu'avait Méhémet Ali de renforcer son armée avec les captifs noirs qu'il y razzierait.

Les basingers ${ }^{1}$, soldats noirs, sont extrêmement appréciés pour leur bravoure et leur fiabilité. Lorsque Zubair Pacha part pour Le Caire afin de plaider sa cause auprès du khédive, il lui apporte en cadeau un bataillon de soldats noirs.

Mais à côté des hommes destinés à l'armée, les esclaves femmes sont plus prisées et se vendent plus cher. Frédéric Cailliaud nous renseigne sur la valeur des esclaves africaines que les Égyptiens capturent durant leur campagne soudanaise vers les années 1820 : 《L Lâge est une des principales bases sur lesquelles s'établit leur valeur vénale. On appelle "commassy" les filles de onze ans et au-dessous; "sédassy" celles qui ont de onze à quinze ans; ce sont les plus estimées, elles valent de 18 à 30 talaris $^{2}$. Les "balègues" sont celles qui ont passé la quinzième année; elles ne valent déjà plus que de 8 à 12 talaris. De vingt à trente ans, elles sont réputées vieilles et l'on répugne à s'en charger [...]. \\ Lors du recensement du Caire effectué vers 1870, sur les 10481 esclaves que comptait la ville, il y avait 8674 femmes pour seulement 1807 hommes.

de 1820

à nos jours
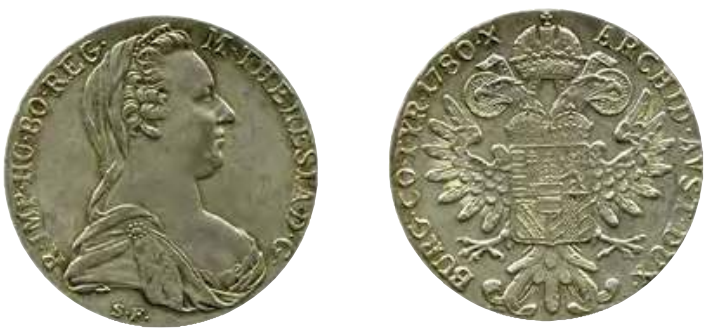

Thaler de Marie-Thérèse.

1 Basingers: anciens esclaves entraînés militairement.

2 Talari: thaler ou dollar autrichien en argent de Marie-Thérèse. 
Les Européens du xixe siècle vont vivre avec la réalité de l'esclavage (voir la correspondance du futur Napoléon avec le sultan du Darfour durant l'expédition d'Égypte, p. 634): en 1821, Cailliaud se plaint de la fuite, à l'approche de Khartoum, d'un esclave qu'il avait acheté (voir p. 555); à partir de 1840, quand le Sud s'ouvre, des traitants «blancs ${ }^{1}$ » participeront avec les autorités et des commerçants soudanais à la traite négrière.

Les voyageurs sont en général sensibles à la détresse des esclaves dont ils croisent les caravanes en partance pour l'Égypte ou pour la mer Rouge, garrotés avec des fourches en bois au cou, et ils décrivent maintes scènes pitoyables. Trémaux dans son Voyage au Soudan oriental de 1848 à 1850 croisera deux caravanes, une première dans le désert entre Korosko et Abou Hamed, et une seconde dans le Sennar, et décrit les coups de courbache pour faire avancer les esclaves fatigués, l'abandon des malades et des vieux, les relatifs meilleurs soins accordés aux jeunes filles, marchandise la plus lucrative.

De même Giegler dénonce les mauvais traitements qu'il observe lors de ses périples dans le Soudan, mais considère que si ses accompagnants et lui-même avaient tenté quoi que ce soit, ils auraient pu être tués par les conducteurs de ces caravanes qui savaient que leur trafic était condamné officiellement par l'administration.

En 1874, il remonte de Gondokoro sur Khartoum par bateau, et s'est arrêté à Fachoda où il doit changer de steamer; mais au moment de son départ, un autre bateau accoste et 150 esclaves sont embarqués, au grand dam de Giegler. Officiellement il s'agit de «recrues», mais le bateau se remplit de femmes, d'enfants, de vieillards et de jeunes hommes, provenant de la zériba du traitant Ghattas, sur la rivière Sobat ${ }^{2}$. Le bateau sur lequel on transporte aussi l'ivoire est totalement surchargé. À l'arrivée aux abords de Khartoum, les captifs sont habillés pour passer inaperçus en ville une fois débarqués. Giegler envoie un long rapport à Gordon qui va le transmettre au khédive Ismail au Caire. Le capitaine qui faisait partie de l'administration va passer plusieurs années en prison. La totalité de l'ivoire est confisquée, et la famille du riche traitant est réduite à la mendicité.

En 1876, sur la route d'el-Obeïd, il rencontre une caravane d'esclaves: 《 une file sans fin d'hommes, de femmes et d'enfants de tout âge. La plupart d'entre eux portaient un anneau de fer au cou, et étaient enchaînés

1 Parmi ceux-ci on peut mentionner le Maltais De Bono, le Français de Malzac.

2 La rivière Sobat est le plus septentrional des affluents du Nil Blanc qu'il rejoint en amont de Malakal (Upper Nile), et qui est formé par la réunion des rivières Pibor et Baro, alimentées par le plateau éthiopien. 
le Soudan

\section{6}

de 1820

à nos jours les uns aux autres à un intervalle de 1,5 mètre. D'autres, ceux qui avaient tenté de s'échapper et avaient été repris, portaient le sha'ba ${ }^{1}$. La caravane est encadrée de noirs et de Soudanais armés pour les faire avancer. \)

Le khédive, pour prouver aux Anglais sa volonté de contribuer à la suppression de l'esclavage, engage Samuel Baker en 1871. Ce dernier s'est rendu célèbre quelques années auparavant par ses explorations aux confins du Sud Soudan en 1863, où il avait rencontré Speke et Grant à Gondokoro.

Lors de son premier passage à Khartoum en juin 1862, Baker avait déjà décrit de façon brutale la situation: \$Nous arrivâmes à Khartoum, résidence du gouverneur général du Soudan égyptien et des consuls de France, d'Autriche et d'Amérique. C'est un séjour immonde. Sa garnison ne vit que de maraude. Tous les employés du gouvernement sont malhonnêtes et voleurs. Le gouverneur ordinairement ruine le pays par ses taxes oppressives et ses malversations. Le Soudan n'exporte que de la gomme, du séné, des cuirs et environ cent mille francs d'ivoire par an. Si cette possession est intéressante pour l'Égypte, ce n'est que parce qu'elle fournit des esclaves aux pays mahométans.

À Khartoum, il y a peu de place pour le commerce légitime; aussi n'en fait-on guère d'autre ici que celui des esclaves et, en général, c'est dans cette catégorie d'affaires qu'il faut ranger le commerce du Nil Blanc. Voici comment cela s'organise. Un aventurier sans ressources trouve pour ce négoce à emprunter à cent pour cent. Il lève une bande de coupe-jarrets et part vers le mois de décembre. Au-delà de Gondokoro, il s'allie à un chef nègre quelconque, cerne un village qui lui est hostile, y met le feu, tue les hommes et emmène les femmes et les enfants, avec le bétail; un tiers des vaches et des bœufs revient aux gens de l'expédition et le reste au négociant, qui rentre graduellement en possession du tout, en troquant - contre des esclaves - ce qu'ont obtenu ses gens, puis en profitant d'une dispute pour tuer le chef son allié dont le peuple est à son tour pillé et mis en esclavage. Le bétail est troqué ensuite contre des esclaves et de l'ivoire. Alors, le négociant, laissant jusqu'à son retour une partie de sa bande continuer les mêmes procédés, prend le chemin de Khartoum. À quelques lieues en avant, il se défait de ses esclaves qu'on expédie vers tous les pays de l'islamisme. Rentré en ville avec son ivoire et son argent, le négociant liquide son emprunt et devient capitaliste à son tour. Tel est le commerce du Nil Blanc. 

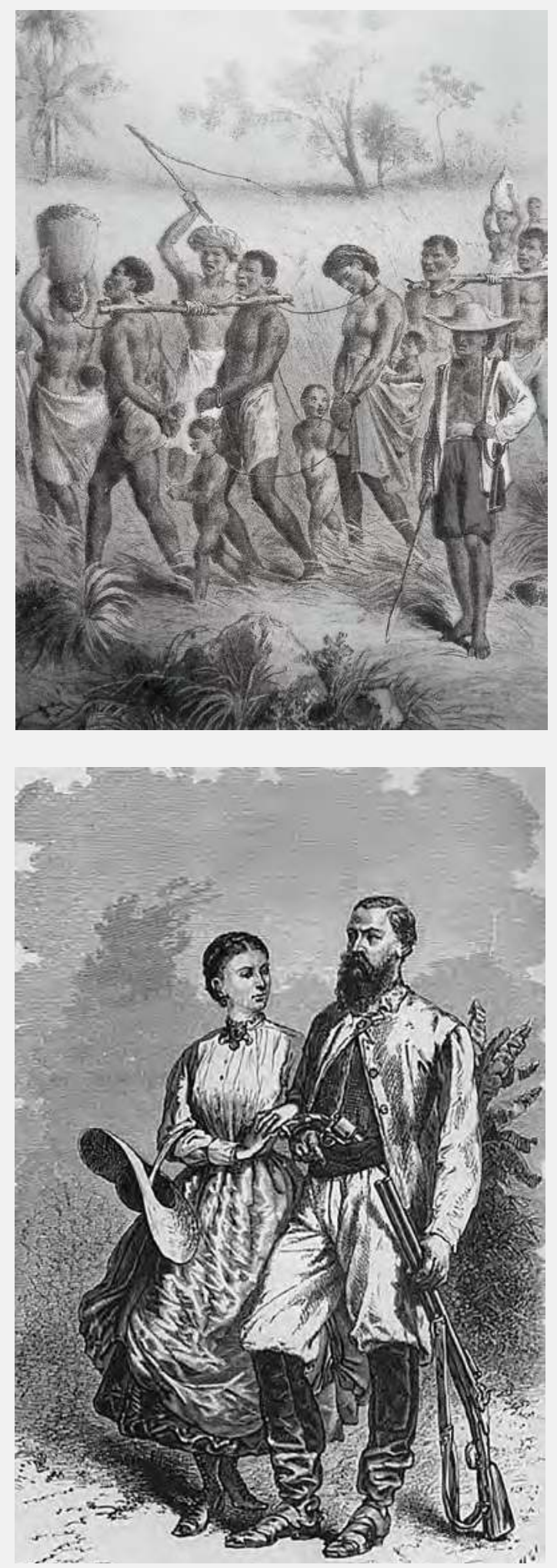

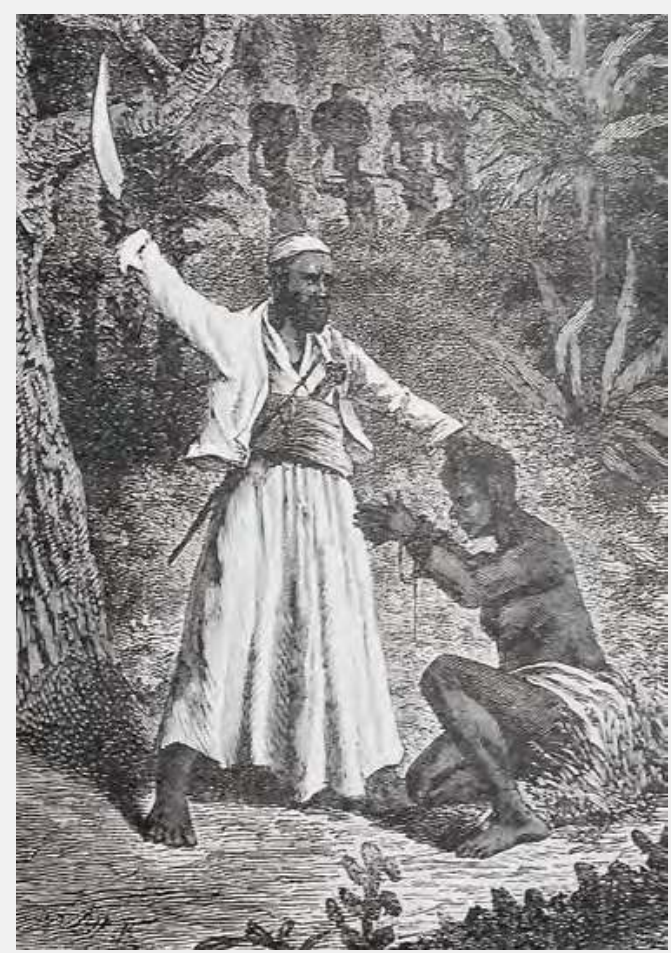

Esclaves (gravure anglaise du XIxe siècle).

Mise à mort de l'esclave malade (gravure du $\mathrm{XIX}^{\mathrm{e}}$ siècle).

Samuel et Florence Baker ${ }^{1}$.

Samuel Baker et ses compagnons d'expédition.

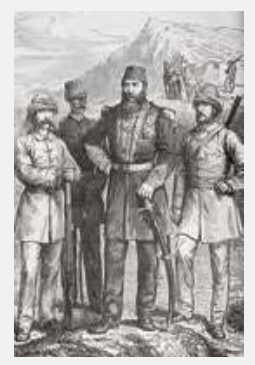

la création

du Soudan

moderne

1820-1885
1 La femme de Samuel Baker provient

de Transylvanie; il l'acheta sur un marché d'esclaves à Vidin (aujourd'hui en Bulgarie). Elle recevra un passeport britannique au nom de Florence Finnian. Elle l'accompagnera dans tous ses voyages et ses expéditions, et deviendra sa femme quelques années plus tard. Samuel Baker ne sera jamais honoré comme le furent les explorateurs britanniques de l'Afrique. L'achat de Florence et leur union libre ont choqué la bonne société anglaise de l'époque, à commencer par la reine Victoria. 


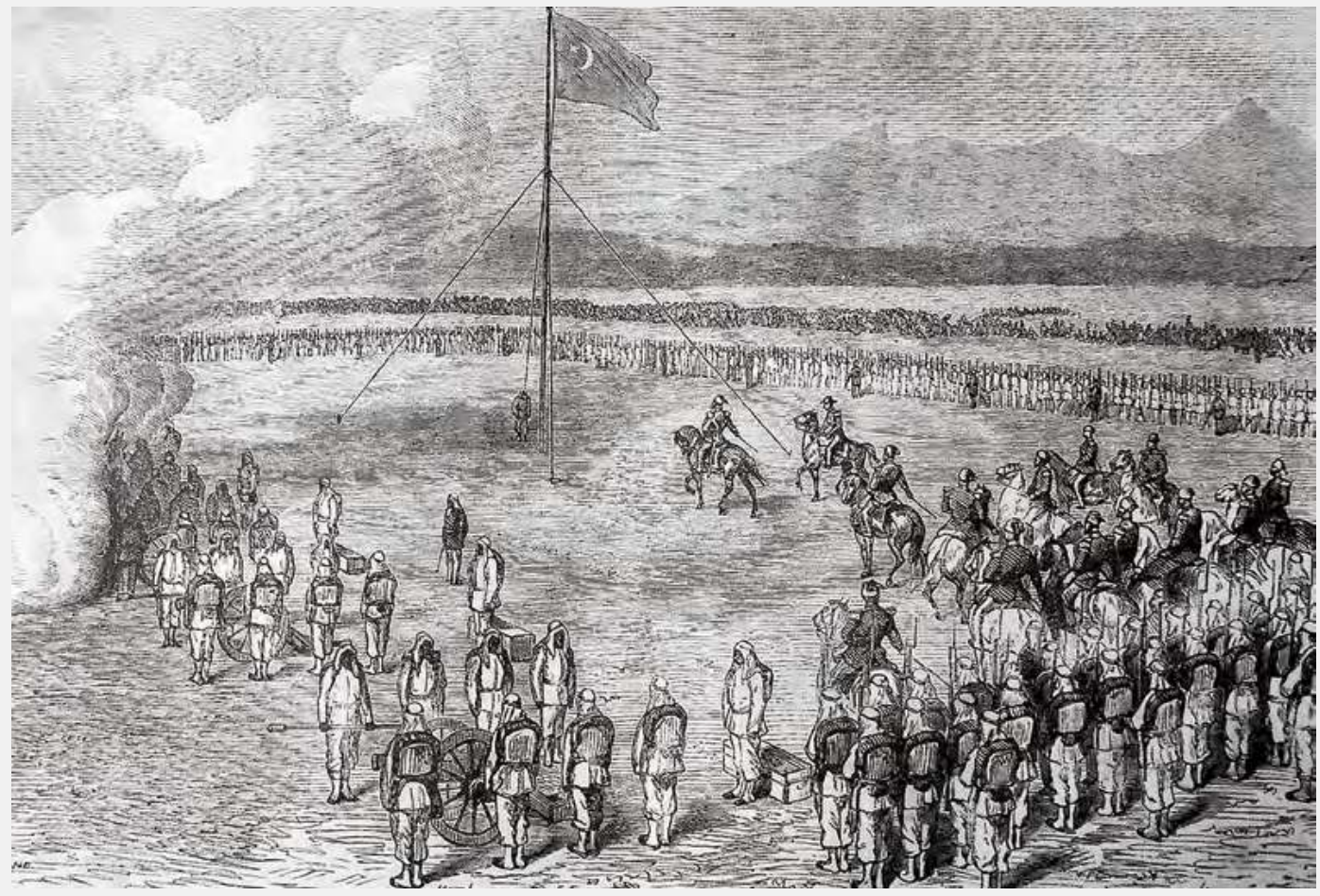

le Soudan

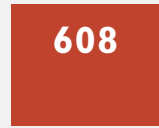

de 1820

à nos jours
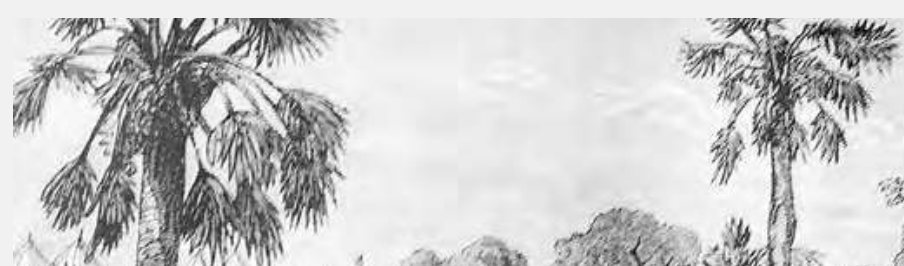

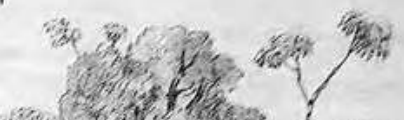

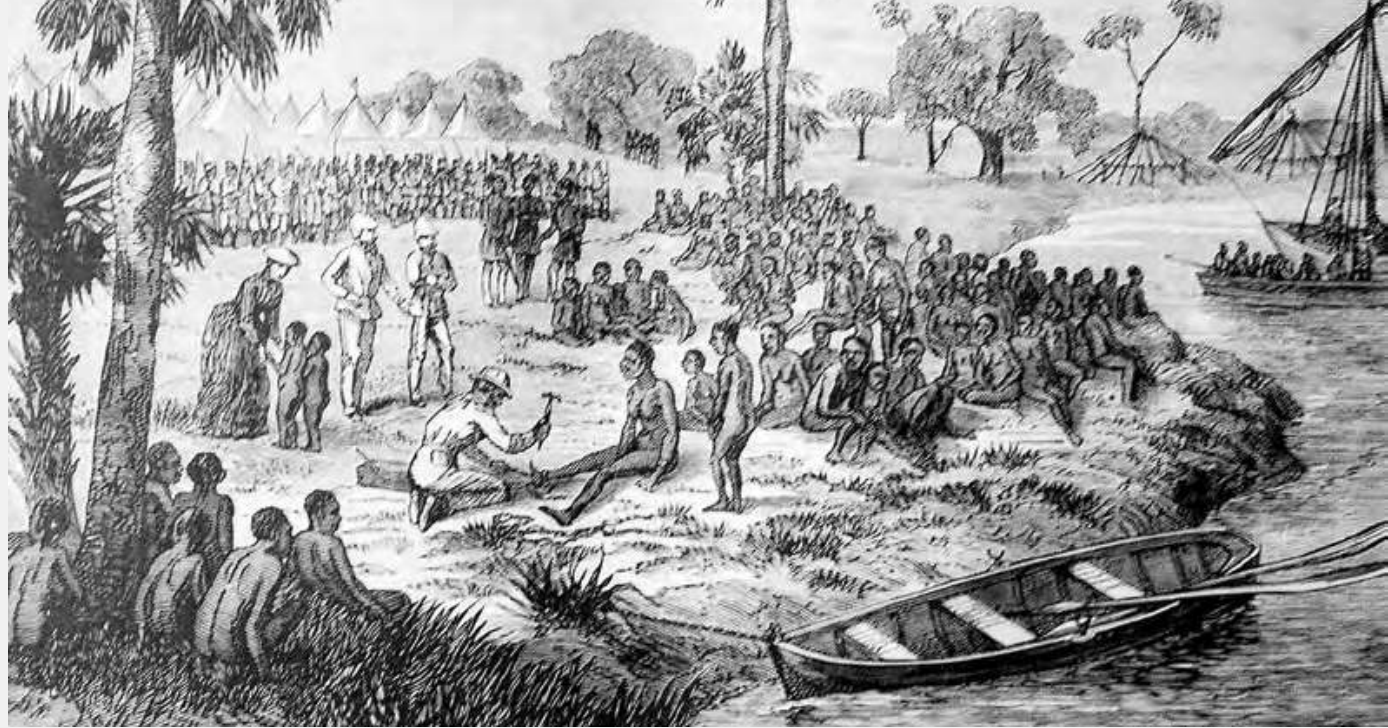

Cérémonie d'annexion de Gondokoro.

Libération d'esclaves par Samuel Baker en 1872. 
Baker ne perçoit pas que, pour les Égyptiens, l'installation de l'administration égyptienne était le but principal de sa mission (officiellement Gondokoro est annexé au Soudan égyptien en 1871) et que cette installation constituait le moyen qui devait permettre la fin du trafic d'esclaves.

Et le fait qu'un chrétien vienne les commander n'est pas accepté par les Égyptiens. Baker, qui arrive en 1871, va rencontrer de nombreuses difficultés pour lancer son expédition. Ladministration de Khartoum ne collabore pas, ni ne lui livre les bateaux et les troupes prévus. Il n'en rejoint pas moins Gondokoro en dépit de nombreux avatars. Là, Baker va s'attaquer directement aux trafiquants, mais ceux-ci vont monter les populations contre lui, et il devra pour se défendre guerroyer contre elles en utilisant finalement les mêmes méthodes que les chasseurs d'esclaves. Il réussit à rapatrier une partie de son expédition (1100 hommes sur 1600) à Khartoum et rédige un rapport victorieux, mais l'échec est patent.

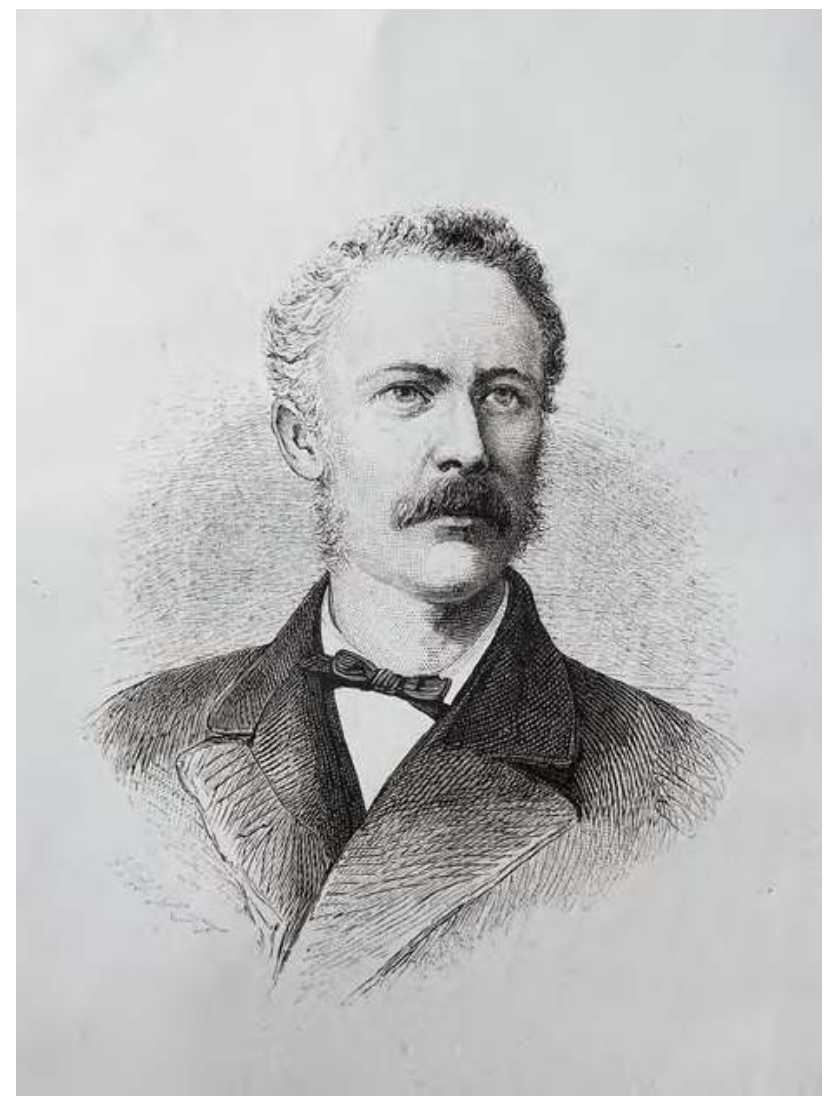


le Soudan

610

de 1820

à nos jours
Charles G. Gordon, qui lui succède en 1874 comme gouverneur de la province d'Équatoria, procédera différemment. Ce colonel des Royal Engineers arrive au Soudan précédé de la sulfureuse réputation de "Chinese Gordon" pour ses succès dans la répression des Taiping en Chine. Mélange de mystique, qui considère qu'il accomplit une œuvre divine, et d'homme pragmatique, qui tentera ultérieurement de négocier avec le Mahdi ou s'associera avec des marchands d'esclaves, il commence par mettre sous monopole d'État le commerce de l'ivoire, ce qu'avait déjà fait Baker, privant ainsi les traitants d'importants profits, et annihilant le prétexte des expéditions dans le Sud Soudan; de plus, il interdit la constitution des armées privées et l'importation des armes et soumet le commerce dans le Sud à autorisation préalable. Gordon anticipe de la sorte la politique du close district qui sera en vigueur de 1924 à 1944 au sud du Soudan. Enfin, il établit une série de postes rapprochés sur le Nil et dans l'intérieur, et s'appuie sur le puissant traitant Abou Su'ud, qui avait saboté les efforts de Baker, en le nommant sous-gouverneur à Gondokoro, avant de le renvoyer à Khartoum pour nonrespect des mesures interdisant l'esclavage.

En 1876, le khédive Ismail le persuade de prendre le poste de gouverneur général du Soudan. En 1877, le khédive signe avec les Anglais une convention contre l'esclavage (en échange de la reconnaissance de sa souveraineté sur la Côte des Somalis), qui prévoit la disparition de la traite négrière en Égypte en 1884 et au Soudan en 1889.

Gordon aura à mettre en œuvre le traité. Après une période de grâce d'une année, il s'attaque aux traitants: de mai à juillet 1878, 697 trafiquants sont arrêtés; les fonctionnaires égyptiens compromis sont renvoyés et Gordon embauche des Européens pour les remplacer. Il est responsable d'une répression brutale à l'encontre des marchands arabes Jallaba: il lance contre eux des cavaliers Danagla ${ }^{1}$, Jaalyin et Chaykyés qui pillent et massacrent les Jallaba. Cette attitude entraînera l'hostilité de ces derniers, qui jouissaient d'un certain prestige, nombre d'entre eux rendant des services aux confréries religieuses.

Sous la période mahdiste, on observe un regain d'activité de la traite, menée par des groupes arabes dans le Sud mais aussi dans ce qui correspond, à l'est de l'actuelle République démocratique du Congo, au nord de l'Ouganda et à la République Centrafricaine. Ces groupes sont en relation avec les explorateurs et les troupes des puissances européennes qui justifient leur présence par la lutte antiesclavagiste dans les derniers espaces non partagés de l'Afrique à la fin du XIx siècle. 
Compromise par une pression fiscale immodérée, l'exploitation systématique du pays et la corruption de l'administration, cette première domination turco-égyptienne aura néanmoins façonné le Soudan moderne en lui créant une façade sur la mer, en lui rattachant les régions nilotiques du Sud, en ouvrant le pays au monde moderne, en introduisant des technologies nouvelles, en développant le commerce, l'agriculture, l'éducation et la santé. Cette période se révèle la plus décisive, plus que celle du condominium considéré comme sa suite (Turkiyya al-thanis ${ }^{1}$ ); les transformations enregistrées vont se transmettre bien au-delà de la chute de Khartoum, en 1885.

La période turco-égyptienne fut pour beaucoup de Soudanais une opportunité. Ceux qui en profitèrent le plus furent les sédentaires qui vivaient le long du Nil, où la mince bande de terre irrigable ne pouvait subvenir qu'aux besoins d'une population réduite. Pendant des siècles, des habitants de ces régions avaient migré individuellement ou par petits groupes pour chercher fortune ailleurs. Ils pourvurent Le Caire de ses domestiques barbarins, l'île Touti de ses cultivateurs, le Darfour de ses guides de caravane et d'enseignants de l'islam. Plus d'une dynastie soudanaise décrit une origine nilotique dans son mythe fondateur. L'installation du régime turco-égyptien et, surtout, l'ouverture du Sud, ménagèrent de nouvelles opportunités aux tribus nilotiques du Nord, et les soixante ans qui précédèrent la Mahdiyya virent se développer une diaspora d'une nouvelle ampleur vers le sud et l'ouest.

Trois groupes surtout furent impliqués dans ce processus: les Jaalayin, les Danagla et les Chaykyés. Les Jaalayin, provenant du Nil entre sa jonction et le confluent de la rivière Atbara, étaient de redoutables commerçants. Les Danagla, natifs de la province de Dongola, étaient des constructeurs et pilotes de bateaux, et s'établirent progressivement vers le sud à mesure de l'épuisement du bois au Nord; d'autres devinrent des trafiquants au Sud. La tribu des Chaykyés bénéficiera des faveurs du régime, auquel ils fournirent une cavalerie irrégulière. L'extension de l'administration au Sud leur permit d'y descendre.

Si la Turkiyya voit l'amorce de l'unification des territoires dont va émerger le Soudan indépendant, elle présente aussi un autre aspect: Méhémet Ali et ses successeurs ont opéré une modernisation rapide et forcée de l'Égypte qui, de province traditionnelle et conservatrice de l'Empire ottoman, s'est muée en un État centralisé et autonome, doté d'une économie, d'une administration et d'un système scolaire propres. Ce processus fut étendu au Soudan égyptien, première région de l'Afrique intérieure à expérimenter les tensions

1 Sa deuxième période turque (en arabe). liées à la colonisation occidentale. L'incompatibilité entre la société traditionnelle et le nouveau modèle européen va engendrer une situation révolutionnaire qui va être résolue par l'apparition de la Mahdiyya

\section{1}

la création du Soudan moderne 1820-1885 